\title{
Introducing Studio Ghibli
}

James Rendell and Rayna Denison

Many readers of this special issue of the Journal of East Asian Popular Culture will already feel that they know Studio Ghibli. Famously founded in 1985 by animation film directors Hayao Miyazaki and Isao Takahata, along with then-magazine editor, Toshio Suzuki, Studio Ghibli has dominated Japan's box office since the mid-1990s. Furthermore, thanks to an international distribution deal with Buena Vista International, a subsidiary of Disney, Hayao Miyazaki's films have become well-known transnational phenomena, garnering international film festival awards and even an Oscar. This international recognition sits alongside the work undertaken by a legion of active fans who have likewise promoted Miyazaki and Ghibli's works outside Japan. However, reflecting on the studio's closure in 2014 - after nearly 30 years of film, television and other kinds of production - there are still many aspects of Studio Ghibli that remain obscure. Despite recent rumours that Miyazaki may be coming out of retirement one last time (a pattern he has been repeating since the late 1990s), the (perhaps temporary) moth-balling of Studio Ghibli's feature production efforts in 2014 presents the scholars in this collection with an opportunity to reconsider Studio Ghibli's local and global significance. This special edition of the Journal of East Asian Popular Culture is therefore intended to strategically address some of the gaps in anime scholarship, and in the scholarship around Studio Ghibli. In this introduction we also seek to provide a more holistic understanding of what Studio Ghibli is, whose work it represents and how it has become a success both at home and abroad.

Our contributors focus on two facets of Studio Ghibli's meanings, but use a wide variety of academic approaches to do so. Their work ranges across historical, cultural industries, branding, transnation and fan studies methodologies and theories, each of which approaches shifting the debates around what Studio Ghibli means to global culture. The first major lens used to examine Studio Ghibli in this collection is a historical-industrial one. Through analyses of domestic Japanese and transnational industrial practices, our scholars seek to reconsider Studio Ghibli's meanings, and to show how much variety there is in what 'Studio Ghibli' means in different times and places. Second, our authors address the roles played by filmmakers, distributors and fans in promoting and spreading the work of Studio Ghibli. From the strategies of producer Toshio Suzuki through to the creative work of fan crafters, our contributors show how alive Studio Ghibli remains, even after its ostensible 
closure. In this way, our special edition takes a new view of the circuits of production and reception through which Ghibli's films flow (Du Gay et al. 2013). Moving away from textual analysis, therefore, the articles contained herein attempt to re-focus critical attention onto Ghibli's contexts; from the contexts of production, through to those of consumption and recycling. In doing so, this collection shows how Studio Ghibli's films are being kept alive, even in the years following the studio's closure. This special issue celebrating Studio Ghibli's 30 year production history thereby demonstrates the continuing power of the company's brand and its legacy in relation to global film culture.

Hayao Miyazaki, and to a lesser extent Isao Takahata, provide one contextual route into the study of Studio Ghibli's meanings. Miyazaki and Takahata have tended to overshadow those around them, but these filmmakers are nonetheless well-known in Japan for their collaborative working practices. Their animation styles, developed through decades of training at some of Japan's top animation studios, including Tōei Dōga (Toei Animation) and Nippon Animation, helped both directors forge strong contacts with everyone from producers through to key animators, who they would later gather around them when creating Studio Ghibli. The consistency in staff has led to a consistency in character design, backgrounds and movement aesthetics at the studio. Their style has remained consistent even as anime aesthetics have warped and changed dramatically in response to the emergence of CG animation technologies. One of Studio Ghibl's major aesthetic legacies, therefore, has to be the retention of earlier decades of Japanese animation styles within its house style; essentially, its preservation of the styles seen in earlier Tōei Dōga film animation and in the World Masterpiece Theatre animated TV series.

That legacy has long been written into scholarly understandings of Studio Ghibli, and few studios have been as highly praised as Ghibli. It is evident in the earliest of work on Miyazaki, as when Helen McCarthy tells us that, instead of comparing Miyazaki and Ghibli to Disney (something that Patrick Drazen also contests, 2003):

I would prefer to call Miyazaki "the Kurosawa of animation." Not only does his work have the same rare combination of epic sweep and human sensitivity that the great live-action director possessed, but it also fails to fit into any of the neat, child-sized boxes into which the West still tends to stuff animation as an art form. (1999: 10)

This tendency to align Miyazaki and his studio with the very best of Japanese cinema is only outdone by the commentary in Japan, where Miyazaki is compared not just to Disney, but to 
US filmmakers like Stephen Spielberg (see Denison, this edition). However, that high praise for Miyazaki leaves the work of other Ghibli directors out of the scholarly picture.

Studio Ghibli has been home to many key figures in Japanese animation history, not least Miyazaki's renowned colleague, Isao Takahata, whose films often surpass Miyazaki's own in terms of experimentation with form and style. Other famous anime directors, perhaps most notably Hideaki Anno, also have connections with the Studio, and Ghibli has trained other directors like Hiromasa Yonebayashi and Gorō Miyazaki. As Helen McCarthy and others have noted, what makes Ghibli different to other Japanese animation studios is its stable, permanent staff roster. Permanent staff have occupied positions at Ghibli since the mid-1990s, instead of doing piece work and undertaking short-term contracts (1999). This stability has helped to maintain the consistent production of a Studio Ghibli style of animation, helped by collaborative working practices the include key personnel like colour designer Michiyo Yasuda through to key animators like Megumi Kagawa and Hitomi Tateno, all of whom are women whose careers have been spent at Studio Ghibli. Therefore, taking a wider contextual of view of Studio Ghibli has the potential to reveal the extensive links forged between Miyazaki, Takahata and a plethora of other Japanese animation creators, whose continuing work may be the strongest examples of Ghibli's aesthetic legacy for Japanese animation.

A significant part of Studio Ghibli’s legacy lies its highly praised animation style. The Ghibli aesthetic is so well-developed that anime critic Jonathan Clements enjoins us to 'spare a though for poor Hiromasa Yonebayashi, who was nominated for an Oscar for Marnie [Omoide no Mānī/When Marnie Was There (2014)], but who is little-known or recognised in the anime world, having worked for a decade to keep someone else's reputation alive.' (2016) As Clements' comments suggest, Yonebayashi and other Ghibli animators' films bear strong hallmarks of a consistent studio style, linked to the work of its two most famous directors, Miyazaki and Takahata. Indeed, Yonebayashi's forthcoming film Mary and the Witch's Flower (Meari to majo no hana, 2017), made for the newly formed Studio Ponoc, has already begun to be likened in style and content to previous Studio Ghibli films.

But the aspect of Studio Ghibli's history that has most inspired academic criticism has been Miyazaki's (and to a lesser extent, Takahata's) marriage of consistent, albeit ambiguous, themes to these aesthetics. For example, Miyazaki's ecological interests are often read through the details of his filmmaking. They are seen in Miyazaki's films in the realistic, if 
impressionistic, way that wind moves through fields of grass, and in the way the first few drops of rain in a shower darken patches on a pathway (McCarthy 1999; Cavallaro 2006). Miyazaki and Takahata's anthropomorphism and zoomorphism also go hand-in-hand with the creation of memorable characters and the studio's interests in ecological conservation (Odell and Le Blanc 2015; Moist and Bartholow 2007; Foster 2012). Miyazaki's detailed depictions of flying machines are, in a similar way, entwined with themes of freedom and subjectivity (Napier 1998; Napier 2005). Ghibli's aesthetics and themes have thereby dominated discussions of the studio and are suggestive of attempts to define Miyazaki and his colleagues as auteur-style directors, bringing them out of the realm of commercial film production in order to celebrate them as artists with universal concerns.

The focus on Studio Ghibli's themes in academic scholarship may help to explain, somewhat, the relative lack of work that places Ghibli's productions within commercial contexts. Miyazaki and Takahata are instead discussed as exemplary transnational auteur directors adhering to "the transnational commerce and practices of auteurism...embedded in the material conditions and commercial strategies of international institutions and networks of circulation' (Lee 2008: 204, emphasis in original). In this special edition, our contributors show how the commercial side of Studio Ghibli includes not just the branding of Miyazaki and Takahata as commercial auteurs (see Carter, this collection), but can also be read in the wide variety of side-projects and advertising work undertaken by the studio. While sometimes analysed (McCarthy 1999; Odell and Le Blanc 2015), these side-projects have only rarely the province of academic scholarship to date, suggesting rich ground for future scholarly work.

Additionally, there is much debate over what counts as a 'Studio Ghibli' film. Many of the books ostensibly on Studio Ghibli include some, or all, of Miyazaki and Takahata's pre-Ghibli works (Hu 2010; Cavallaro 2006), because they focus on the directors rather than their studio. This has the effect of extending Studio Ghibli's history backwards in time to periods before its creation, most notably in relation to Miyazaki's Nausicaä of the Valley of the Wind (Kaze no tani no Naushika, 1983, for more see Denison, and Yoshioka, this collection). Moreover, not all of the films released by Ghibli in Japan have been distributed to Western audiences. Most notably the experimental, CG animated Ghiblies (Giburīzu, a television short, Yoshiyuki Momose, 2000) and Ghiblies 2 (theatrically released with The Cat Returns, Neko no Ongaeshi, Yoshiyuki Momose, 2002) have yet to be released in the USA or UK, despite Ghiblies 2 being included in the Japanese DVD release for The Cat Returns. 
Similarly, Studio Ghibli's home distribution label is becoming a home for world 'art' animation, including its own. For example, the 'Full of Ghibli' (Jiburi ga ippai) distribution label has released experimental ancillary works such as Iblard Time (Ibarādo jikan, Naohisa Inoue, 2007), a film that focuses on animated background images, helping to cement the construction of Ghibli as a home for animation art. The studio's distribution of many of these ancillary and pre-Ghibli texts in Japan also reinforces the impression that Studio Ghibli has much a longer history and broader meanings in Japan than elsewhere. This is a significant distinction, and one confirming that the meanings of Studio Ghibli have become quite porous. Some films have become firmly understood as part of Studio Ghibli's canonical history despite pre-dating the company's formation, while a different corpus of texts provides distinctive domestic and transnational meanings and associations for the studio inside and outside of Japan.

In suggesting that there are aspects of Studio Ghibli that remain hidden from global view, we also note that this is due to the successful dissemination of some of its more high profile films world-wide. As a consequence, a significant amount of the existing work on Studio Ghibli has been predicated on a discussion of the cultural lenses through which the Studio as its products might be viewed. Rayna Denison has argued, for instance, that Miyazaki’s Oscar-winning Spirited Away (Sen to Chihiro no kamikakushi, 2001) can be read as a high 'mutable' text, and that the phases of translation and distribution it went through as it travelled outside Japan allowed Miyazaki's film to be continually repositioned for a variety of global animation markets (2007: 319). Taking a different view of the same film, Shiro Yoshioka writes that even in Spirited Away's domestic incarnation, Miyazaki's 'sense of Japanese culture as a part of Asia made his view different from conventional approaches to Japaneseness, which tended to focus on the uniqueness of Japanese tradition' (2008: 257). Both Yoshioka and Denison thereby point to the national instability, and transnational flexibility, of Spirited Away, a theme extended in the work of Daniela Pizzuto in this collection.

Susan Napier, likewise, sees Spirited Away as a film pulled between local and transnational polls when she argues that:

Spirited Away is less an upbeat fantasy than a complex exploration of a contemporary Japan that is searching for what might be termed cultural recovery, or perhaps cultural rehabilitation, in a corrupt postindustrial society. [...] Embodying in certain ways the 
tension between kokusaika [internationalization] and the furusato [local/home town], Spirited Away may also be seen as participating in a significant current debate concerning globalization. (2006: 288-289)

These commentaries all respond to the heightened global popularity of Studio Ghibli's films in the wake of Spirited Away's Academy Award win for Best Animated Feature in 2003, which accorded Spirited Away with a global reputation beyond that enjoyed by other Japanese anime or even, at that time, other forms of contemporary Japanese cinema.

The fact that there is considerable debate around how to best position Spirited Away within world culture is a testament on one hand to the complexity of its representational schema, but also to its distributors' ambitions, on the other. It is for this reason that our collection retains a structure that moves from the local towards the global (see Carter and Pizzuto, this collection). Our authors begin with locally-focused considerations of how Studio Ghibli operates in Japan, before moving on to increasingly expansive views of the transnational and global cultures forming around Miyazaki and his studio.

Several of our authors question what 'Studio Ghibli' means in these differing global contexts. Studio Ghibli is not just an animation studio: as Shiro Yoshioka demonstrates in his article about producer Toshio Suzuki in this special edition, Ghibli is also a major cultural industry, dealing in everything from film distribution, to theme park ownership, to licensing and commercial production for other companies. By decentring Miyazaki's importance in relation to Studio Ghibli, Yoshioka makes an important intervention in the debates about Ghibli-as-art, revealing the company's often hidden industrial side. Similarly, within the work on Studio Ghibli's brand presence, there has been a tendency to focus on the contemporary meanings of the company (for example, seen in Denison 2015), rather than examining its history and development. For this reason, Rayna Denison takes an historical view of Studio Ghibli, and in analyzing the period around Castle in the Sky (Tenkū no shiro Lapyuta, Hayao Miyazaki, 1985), she shows how little weight the studio carried on the release of its first film. In this way, our contributors show that Japan's most famous animation studio has greater inherent complexity and depth than previous discussions might admit. Moreover, the studio itself seems to have become more important as its founding animators have aged, taking personal animation brands and transforming them into corporate ones. 
As the discrepancies between art and industry show, one of the most significant questions to be asked as Ghibli ceases production is: what has been its cultural impact? Depending on the barometer by which one measures cultural impact, Studio Ghibli provides very different findings at both a national and transnational level. Moreover, when one starts to consider the holistic potential by which value is ascribed to the studio, its staff, films and other media content, and brand identity, it becomes apparent that the significance of the studio is much greater than the sum of its parts. Most recently, upon the announcement of retirement by Ghibli's two principle creators, Miyazaki and Takahata, the impact was global. This news was deemed of high (trans)cultural significance and has created an ongoing ontological insecurity around the studio. The Wind Rises (Kaze tachinu, 2013) and The Tale of the Princess Kaguya (Kaguya hime no monogatari, 2013), directed by Miyazaki and Takahata respectively, not only focus on death in different ways - but also offer potential swan songs for these directors.

These melancholic discourses are often premised on the cross-cultural comparison with Disney; a West versus East dichotomy that centres on animation and notions of artistic quality. If Disney is seen as problematic in its representations of gender, race and consumerist ideologies (see Giroux 1994), emblematic of the wider cultural imperialism of Hollywood (Costanzo 2014: 27-8), then Ghibli is often positioned antithetically as national/world cinema and artistically niche (Crofts 2000: 2; Nagib 2006: 30; Badley and Palmer 2006: 2). This is often, inadvertently, reinforced by the extensive detailed analyses of Ghibli films within academia that explore the green politics and strong female characters present within the studio's catalogue. While this research yields important findings, the reading of Ghibli as the (trans)cultural remedy to the Disneyfication of mass media is not without its issues.

Firstly, within Japan, Ghibli is largely perceived as offering mainstream blockbuster output (Denison 2008), supported by a museum and large arrays of official merchandise, the wider remit of the company also includes producing other forms of media content under a number of subsidiary brands (Denison 2015: 124-9). Secondly, the questioning of the Ghibli/art versus Disney/mainstream binary is also extended to the transnational dynamics of global film circulation. Disney's acquisition of Ghibli's films for US and European distribution means that the US conglomerate has played an important role in not only disseminating Studio Ghibli's output to wider audiences in the West, but also in supporting its success through translation, marketing campaigns and theatrical trailers. As a part of this process, Disney has framed Studio Ghibli's films in ways more concordant with Disney's 
own themes and ideologies; a relationship analysed in depth in Laz Carter's article in this special edition, which examines the representation and negotiation of foreignness and localization between Japanese film trailers and Disney-made trailers for the US for Miyazaki’s hit Spirited Away (2001).

But while the official release of Ghibli films has extended its cultural impact globally, such offerings are not always the championed forms by transnational fans. As Daniela Pizzuto illustrates in her article in this collection, local versions can become problematically 'authentic', as was the case in Pizzuto's research into the various releases of Princess Mononoke (1997) in Italy. Pizzuto shows that the challenge of entering new markets is both linguistic and cultural, and that even the companies working locally to domesticate Studio Ghibli films can meet with resistance from audiences desiring more immediate access to Studio Ghibli films. Moreover, fans also play important roles, as Pizzuto's research into fan opinions in Italy shows, fans play important roles as gatekeepers and authenticators for Ghibli films. Therefore, while both mainstream and independent distributors have played important roles in creating a transnational audience for Ghibli films, online/digital media and audiences also play salient roles in the circulation and acquisition of Ghibli texts within a global context.

Through shadow economies whereby films are consumed via non-official channels (Lobato 2012), from the purchase of bootlegs to importing, and from streaming to downloading, fans can often obtain Ghibli texts before official release dates in their respective countries. As Susan Napier has demonstrated in her work on the US fandom for Studio Ghibli, fans have been proselytising for the spread of Ghibli's films for decades, and continue to celebrate the studio's work at a wide range of events from fan conventions through to specific online forums. Napier suggests that the value of Studio Ghibli to fans may be

that Miyazaki's subtle and complex world view allows them to "break the rules" of Western culture, to go beyond the Hollywood happy endings, or the need for a defined good and evil, and embrace the world in all its ambiguity, heartbreak, and hope. (2007: 204)

Just as the transnational reproduction, promotion and dissemination of Studio Ghibli's texts worked to spread Miyazaki's cinema as a new kind of art animation, fans have actively 
embraced that cinema for the resistant and ambiguous subcultural capital it affords (Thornton 1995; Jancovich 2000).

Moreover, online audiences can play key roles in spreading, translating and archiving materials relating to Studio Ghibli. In some cases, for example, fans provide subtitles for otherwise unavailable films so others can enjoy them (Lee 2011); or, they may record, compile and spread ancillary texts, as seen in recent YouTube compilations of Ghibli's work in television advertising and music videos. The creativity bound up in fan relationships between international audiences, industry and online media is explored in Lori Hitchcock Morimoto and Pizzuto's research in this special edition. Both scholars highlight the need to not only consider the cultural impact of Ghibli texts themselves, and the industry players involved in the framing and distribution of said texts, but also active audiences' roles in creating meaning around the studio, and in keeping its meanings alive following the studio's closure.

This includes the work of transnational fans who champion Studio Ghibli within fan communities, but also the ways in which a range of audience members participate in strengthening and widening the significance of the studio, sometimes in tangential, unexpected ways. Such affective engagement is explored at length in both Morimoto's and James Rendell's articles, with both contributions analysing how fan-produced content illustrates and perpetuates strong emotional investments with Studio Ghibli. Morimoto analyses the 'memeifcation' of the emblematic bus-stop scene in My Neighbor Totoro (Tonari no Totoro, Hayao Miyazaki, 1988), in which fans spread creatively adapted images based on Miyazaki's popular film. Morimoto investigates an audience-base that spills over from Ghibli into other forms of Japanese and global popular culture fandom, where fans create new meanings for Ghibli by mixing and matching its iconic images with other characters and franchises from global popular culture. Rendell, by contrast, focuses on fancrafts as a prominent fan practice. He shows how crafters have been immersing themselves in the Ghibli world, and examines how their creative work reinforces the eco-politics and ideologies of the studio.

Both articles also attest to the pertinence of online social media as spaces for fans to engage with other likeminded audiences from around the world, and they show that, as the platforms for fan engagement and activity proliferate, fandom itself is changing in the ways it makes use of, and displays, its favoured texts. At the same time, social media is connecting 
general consumers to active fans in a growing grey-market that links social back to real-world activities like traditional crafts. This connection allows fans to perform their fan identities as tangible markers of Ghibli's transcultural impact, even when the company itself resists the lure of international licensing of merchandising.

By highlighting the myriad ways that one might read the cultural impact of Studio Ghibli both locally and globally, this special edition of the Journal of East Asian Popular Culture seeks to highlight the significance of the company at these various levels. Focusing on both the industrial contexts of production and re-production, while being attentive to the unauthorised ways that fans and consumers adapt Studio Ghibli's works, allows us to rethink many of the preconceptions that linger around Miyazaki and Takahata's filmmaking. This collection also endeavours to attest to Studio Ghibli's diverse forms of cultural impact by offering a variety of perspectives, frameworks and arguments on Ghibli that seek to go beyond the films made by the studio. We hope to address key aspects of Ghibli's cultural meanings, revealing those that have played significant roles in shaping the company at an industrial level. Our investigations of Ghibli's ever-expanding global reach, from the initial stages of proprietary marketing through to the work of fans and other consumers in spreading Ghibli's most iconic imagery, are intended to counter claims of the death of Ghibli. In exploring 30 years of Studio Ghibli's history and meanings, therefore, this special edition argues that even the 'closure' of Studio Ghibli does not, in many respects, mean the end of Studio Ghibli.

\section{Bibliography}

Badley, L. and R.B. Palmer (2006), 'Introduction', in L. Badley, R.B. Palmer and S.J. Schneider (eds), Traditions in World Cinema, Edinburgh: Edinburgh University Press, pp.112.

Cavallaro, D. (2006) The Anime Art of Hayao Miyazaki, Jefferson, NC: McFarland.

Clements, J. (2016) 'When Marnie was There', Schoolgirl Milky Crisis, https://schoolgirlmilkycrisis.com/2016/08/26/when-miyazaki-was-there/. Accessed 13 October 2016. 
Costanzo, W.V. (2014), World Cinema Through Global Genres, Chichester: Wiley Blackwell.

Crofts, S. (2000), 'Concepts of National Cinema', in J. Hill and P. Church Gibson (eds.), World Cinema: Critical Approaches, Oxford: Oxford University Press, pp.1-10.

Denison, R. (2007) 'The Global Markets for Anime: Miyazaki Hayao’s Spirited Away (2001)', in A. Phillips and J. Stringer (eds.), Japanese Cinema: Texts and Contexts, London: Routledge, pp. 308-321.

- (2008), 'The Language of the Blockbuster: Promotion, Princess Mononoke and the Daihitto in Japanese Film Culture', in L. Hunt and L. Wing-Fai (eds), East Asian Cinemas: Exploring Transnational Connections on Film, London and New York: I.B. Tauris, pp:101119.

— (2015), Anime: A Critical Introduction, London and New York: Bloomsbury.

Drazen, P. (2003), Anime Explosion!: The What? Why? and Wow! of Japanese Animation, Berkeley, CA: Stonebridge Press.

Du Gay, P., S. Hall, L. Janes, A. Koed Madsen, H. McKay and K. Negus (2013) Doing Cultural Studies: The Story of the Sony Walkman, $2^{\text {nd }}$ Edition, London: Sage.

Giroux, H. (1994), 'Animating Youth: The Disneyfication of Children's Culture', Socialist Review, 24:3, pp.23-55

Hu, T.Y. (2010) Frames of Anime: Culture and Image-Building, Hong Kong: Hong Kong University Press.

Jancovich, M. (2000) ““A Real Shocker”: Authenticity, Genre and the Struggle for Distinction,' Continuum, 14, pp.23-35.

Kelts, R. (2006), Japanamerica: How Japanese Pop Culture Has Invaded the U.S., New York and Basingstoke: Palgrave Macmillan.

Kendrick, J. (2001), 'What is the Criterion? The Criterion Collection as an Archive of Film as Culture', Journal of Film and Video, 53:2-3, pp.124-139. 
Lee, H.K. (2011), 'Participatory Media Fandom: A Case Study of Anime Fansubbing', Media, Culture and Society, 33:8, pp.1131-1147.

Lee. N.J.Y. (2008), 'Salute to Mr. Vengeance! The Making of a Transnational Autuer Park Chan-Wook', in L. Hunt and L. Wing-Fai (eds.), East Asian Cinemas: Exploring Transnational Connections on Film, London and New York: I.B. Tauris, pp. 203-219.

Lobato, R. (2012), Shadow Economies of Cinema: Mapping Informal Film Distribution, London: BFI Publishing.

McCarthy, H. (1999), Hayao Miyazaki Master of Japanese Animation: Films, Themes, Artistry, Berkeley, CA: Stonebridge Press.

Moist K.M. and M. Bartholow (2007), 'When Pigs Fly: Anime, Auteurism, and Miyazaki’s Porco Rosso', Animation: An Interdisciplinary Journal, 2:1, March, pp. 27-42.

Nagib, L. (2006), 'Towards a Positive Definition of World Cinema', in S. Dennison and S.H. Lim (eds.), Remapping World Cinema: Identity, Culture and Politics in Film, London and New York: Wallflower Press, pp.30-37.

Napier, S. (1998), 'Vampires, Psychic Girls, Flying Women and Sailor Scouts: Four Faces of the Young Female in Japanese Popular Culture', in D.P. Martinez (ed.), The Worlds of Japanese Popular Culture, Cambridge: Cambridge University Press, pp.91-109.

— (2005), Anime from Akira to Howl's Moving Castle: Experiencing Contemporary Japanese Anime, New York: Palgrave.

— (2006) 'Matter out of Place: Carnival, Containment, and Cultural Recovery in Miyazaki's Spirited Away', Journal of Japanese Studies, 32:2, Summer, pp.287-310.

- (2007) From Impressionism to Anime: Japan as Fantasy and Fan Cult in the Mind of the West, New York: Palgrave.

Odell, C. and M. Le Blanc (2009) Studio Ghibli. London: Kamera.

Thornton, S. (1995) Club Cultures: Music, Media, and Subcultural Capital, Middletown, CT: Wesleyan University Press. 
Yoshioka, S. (2008), 'Heart of Japaneseness: History and Nostalgia in Hayao Miyazaki's Spirited Away', in M.W. MacWilliams (ed.) Japanese Visual Culture: Explorations in the World of Manga and Anime, Armonk, NY: ME Sharpe, pp.256-273.

\title{
Toshio's Movie Castle: A Historical Overview of Studio Ghibli's Collaboration and Promotional Strategies
}

Shiro Yoshioka, Newcastle University

\begin{abstract}
While so-called 'Ghibli films' attract global academic and popular attention because of their technical and textual genius, the current fame of the studio and commercial success of its films is in large part the product of an intricate system of promotion and advertising developed in the 1980s. At the nexus of the studio's commercial success is Toshio Suzuki, the key producer at the studio. This paper argues that the success of the studio owes much, not only to the superb quality of the films it has created, but also to its relationship with other parties involved in filmmaking, such as publishing house Tokuma shoten, TV broadcasting company NTV and film distributors Tōhō and Tōei, relationships developed by Suzuki. The links with these companies forged in the 1980s enabled Ghibli to come into existence and continue to thrive by virtue of their financial and promotional support. Besides detailing how the links were forged and their significance for Ghibli, this article will also examine how promotional strategies played an important role in making Ghibli films and the name of Hayao Miyazaki (and to a lesser extent film director Isao Takahata) widely known in Japan in the 1980s. For example, one of Suzuki's key strategies was advertising campaigns involving 'tokubetsu kyōsan kigyō' (special sponsors) that did not directly fund the films. For Suzuki, Ghibli originally was a locus in which Miyazaki and Takahata to create the type of films they wanted. As such, the primary concern for him as the producer was to motivate and protect the creators so that they could keep on creating films. Therefore, this article will examine the connections between Suzuki's creative work as Studio Ghibli's main producer, while
\end{abstract}


investigating how the links he forged with outside companies led to unprecedented levels of success for his nascent studio.

Keywords: Suzuki Toshio, Tokuma shoten, Advertising, Tie-in campaigns, Kiki's Delivery Service, Princess Mononoke 


\section{Toshio's Movie Castle: A Historical Overview of Studio Ghibli's Collaboration and Promotional Strategies}

Shiro Yoshioka, Newcastle University

I believe that the uniqueness of Studio Ghibli lies in the fact that it is successful in maintaining both 'quality of the content [of its films]' and 'commercial success.' However great the works one continues to create with great ambition, in a country like Japan where the government is not particularly interested in protecting film industry, by simply doing that [creating good films with high ambition], one cannot keep creating films for a long time due to financial difficulties in maintaining the business.

Toshio Suzuki, Producer, Studio Ghibli

(Suzuki 1996: 130)

Why are 'Ghibli films' so popular both in and outside Japan? One very simple possible answer to the question is: the films are aesthetically and thematically superb. That may well be true. However, at the same time, it is only half true. As Toshio Suzuki, the producer for Studio Ghibli says in his essay quoted above, however great 'Ghibli films' are, they did not become Japan's, and even the world's, favourite simply because of their aesthetic and thematic splendour. Unlike typical TV animation that is often created under tightly restricted schedules and budgets, films created by Ghibli are high profile, high stake features that are prepared over years and with a budget of hundreds of millions of yen. As such, the films, just like any other products, need to be promoted and sold so that the studio can make profit and keep the business running. There also have to be sponsors. We have to note that Studio Ghibli has its own mechanism to finance, promote and sell its films, and that there is a man by the name of Toshio Suzuki who is responsible for that mechanism. As discussed throughout this article, it is not that Suzuki developed some kind of revolutionary mechanism to sell films, or he is the only person responsible for making important decisions on the studio. However, he did play a crucial role at key moments in the studio's history by establishing connections with companies and people in and outside the film industry. He asked for and/or followed their advice and, as discussed in detail below, that greatly contributed to commercial success of Ghibli films. Therefore, it hardly is an overstatement to say that without Suzuki, Studio Ghibli would not have enjoyed the success it achieved, or that it might not even have come into existence because, as detailed in the next section of this article, Suzuki played a crucial 
role in founding the studio by liaising between the creators and the sponsors as well as undertaking practical work to establish the studio as a company.

This article will examine how Suzuki developed promotional strategies for Studio Ghibli. Knowing about his strategies as well as his background, especially his link with publishing house Tokuma shoten, will enable us to understand key factors that contributed to current fame of the studio, besides the quality of its products. Suzuki has spoken and written extensively about the history of Ghibli as well as himself. This article will follow Suzuki's career chronologically, mainly using his interviews and essays, few of which are available in English. This approach will allow us to examine and critique the 'official' history of Ghibli as it is presented by the studio and Suzuki. The article will consist of three sections: the first one will overview Suzuki's personal background, how he came to work with Hayao Miyazaki and Isao Takahata, and his contribution to founding of the studio. The second section will be on his early days at Ghibli up to Kiki's Delivery Service (Majo no takkyūbin, Hayao Miyazaki, 1989). It is in this period that Suzuki learned significance of marketing as a way to allow creators to continue to create films and built up the promotional system for Studio Ghibli's films by active use of tie-in campaigns and association with other media companies, especially television station Nippon terebi hōsōmō (Nippon Television Network Corporation, hereafter NTV). The third section will focus on that system's development in the 1990s. I argue that the phenomenal success of Princess Mononoke (Mononokehime, Hayao Miyazaki, 1997) owes much the massive promotion campaign and strategic 'occupation' of cinemas all over Japan planned by Suzuki.

\section{The early days}

Suzuki's link with anime/manga as well as film in general began in his childhood. His love and knowledge of these media would eventually lead him to Ghibli as seen in brief outline of his life below. Suzuki was born in Nagoya in 1948. His family owned a business that produced and sold clothes. The family was upper-middle class. The Suzukis were the second family to have a TV set in their neighbourhood and Suzuki's parents liked films, and they often took him to cinema. While his mother preferred western films, father liked Japanese ones. Suzuki's father was also good at drawing pictures and liked manga. Suzuki recalls that his father bought many manga magazines and piled them up in a room, so Suzuki often stole into the room when it was still dark and spent the whole day there. (Suzuki 2011: 227-230)

After graduating from Keiō University, Suzuki joined publishing house Tokuma shoten in 1972. He wrote articles about topics ranging from gossip and scandals to social and 
political issues for weekly magazine Asahi geinō. Suzuki's first involvement in the anime/manga world was through a short-lived manga magazine Comic \& Comic (Komikku \& komikku). Although he enjoyed writing for the weekly magazine, he was forced to leave the editorial office after he had a personal conflict with his boss. Suzuki often had conflicts with his boss and one day, when Suzuki was told to interview eight people by the next day, Suzuki told him that it was impossible to finish in time by himself and asked for an assistant. The boss simply said 'Okay, so you cannot do this by yourself' and stopped asking him to do any further assignments. (Suzuki 2013a: 65-82) Nevertheless, as an editor, Suzuki had worked closely with many manga artists and also film directors who wrote plots for some of the manga in the magazine, beginning to amass a network of industry contacts.

Undeterred, Suzuki then joined editorial board of a magazine TV Land (Terebi rando). The magazine was for children, mainly featuring the heroes of TV shows and anime, but it was not selling well. Hideo Ogata, the chief editor of the magazine, tried various strategies to boost the sales. One of them was to publish a series of extra volumes focusing on a single anime series, targeting slightly older readers. The series was titled Roman Album (Roman агиbати), and the first volume was on the hugely popular anime franchise Space Battleship Yamato (Uchūsenkan Yamato, Leiji Matsumoto, the manga was published in Shōnen magazine 1974-75). The series turned out to be successful, and still continues today as a multimedia franchise (Ogata 2004: 13-15, 23-24, 44-47). The Roman Album series was a connection that Suzuki would go on to utilise, producing special issues for many of Miyazaki and Takahata's films.

Having realized how popular anime was, Ogata decided to publish a magazine specializing in Japan's growing anime culture, which would be later named Animage (Animēju), and Suzuki embarked on the project. However, although he liked manga, Suzuki had no knowledge of anime. To write articles for the inaugural issue of the magazine and learn about anime, Suzuki met three high school girls Ogata knew. The girls told Suzuki about anime including popular works at the time and also classics. One of the classics they mentioned was Isao Takahata's Horus: Prince of the Sun (Taiyō no ōji Horusu no daibōken, 1968). Before he could see the film, he decided to interview Takahata as well as Miyazaki, who also worked on the film, because very little time was left before the deadline for the article. Suzuki's first impression of the two men was that they were 'weirdos': Takahata told Suzuki why he did not want to have the interview, spending an hour telling Suzuki as much over the phone, whereas Miyazaki insisted that he have sixteen pages for his interview (Suzuki 2013a: 92). Upon seeing the film, however, Suzuki was captivated. He later said that 
the film changed his life (Suzuki 2013a: 94). Suzuki recalled that he was surprised because Takahata had created a cartoon film with the Vietnam War in mind (Suzuki 2013a: 93). Thus, the long association between Suzuki as well as Tokuma shoten and the two directors began.

As a consequence, the August 1981 issue of Animage became the first magazine to feature Miyazaki. The issue sold 320,000 copies while the average issue sales up to July in 1981 was 270,000 (Ogata 2004: 147), demonstrating Suzuki's eye for talent, and the popular appeal of Miyazaki even as a young animator. Furthermore, the manga version of Nausicaa of the Valley of the Wind (Kaze no tani no Naushika) by Miyazaki began in the February 1982 issue of the magazine. Miyazaki has jokingly recalled that he was persuaded into serializing the manga after repeatedly talking with Suzuki and Mitsuru Kameyama, another editor at Animage, because he felt obliged for the coffee they bought for him at every meeting (Miyazaki 2013: 92). This personal, off-hand account of the beginning of the relationship between Miyazaki and Tokuma shoten, through Suzuki's influence belies the impact of the publishing house on the history of Studio Ghibli.

Miyazaki's manga turned out to be very popular. The sales of the issue of Animage in which Nausicaa started jumped up by 20,000 copies from the previous month (Ogata 2004: 163). Encouraged by the reaction, Ogata began to think of the possibility of making the manga into a short film. Yasuyoshi Tokuma, the president of Tokuma shoten, was keen to expand his business beyond print media by collaborating with other audio and visual media companies, so he supported the project. Eventually the project grew into a feature film and was released in 1984. Ever since, Tokuma shoten has continued to be involved in production of films by Miyazaki and Takahata, and once Ghibli was established, maintained close link with the studio by publishing various print and audio materials. While it was Ogata and Tokuma who actually made decisions, the link between Takahata, Miyazaki and Tokuma shoten would not have existed unless Suzuki 'discovered' them in the first place.

Suzuki also went on to play important roles in the production of the film version of Nausicaa. For example, Miyazaki insisted that Takahata be the producer of the film, but Takahata kept on refusing. Since Suzuki was writing about the production of a film by Takahata in 1981 for Animage, Suzuki basically 'met him every day' (Suzuki 2013a: 106). Seeing Miyazaki burst into tears one evening saying that while he had devoted everything to Takahata in his youth when they were colleagues at Tōei animation studio, and yet Takahata did nothing for him, Suzuki relates that he did something he never did again: he, shouted at Takahata. In his account of the incident, Suzuki relates that he accused Takahata of deserting his best friend when Miyazaki needed help. Famously, as a result, Takahata finally agreed to 
be the producer (Suzuki 2013a: 114-115). Suzuki then shadowed Takahata as the producer, and subsequently helped in finding animators and asking Tokuma shoten for more funds (119). In this early work with Takahata and Miyazaki, Suzuki began to act as a pseudoproducer, a role he would later occupy formally at Ghibli.

Additionally, Suzuki influenced the content of Nausicaa. In Miyazaki's original storyboards, the ending of the script was different from what it is now in the film. Instead of Nausicaa being hit by rampaging Ōmu, the story ends abruptly when Nausicaa lands in front of them. Suzuki relates that found the ending unnatural and discussed it with Takahata, who agreed with his view. Eventually they concluded that the ending should be changed to what it is now, and persuaded Miyazaki (Suzuki 2014a: 48). Suzuki developed this strategy and has continued to have influence on the themes and content of the Studio Ghibli's films, especially those by Miyazaki and Takahata, including Miyazaki's The Wind Rises (Kaze tachinu, 2013). It was, for instance, Suzuki who persuaded Miyazaki to create a film on the Zero fighter and its designer (Suzuki 2014a, 213-214). In the case of Miyazaki’s Princess Mononoke (1997), Suzuki even changed the title of the film from Ashitaka sekki ('The Legend of Ashitaka') as originally proposed by Miyazaki without his consent (Suzuki 2014a: 86-87; Miyazaki 2002: 169; Miyazaki and Yōrō 2002: 38-39). As this demonstrates, Suzuki grew in creative influence at the studio, moving from peripheral attempts to influence content to become one of Studio Ghibli's most significant creative voices.

The completed film of Nausicaa brought 915,000 audience members to cinemas earning 742 million yen (Kanō 2006: 65). However, at this stage, Suzuki claims he was not interested in the commercial success of the film because all he cared about was to simply create it (Suzuki 2013a: 124). In the light of his subsequent and continual involvement with Takahata and Miyazaki's films, this reads disingenuously. However, as discussed in the next section, Suzuki's attitude to filmmaking remained the same until he actually confronted the possibility that Miyazaki and Takahata could no longer create films due to their lack of commercial success. Nor was Suzuki active in promoting Nausicaa at this early stage in his involvement with the filmmakers. Promotion and advertising were left for advertising agency Hakuhōdō, which funded Nausicaa together with Tokuma shoten, and Meijā, an agency specializing in promotion of films. It was from Castle in the Sky (Tenkū no shiro Rapyuta, Hayao Miyazaki, 1986) that Suzuki began to pay more attention to promotion and funding.

\section{The foundation of Ghibli and strategies for promotion}


The next film Miyazaki created was Castle in the Sky. Suzuki's accounts show that Tokuma shoten was eager to fund the project. However, the problem with the film was that there was no animation studio which Miyazaki could use as his base. The studio that had created Nausicaa was no longer in business. Takahata, who agreed to be the producer again, and Suzuki asked various studios they knew for cooperation, only to be rejected. Eventually, Takahata decided that the best solution would be to found a new studio to be owned by Tokuma shoten (Suzuki 2013b: 55-56; Studio Ghibli 2013a: 33). Suzuki, representing the editorial board of Animage, proposed Takahata's decision to Yasuyoshi Tokuma. Tokuma approved the proposal, and Suzuki undertook the practical work for founding the studio, such as converting a company owned by Tokuma shoten that only existed on paper into Studio Ghibli, and finding an actual building to be used as the studio (Studio Ghibli 2013a: 33; Suzuki 2013b: 56-57). Again, it was Takahata and Tokuma who made the actual decision, however, had it not been for the connection between them, which owes much to Suzuki in the first place, Studio Ghibli as we know it today may not have existed at all.

It was from Castle in the Sky that Suzuki began to be involved in the process of promotion and negotiation with sponsors. Working together with Takahata, Suzuki recalls learning tips on dealing with tie-in partners. One particularly important lesson was that the rights to use materials from the film including the characters in advertisements and other materials for tie-ins should be strictly under the control of the studio and creator rather than the partner companies. For Castle in the Sky, Toshiba and food company Ajinomoto became tie-in partners. Toshiba produced a 'Rapyuta [the original Japanese title of Castle in the Sky] version' hi-fi system and Ajinomoto sold a juice drink named 'Tenkū no shiro Rapyuta,' exactly the same as the title of the film (see Denison, this collection for more on Castle in the Sky's promotional campaign). In the first contract they presented to Takahata, these companies retained the right to use any materials from the film freely in their advertisements. Takahata, however, did not accept the item in the contract. Instead, he only allowed them to use the logo of the film. Suzuki later recalled that 'that was the first time that I learned what a contract is all about' (Suzuki 2013a: 133).

Another lesson Suzuki learned through the experience of working with these companies was that he should not accept any funds from tie-in partners. For Castle in the Sky, the two partners also paid part of the production cost of the film when Tokuma shoten's contributions fell short. However, as Suzuki sees it, depending on these partners as sponsors can compromise the authority of the creator and the studio over the use of materials in advertisements and lead to a risk of advertisements that are totally different from the actual 
film being made simply for promotion of the tie-in products rather than the film itself (2005). Actually in the case of Nausicaa, promoting the title of the film was prioritized, and as a result, there were a number of collaborations that had nothing to do with the actual content of the film. For example, advertising agency Hakuhōdō organized a campaign titled 'Nausicaa Girl.' This was a public audition for a young female aidoru who would sing the theme song of the film. Out of 7,611 applications, Yasuda Narumi was chosen, but her song titled 'Kaze no tani no Naushika' (Nausicaa of the Valley of the Wind) was never used in the film (Kanō 2006: 63). Takahata was disdainful about the campaign because it ignored the actual content of the film (Komatsubara 1984: 66). Takahata's rejection of the contract for Castle in the Sky can be understood in the light of this previous experience.

The decision not to allow the tie-in partners to use materials from the film, however, was problematic because it curtailed the possibilities regarding the promotion of the tie-in products and the film. The juice drink did not sell well even though it was released in summer, the best season for sales of soft drinks (Suzuki 2005: 92). The film itself was not as successful as Nausicaa, either. The audience numbers and revenue fell to 775,000 and 583 million yen respectively (Studio Ghibli 2013a: 46). The experience left strong impression on Suzuki. Later when Suzuki began to establish strategies for promotion of films after establishment of Ghibli, he made it clear that tie-in projects for Ghibli films would not involve any exchange of funds, and while the tie-in partners are allowed to use materials from the films, the way they are used is strictly controlled by the studio (Studio Ghibli 2013a: 46). In the next section we will see how that system functions, using Kiki's Delivery Service as an example.

\section{Establishment of the 'Ghibli method': Kiki's Delivery Service}

The double bill of Miyazaki's Tonari no Totoro/My Neighbor Totoro and Takahata's Grave of the Fireflies (Hotaru no haka,1987), the second project by Studio Ghibli, was marginally more successful than Castle in the Sky with audience figures of 801,000 and 588 million yen of revenue. However, the figures account for two films rather than one (Studio Ghibli 2013b, 37). One significant development for Totoro was the creation of character merchandise. The popularity of Totoro surged after the cinematic release ended. One of the reasons was the stuffed toys of the main character Totoro, which were first sold in 1988. These were originally displayed in cinemas before the film was released. They turned out to be popular, and a division of Tokuma shoten mass-produced them (Kanō 2006: 125). In 1989, My Neighbor Totoro was shown on TV for the first time as a part of promotion for Kiki's 
Delivery Service (Majo no takkyūbin, Hayao Miyazaki, 1989), as discussed in a moment. In the programme, thirty stuffed toys of Totoro were given to the viewers after a draw which attracted more than 300,000 entries (Anon. 1989: 38). The merchandise contributed to the popularity of the film, but it was not an integral part of its promotional campaign. Although these toys helped to ameliorate the deficits from the production, Suzuki was, and still is, determined that 'the film comes first, then the merchandise' and 'the content [of the film] should never be changed for the sake of [selling] merchandise.' (Suzuki 2014a: 84) He even says that he was careful so that the sales of merchandise stay within a certain limit of overall sales of products of the studio because Ghibli is a company made to sell films more than anything else (Suzuki 2014a: 243).

As a result of continuous decline in audience numbers and revenue at cinemas across the first two releases by Ghibli, by the time the studio embarked on its third project, Kiki's Delivery Service, there was scepticism within the film industry about the outlook of the studio. As Suzuki famously and repeatedly recollects, one producer at the distributor Tōei told him that Kiki would be the last film for Miyazaki, and the company agreed to distribute the film only because Japanese logistics giant Yamato un'yu was backing the project. (Kajiyama 2004: 30-31) Even after Totoro, Suzuki states that 'I did not care even if [the film] did not attract an audience as long as we could make something confidently.' (Suzuki 2013a: 158) However, the remark by the Tōei producer upset and infuriated him. Suzuki was now determined to make Kiki's Delivery Service commercially successful. He turned to TV station Nippon terebi hōsōmō (NTV), asking for sponsorship because he believed that involving a TV station would make the film more successful (Suzuki 2013a: 158).

NTV already had a link with Tokuma shoten. In the early 1980s the station bought the rights to broadcast Miyazaki's first feature film Lupin III: Castle of Cagliostro (Rupan III sei: Kariosutoro no shiro, 1979). Whenever the film was shown on NTV, the viewing rate was always over 20 per cent, which is remarkably high for Japanese television programme. Later, Tokuma shoten, under Ogata's initiative, negotiated with NTV for the exclusive rights for broadcasting Nausicaa and also Castle in the Sky. NTV agreed to buy both films, and again they boasted high viewing rates once put on the small screen (Yokoyama 2004: 289-290). One important reason for Tokuma shoten to approach NTV for broadcasting rights for Nausicaa was that, unlike other stations that insisted the films be shown from $7 \mathrm{pm}$, assuming that the main audience would be children, NTV offered to show Nausicaa from 9pm. The decision was right because when the film was broadcast, it succeeded in appealing to adult 
audiences, and the viewing rate for the first broadcast was as high as 16 per cent. (Kajiyama 2004: 33) The convention of broadcasting Ghibli films from 9pm continues today. Based on these successes, NTV readily accepted the sponsorship proposal for Kiki, joining Tokuma shoten and Yamato un'yu. It still remains as one of the sponsors and an important player in promoting Ghibli films to this day.

The first thing Suzuki did at NTV, prompted by Seiji Okuda, the man responsible for promotion of the film at NTV, was to meet various directors and producers within the station, giving away merchandise from previous Studio Ghibli films. At the time, within the TV station, it was only young directors who knew Miyazaki's name. Therefore, it was necessary to promote the film to various other people within the station so that they would cooperate in promoting the film during their programmes (Okuda 2015a: 53).

The strategy for promoting the film on television devised by Okuda was simple but extensive and rigorous. The campaign was mainly three-fold:

- Continuous exposure: Having a girl dressed as Kiki, the protagonist of the film, stand behind the broadcaster in the station's daily live morning show Zoom in!! Morning! (Zümu in!! Asa!) for six months up to the release of the film ${ }^{1}$

- Special programmes on Kiki and Miyazaki: A programme consisting of interviews with young girls of the age of the protagonist including Suzuki's daughter, to find out what they feel about their lives, as well as a fly-on-the-wall documentary about the production of the film

- Denpa jakku (Hijacking of the airwaves): Promoting the film in every possible programme all day as well as showing past films by Miyazaki.

(Okuda 2015a: 52)

In addition, Miyazaki appeared on NTV's news shows for interviews. Campaigns were also held outside Tokyo, where the station is based because, as with all other Japanese TV stations, NTV has a string of keiretsu or affiliated TV and radio stations all over the country. For example, Miyazaki, along with Suzuki and Okuda, did a tour of Nagoya, Osaka and Fukuoka, wherein Miyazaki appeared in regional programmes for TV and radio as well as having interviews with newspapers and magazines. He also appeared in Zoom in!! Morning! while he was in Fukuoka (Okuda 2015a: 52-55). 
The tie-in advertising was further developed from Castle in the Sky. Unlike the previous film, advertisements for Kiki did feature screen captures from the film. The advertisement by Yamato un'yu, for example, carried a picture captured from the film where the protagonist Kiki and her cat Jiji are looking out of a window. However, the accompanying text makes no direct reference to the film apart from the very last sentence that says 'Yamato un'yu wa Majo no takkyūbin no seisaku ni sanka shite imasu (Yamato un'yu sponsors production of Kiki's Delivery Service).' At the bottom of the advertisement are the title of the film and credits for the director, the author of the original book and sponsors placed side by side with corporate logo of Yamato un'yu. The main copy at the top as well as the rest of the text emphasizes how caring and humane the services provided by the logistics company were, as if a mother cat cares for her kittens, alluding to the logo of the company featuring a black cat carrying its kitten, and also to Jiji the black cat in the film. Therefore, at the nexus of the advertisements for Kiki was a form of cross-promotional convergence in imagery - all with caring and warm connotations - that worked to conceptually link the logistics company and the film.

This type of campaign became a regular feature of ensuing Ghibli films. Suzuki states that tie-in partners are increasingly willing to run campaigns that actively promote the fact that they are partners in support of Ghibli and its films, rather than simply promoting their own products using the film as a catalyst. According to Suzuki that is because the general public in Japan has a very strong and positive image of the studio's films, and by announcing that they are in support of Ghibli's films, the tie-in partners can also associate themselves with the image of the films and the studio (Suzuki 1996: 130). Kiki became Studio Ghibli's most successful film to date thanks in part to Suzuki's promotional strategy, and the most successful film of 1989 earning 2.17 billion yen with audiences of 2.64 million (Studio Ghibli 2013c: 45). Together with Totoro, whose popularity surged after TV broadcast as a part of promotion for Kiki, the success of Kiki's Delivery Service firmly established the reputations of Miyazaki and the studio.

\section{The 'Suzuki theory': Princess Mononoke}

During production of Kiki's Delivery Service, Miyazaki was thinking about closing Studio Ghibli once the project was over because in his view, either within three years of foundation, or after completing three projects, the members of staff at animation studios begin to lose passion for their work and 'enter a lethargic stage,' making both the studio itself and its 
creations become conservative (Miyazaki 2014: 89). Hearing the idea, Suzuki reportedly opposed it. After discussions, they decided that Studio Ghibli would continue by employing animators as full-time employees of the studio rather than on contract only for the periods of production. To fully support the studio, Suzuki quit Tokuma shoten and joined Ghibli as a producer (Studio Ghibli 2014: 49-50, 52). As a result, Suzuki now began to fully and solely engage with the studio rather than acting as a go-between for Ghibli and Tokuma shoten.

The strategies for promotion developed for Kiki were further enhanced in the films that followed. By the time of Miyazaki's Princess Mononoke, Suzuki came to believe that the revenue from a film equals the amount of budget for publicity (Okuda 2015b: 92). For the studio, Mononoke was a high-stakes and high-risk project because of its large budget of more than 2 billion yen. The break-even-point of the film was estimated to be at least 3.6 billion yen. This was well beyond the highest revenue from the studio's films at that time, with 2.7 billion yen made by Miyazaki's Porco Rosso (Kurenai no buta) in 1992, thanks to, among other factors, an extensive promotional campaign involving NTV, Tokuma shoten and the sponsor of the film, Japan Air Lines. The campaign included an airship featuring the logo of the film and the sponsor as well as an image of the protagonist of the film flying over the Greater Tokyo area (Studio Ghibli 2015: 30; Anon. 1996: 49). Suzuki decided to set a bold target. Before eventually raising the bar to 6 billion yen, with the ambition to break the record of the most successful film ever shown in Japan (5.7 billion yen), he was aiming at 5 billion yen and planned to run promotional campaigns that were worth the same amount. At a 'gasshuku' (training camp) in which stakeholders of the film stayed in accommodation owned by NTV for two days, Suzuki presented the details of his plan, indicating the breakdown as follows:

- Funds for publicity paid by the distributor Tōhō: 500 million yen

- Funds for publicity paid by the studio and other sponsors: 200 million yen

- Tie-in projects with Nippon Life Insurance Company: an equivalent of 1 billion yen

- Promotion of Totoro and Whisper of the Heart (Mimi o sumaseba, Yoshifumi Kondō, 1995), two previous works of the studio sold by Buena Vista Home Entertainment as VHS/DVD

- Collaboration with newspapers the Yomiuri shinbun and Sports Nippon

- $\quad$ TV programmes on NTV and its regional associates as well as Japanese public broadcasting station NHK 
- Collaboration with Tokuma shoten [to publish books, magazines and other print materials promoting the film, the studio and Miyazaki]

- Previews organized by another publishing house, Kōdansha, inviting 10,000 people through twenty seven magazines published by the company

- Publicity campaigns in music stores by Tokuma Japan Communications, the company responsible for selling CDs related to Ghibli

- Events at Takashimaya department stores

- Other publicity campaigns

(Okuda 2015b: 91-92)

Under Suzuki's leadership most of these were materialized together with conventional promotional strategies including broadcast of past Ghibli films on NTV, a documentary following the production of the film which was eventually made into a programme to be sold as VHS/DVD and a promotional tour by Miyazaki and Suzuki to no less than 20 destinations around Japan. Newspapers and magazines carried numerous advertisements and feature articles during the period leading to the release (Kanō 2006: 210). The total number of pages of magazine articles featuring the film reached 109 (Anon. 1997: 22). Suzuki was actively involved in the production of these advertisements by deciding the overall layout of the advertisements especially the size and position of the main copy (Studio Ghibli 2002: 344).

While many of these promotional ideas began with Kiki, one notable addition is the previews in association with publishing house Kōdansha. These were first organized for Porco Rosso by JAL, NTV, Tokuma shoten and Kōdansha, having no less than 32 previews in fifteen days in cities all over Japan (Anon. 1996: 49). In an interview, Suzuki has explained that these previews were doubly effective because the audience would spread positive word of mouth and because they would function as publicity when the previews were announced on NTV programmes (Suzuki 2014b: 54). For Mononoke, 130 previews were planned, but due to delay in production, there actually were 70 (Kanō 2006: 210). At the 'camp,' Suzuki also explained that if the distributor Tōhō cooperated so that Mononoke could be shown at its 'best cinemas,' that is to say prestigious, larger and conveniently located ones all over Japan, then the revenue would reach the target of 5 billion yen (Okuda 2015b: 92).

Through the experience with Porco Rosso and Takahata's Pom Poko (Heisei tanuki gassen ponpoko, 1994), Suzuki became aware that besides promotion, the choice of cinemas 
and the duration of exhibition were essential factors for the success of the studio's films, especially when they were in competition with major foreign films. For example, the releases of both Porco Rosso and Mononoke coincided with the Japanese releases of Steven Spielberg films Hook (1991) and Jurassic Park (1993) respectively, and Pom Poko with Disney's The Lion King (Roger Allers and Rob Minkoff, 1994). In all cases, the Ghibli films beat the American ones. One significant factor for the victory was that the Ghibli films were shown at more prestigious cinemas for longer periods than their American competitors. Japanese cities outside Tokyo in the early 1990s often had two cinemas at most where films distributed by Tōhō were shown. One of them tended to be less prestigious and smaller than the other. Thanks to Fumio Nishino of Tōhō, who began to work closely with Suzuki in the late 1980s, from Porco Rosso onwards, Ghibli films were shown at the larger cinemas (Suzuki 2013a: 176-177, 182-183). For Mononoke, Suzuki again asked Nishino whether it was possible to show the film in best cinemas in Japan, many of which had already been booked for Jurassic Park. The executives of Tōhō were sceptical about Mononoke because of its grave and complicated themes that were totally different from previous Miyazaki films, but Nishino persuaded them to make a special arrangement for Mononoke (Suzuki 2015: 69-70). In addition, by the time of Mononoke, cinema complexes were sprouting in Japan. The managers of these newer cinemas offered to show Ghibli films because the reputation of Miyazaki and Ghibli had already been firmly established (Ichikawa, Ise, Okuda, Takai and Suzuki 2015: 13). Eventually, the film was opened in 260 cinemas in Japan out of 1,800 in total (Kanō 2006: 211).

By the time the film was released, interest in Mononoke in Japan had already surged, helped by Miyazaki's suggestion that this would be his last film. Mieko Hara, a designer at Tōhō working on newspaper advertisements for the film, recalls that she received phone calls from cinemas the evening immediately before the opening saying there were long queues outside the cinemas for advance tickets, even though the box offices were to be closed at seven, and that this was something that had never happened before (Studio Ghibli 2002: 345). The revenue for Mononoke easily achieved the target of 6 billion yen and eventually reached a staggering 11.3 billion yen to become the most successful film released in Japan at the time (Studio Ghibli 2015: 49). The way Mononoke succeeded - a massive promotional campaign making full use of tie-in projects, previews and media coverage before release of the film leading to the heightening of interest for people for whom the names Ghibli and Miyazaki were already synonymous with high-quality animation features - indicates that the success of 
Mononoke was not simply due to its content or technical achievement, but also to the success of previous Ghibli films and the massive promotional campaign that led to swelling expectations for the film.

\section{Conclusion}

After phenomenal success of Mononoke, Suzuki continued to coordinate promotion for Ghibli films as well as those from other studios such as Mamoru Oshii's Ghost in the Shell 2: Innocence (Inosensu, 2004). Miyazaki’s Spirited Away (Sen to Chihiro no kamikakushi, 2001) earned no less than 3.04 billion yen to be the most successful film shown in Japan as of 2016. Other Miyazaki films such as Mononoke, Howl's Moving Castle (Hauru no ugoku shiro, 2004) and Ponyo (Gake no ue no Ponyo, 2009) were among the ten most successful films shown in Japan until Ponyo was pushed out by another anime, Makoto Shinkai's Your Name (Kimi no na wa, 2016) in 2016, and other Ghibli films such as The Wind Rises, The Secret World of Arrietty (Karigurashi no Arietti, Hiromasa Yonebayashi, 2010), Tales from Earthsea (Gedo senki, Gorō Miyazaki, 2006) and double bill of The Cat Returns (Neko no ongaeshi, Hiroyuki Morita, 2002) and Ghiblies Episode 2 (Giburīzu episōdo 2, Yoshiyuki Momose, 2002) are among the 100 most successful films shown in Japan as of 2017, each ranked at eighteenth, $41^{\text {st }}, 66^{\text {th }}$ and $95^{\text {th }}$ respectively (Kōgyō tsūshinsha, 2017). We should note that films by young and lesser known directors are also successful in terms of revenue, although not to the same degree as Miyazaki.

These films, however, were not necessarily well-received. For example, Gedo senki, the first film directed by Miyazaki’s son Gorō Miyazaki, was severely criticized both in and outside Japan. A newspaper and two magazines in Japan (newspaper Supōtsu hōchi, weekly magazine Shükan bunshun and film magazine Eiga hihyō) named the film as the worst one shown in Japan in that year. Ursula K. Le Guin, the author of the original novel, also commented that the film was 'quickly made,' 'exciting' but 'incoherent,' '[t]he imagery is effective but often conventional' and 'does not have the delicate accuracy of "Totoro" or the powerful and splendid richness of detail of "Spirited Away."' (Le Guin, 2006)

These examples indicate that current 'popularity' of Ghibli films in Japan is not necessarily and simply owing to their quality as film but the name of Ghibli as a brand. As I attempted to show in this article, the brand was established not solely by excellent works by Miyazaki and Takahata as auteurs per se; rather, their commercial success owes greatly to the strategies used to promote and sell Studio Ghibli's films. These strategies were devised by 
Suzuki from the 1980s onwards, and impacted on domestic understanding of the films helping to turn them into enormous hits. Suzuki, as much as, or in some aspects even more than, Takahata and Miyazaki, contributed to building and developing Studio Ghibli, the castle at the heart of 'The Kingdom of Dreams and Madness,' as Mami Sunada (2013) calls it.

\section{Notes}

${ }^{1}$ For more details on this programme, see A. Painter (1996), "Japanese daytime television, popular culture and ideology". John Treat (ed.), Contemporary Japan and Popular Culture. Honolulu: University of Hawaii Press, pp.197-234.

\section{Bibliography}

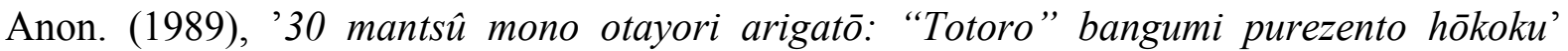
Animēju July 1989, p.38.

Anon. (1996), 'Senden keikakusho' in Studio Ghibli (ed.), Sutajio jiburi sakuhin kanren shiryōshū IV, Tokyo: Tokuma shoten, pp.48-49.

Anon. (1997), ‘'160 oku en taiketsu kyō sutāto: Miyazaki Hayao, Supirubāgu ryō kantoku 5 ne buri makkō shōbu,' Hōchi shinbun, 12 July, p.22

Denison, R. (2010), 'The Language of the Blockbuster: Promotion, Princess Mononoke and the Daihitto in Japanese Film Culture" in Leon Hunt and Leung Wing-Fai (eds.), East Asian Cinema: Exploring Transnational Connections on Film, London: I. B. Tauris, pp103-119.

Gomery, D. (2003), 'The Hollywood Blockbuster: Industrial Analysis and Practice( in Julian Stringer (ed), Movie Blockbusters, London: Routledge, pp.72-83.

Gray, J. (2010), Shows Sold Separately: Promos, Spoilers, and Other Media Paratexts, New York: New York University Press.

Kajiyama, H. (2004), Jiburi majikku: Suzuki Toshio no 'sōmōryoku', Tokyo: Kōdansha.

Kanō, S. (2006), Miyazaki Hayao zensho, Tokyo: Firumu Āto Sha. 
Komatsubara, K. (1984), 'Wakai hito yori supīdo kan wa ochiru to shitemo chimitsusa dewa makenai. Animētā ni jumyō wa nainoda!!' Comic Box, May/June 1984, pp.66-67.

Kōgyō tsūshinsha (2016), 'Rekidai ranking: CINEMA ranking tsūshin,' http://www.kogyotsushin.com/archives/alltime/. Accessed 11 May 2016.

Le Guin, U.K. (2006), 'Ursula K. Le Guin: Gedo Senki, a First Response,' http://www.ursulakleguin.com/GedoSenkiResponse.html. Accessed 11 May 2016.

Miyazaki, H. (2002), Kaze no kaeru basho, Tokyo: Rokkingu On.

— (2013), “Naushika” tanjō made no shikō sakugo,' in Studio Ghibli and Bunshun bunko (eds.), Jiburi no kyōkasho 1: Kaze no tani no naushika, Tokyo: Bungei Shunjū, pp.82-105.

— (2014), Turning Point, (trans. B. Cary, F. L. Schodt), San Francisco: Viz Media.

Miyazaki, H. and T. Yōrō (2002), Mushi me to ani me, Tokyo: Tokuma shoten.

Ogata, H. (2004), Ano hata o ute: Animēju keppūroku, Tokyo: Ōkura Shuppan.

Okuda, S. (2015a), 'Purodūsā Okuda Seiji ga kataru "mōhitotsu no jiburi shi” : rensai dai 4kai: "Majo no takkyūbin" o meguru futari no funki. Eiga senden wa terebi o furukatsuyō suru jidai e,' Neppū, January 2015, pp.45-57.

— (2015b), 'Purodūsā Okuda Seiji ga kataru "mōhitotsu no jiburi shi” : rensai dai 13 kai: Gekitō "Mononokehime" (kōhen) - Kurokawa no techō ni kakusareta shinjitsu,' Neppū, October 2015, pp.83-94.

Painter, A. (1996), 'Japanese daytime television, popular culture and ideology,' John Treat (ed.), Contemporary Japan and Popular Culture. Honolulu: University of Hawaii Press, pp.197-234. 
Studio Ghibli (2002), Naushika no 'shinbun kōkoku' tte mitakoto arimasuka: jiburi no shinbun kōkoku 18 nenshi, Tokyo: Tokuma shoten

- (2013a), 'Sutajio setsuritsu to "Tenkū no shiro rapyuta",' in Studio Ghibli and Bunshun bunko (eds.), Jiburi no kyōkasho 2: Tenkū no shiro rapyuta, Tokyo: Bungei Shunjū, pp.33-47.

— (2013b), 'Sutajio jiburi monogatari: Tonari no totoro hen",' in Studio Ghibli and Bunshun bunko (eds.), Jiburi no kyōkasho 3: Tonari no totoro, Tokyo: Bungei Shunjū, pp.25-38

— (2013c), '"Majo no takkyūbin" no hitto to shainka,' in Studio Ghibli and Bunshun bunko (eds.), Jiburi no kyōkasho 5: Majo no takkyūbin, Tokyo: Bungei Shunjū, pp. 37-52.

- (2014), 'Sutajio jiburi monogatari: “Kurenai no buta” to shin sutajio kensetsu,' in Studio Ghibli and Bunshun bunko (eds.), Jiburi no kyōkasho 7: Kurenai no buta, Tokyo: Bungei Shunjū, pp. 25-36.

- (2015), 'Sutajio jiburi monogatari: Mizou no taisaku "Mononokehime”,' in Studio Ghibli and Bunshun bunko (eds.), Jiburi no kyōkasho 10: Mononokehime, Tokyo: Bungei Shunjū, pp. $25-55$.

Sunada, M. (2013), Yume to kyōki no ōkoku, Tokyo: Dwango.

Suzuki, T. (1996), 'Sutajio jiburi no 10 nen - sono rekishi to genjō,' in Studio Ghibli (ed.), Sutajio jiburi sakuhin kanren shiryōshū I, Tokyo: Tokuma shoten, pp.128-131.

— (2005), Eiga dōraku, Tokyo: Pia.

- (2011), Jiburi no tetsugaku, Tokyo: Iwanami Shoten.

- (2013a), Kaze ni fukarete, Tokyo: Iwanami Shoten.

- (2013b), 'Shakkin o seotte hossoku shita "sutajio jiburi”,' in Studio Ghibli and Bunshun bunko (eds.), Jiburi no kyōkasho 2: Tenkū no shiro rapyuta, Tokyo: Bungei Shunjū, pp.48-61. 
— (2014a), Shigoto dōraku shinban: sutajio jiburi no genba, Tokyo: Iwanami Shoten.

— (2014b), “'Josei ga tsukuru hikōki no eiga”: Miyazaki Hayao no odorokubeki ketsudan,' in Studio Ghibli and Bunshun bunko (eds.), Jiburi no kyōkasho 7: Kurenai no buta, Tokyo: Bungei Shunjū, pp. 37-55.

- (2015), 'Chie to dokō no ōbakuchi! Mizou no "Mononokehime daisakusen”,' in Studio Ghibli and Bunshun bunko (eds.), Jiburi no kyōkasho 10: Mononokehime, Tokyo: Bungei Shunjū, pp. 56-77.

— (2016), Jiburi no nakama tachi, Tokyo: Shinchōsha.

Takai, H, M. Yabe, M. Ichikawa, S. Ise, S, Okuda, T. Suzuki (2015), 'Tokushū “Jiburi no dai hakurnkai Tōhō no rekidai purodūsā ga ōi ni kataru,' Neppū, September 2015, pp.4-32.

Takahata, I. (1968) Taiyō no ōji Horusu no daibōken, Tokyo: Tōei dōga.

Yokoyama, M. (2004), 'Shiretsu na tatakai “terebi hōeiken”,' in Hideo Ogata, Ano hata o ute: Animēju keppūroku, Tokyo: Ōkura Shuppan, pp.289-291 


\title{
Before Ghibli was Ghibli: Analysing the Historical Discourses surrounding Hayao Miyazaki's Castle in the Sky (1986)
}

Rayna Denison, University of East Anglia

\begin{abstract}
:
While Studio Ghibli may have become Japan's most important and successful animation studio, its early significance is far more debatable in relation to the success of its films. Normally viewed from the present moment, Studio Ghibli's brand significance is unmistakable, having become a producer of world renowned animation, and a distribution label for its own animated hit films and other high profile animation in Japan (Denison 2015). To challenge this perception of Ghibli's brand significance, this article revisits the early history of Studio Ghibli in order to examine the discourses around the formation of the studio. Using Studio Ghibli's first official film release, Castle in the Sky (Tenkū no shiro Lapyuta, 1986) as a case study, this article argues for a corrective analysis of the importance of Studio Ghibli to animator Hayao Miyazaki's first 'Ghibli' film. The article demonstrates that throughout this release, there was a tension between art and industry that would become the hallmark of Ghibli's style, but that the company itself may have had little to do with that brand's early conception.
\end{abstract}

Keywords: Studio Ghibli, anime history, Castle in the Sky, brand, advertising 


\section{Before Ghibli was Ghibli: Analysing the Historical Discourses surrounding Hayao Miyazaki's Castle in the Sky (1986)}

Rayna Denison, University of East Anglia

For more than two decades Studio Ghibli has been Japan's pre-eminent animation studio. As such, Studio Ghibli has emerged as a studio brand that represents a wide variety of products, from feature films to short animated films, to advertising campaigns for corporate partners and clients, to a studio museum and extensive merchandising. This broad spectrum of branded production in Japan has resulted in discourses around Studio Ghibli consistently flitting between oppositions of art and industry. I have argued elsewhere that this tension between art and industry means that 'Studio Ghibli' has developed significantly different meanings inside and outside of Japan, dependent upon the flows of its films and their promotion in different markets (Denison 2015). Alternatively, Thomas Lamarre, taking a textual view, argues that

Ghibli walks a fine line, between mass or generic appeal and an insistence on animation that, in the manner of high art or pure art, affords aesthetic distance and allows contemplation rather than thrills and observation. Out of this oscillation between mass art and high art emerges the brand, the Ghibli brand. (2009: 98 emphasis in original)

Lamarre's textual vision of the Studio Ghibli brand, like my own plural and industrial version, signals tension between the perceptions of Studio Ghibli films as art and industry. In other words, the expansiveness of Studio Ghibli's brand meanings act simultaneously as a testament to the company's global reach and also to its distinctiveness as a creative and industrial entity.

The tensions held within the brand, however, are not just a product of the current period, in which we are able to look back and reflect on what Studio Ghibli means as it becomes part of the history of Japanese animation production (however temporarily). The idea that Studio Ghibli has 'closed' is itself misleading. Instead of stopping, Studio Ghibli is now primarily functioning as a film producer, rather than creator, which can be seen in its latest co-production, The Red Turtle (La tortue rouge, Michaël Dudok de Wit, 2017) and it is still one of Japan's biggest distributors of world animation. Therefore, instead of assuming that Studio Ghibli's brand is a transhistorical entity, and now a thing of history, I want to 
examine the studio's historical trajectory, focusing on its earliest moments. To this end, I revisit the discourses around the film that was, officially at least, the first product made by Studio Ghibli: Hayao Miyazaki’s 1986 film Laputa: Castle in the Sky (Tenkū no Shiro Rapyuta, hereafter, Castle in Sky, the title it is best known for in English). Through this examination of Studio Ghibli's history, I argue that the company's earliest moments are marked by an intensification of the debates around art and industry that would coalesce in the Studio Ghibli brand later on.

Reconsidering the history of Studio Ghibli through the discourses around Castle in the Sky shows, on the one hand, how much remains to be learned about the history of animation in Japan, and, on the other hand, how high the stakes were for the filmmakers on the release of this film. Toshio Suzuki, the co-founder, CEO and head producer at Studio Ghibli (for more see Yoshioka, this collection), has written about how unusual Ghibli's standalone, feature film production strategy was in the 1980s, when most of the animated films being made were either adaptations of novels or manga, or theatrical versions of popular television shows (2011: 4). Concurring with Ryota Fujitsu's assessment of Ghibli's filmmaking strategy as 'high cost, high risk, high return' (2004: 205), I focus on how the promotional discursive surround for Castle in the Sky worked to manage risk (Klinger 1997). Through the use of contemporary discourse, I seek to demythologize Castle in the Sky's position within the history of Studio Ghibli, and to consider what this suggests about the early life of the studio. In doing so, Studio Ghibli is here viewed as a part of Japan's cultural industries (Hesmondhalgh 2007), whose discursive traces may reveal much about the place of studios within Japanese film and media culture.

Furthermore, I investigate how the discourses around the release of Castle in the Sky worked to explain the film's production process, the working practices of its creators and where Studio Ghibli fits within this narrative. Accordingly, I focus primarily on contemporary promotional interviews with core members of the production team, not least Hayao Miyazaki, as director, and Isao Takahata, who acted as his producer. However, I extend this analysis by analysing popular media discourses circulating around the time of Castle in the Sky's Japanese release, especially articles appearing in Japanese newspapers and in Animage magazine, a specialist anime magazine owned by Ghibli's parent company Tokuma shoten (Tokuma publishing). By revisiting these sources I look to reconstruct and analyse Castle in the Sky's original release in order to suggest that the tensions between art 
and industry that linger around Studio Ghibli's brand identity have always been a part of its success as a producer of popular 'art' animation.

\section{The 'first' Ghibli film?: From Nausicaä of the Valley of the Wind to Castle in the Sky}

The need to revisit Castle in the Sky's history is made obvious by the fact that there are still arguments over whether or not it is actually even Studio Ghibli's first film. The debate is first seen in scholarly accounts when Helen McCarthy declares that

After the success of Nausicä̈ of the Valley of the Winds [sic.], Miyazaki and Takahata set up their own production office and studio. Tenku no Shiro Laputa (Laputa, Castle in the Sky) was not the first production by Studio Ghibli, but it was the first in the style we have come to associate with the studio. (1999: 94)

It is worth noting that the production office McCarthy refers to is Nibariki, which Miyazaki and Takahata set up as a private office in the Suginami ward of Tokyo, which is famous for animation production. Studio Ghibli was set up separately some time later in 1985. This is significant because, already, it is possible to see how Miyazaki and Takahata's companies were collapsed into 'Studio Ghibli' early in its English language criticism. What is more interesting here is that McCarthy is invoking a popular debate when she states that Castle in the Sky was not the first Studio Ghibli film. The debate seems to revolve around two separate issues: first, Studio Ghibli's own attempts to retroactively incorporate Hayao Miyazaki's first major hit film, Nausicaä of the Valley of the Wind (Kaze no tani no Naushika, 1984), under its distribution and brand labels; and, second, fans' and journalists' assessments that the relationship between Topcraft Studio and the formation of Studio Ghibli was more than just close (for more on the discussion by fans, see The Hayao Miyazaki Web). This latter debate is especially interesting simply because it has not entered into the academic scholarship around Studio Ghibli.

Regarding the first debate, which is primarily an industrial one, Nausica $\ddot{a}$ of the Valley of the Wind was produced by Tokuma shoten at the behest of the editorial staff at its Animage magazine, and so reflected much of the same ownership as Miyazaki's later films. Consequently, while scholarly Japanese sources routinely cite Castle in the Sky as the first Studio Ghibli film (Fujitsu 2004; Kanō 2006), the official Studio Ghibli website contradicts them by listing Nausicaä of the Valley of the Wind under its products (Studio Ghibli, n.d.). Although the Studio Ghibli website does make it clear that Studio Ghibli was founded after 
Nausicaä of the Valley of the Wind, it paradoxically also contends that Nausica $\ddot{a}$ was the 'first' film in the studio's official canon. Therefore, in Japan, as outside, this debate centres on important questions of rights and of the profits to be had from distribution. Studio Ghibli's distribution label, Jiburi ga Ippai (Full of Ghibli) distributes Nausicaä of the Valley of the Wind in Japan on Blu-Ray and DVD, and, consequently, making it part of the studio's chronology asserts the film's canonical status. ${ }^{1}$ This incorporation, by distribution and industrial history, creates industrial ambiguity around the status of Nausicaä of the Valley of the Wind, which alone among Miyazaki's many pre-Ghibli works has been fully canonised within the history of Studio Ghibli.

In the second debate, and perhaps as a consequence of the ambiguous rendering of Nausicaä of the Valley of the Wind's industrial status in Japan, transnational fans were quick to point to the industrial similarities between Topcraft studio, which produced Nausicaä of the Valley of the Wind, and the original composition of Studio Ghibli at the time of Castle in the Sky. The Hayao Miyazaki Web, an early and significant fan collective, argue that many of the animators working at Topcraft moved to the newly formed Studio Ghibli when Topcraft shuttered its feature film production studio mid-1985 (Team Ghiblink, n.d.). The overlap between personnel is significant - with Topcraft's Toru Hara acting as the first Studio Ghibli manager (Fujitsu 2004: 207), and with key animators like Yoshinori Kanada, Megumi Kagawa and colour designer Michiyo Yasuda joining Ghibli at this time from the defunct studio (for more, see Clements and McCarthy 2006). Aesthetically, then, most of Miyazaki's significant collaborative relationships are in evidence for Nausica $\ddot{a}$ of the Valley of the Wind; but, industrially, Miyazaki co-founded his Studio Ghibli at the behest of Tokuma shoten in 1985 only after that initial film's success. While the exact relationship between the closure of Topcraft and the formation of Ghibli remains somewhat obscure, what is interesting here is the way both debates suggest a commingling of aesthetic and industrial factors in Studio Ghibli's creation. The debates both revolve around aesthetics on one level - the sharing of personnel and the cohesion of aesthetics across a brand - while on another level, both debates can be clarified and better understood through an industrial lens.

Asserting that Nausicaä of the Valley of the Wind is Studio Ghibli's first film, however, lessens the significance of, and attention paid to, Studio Ghibli's other potential 'first' film: Castle in the Sky. In contrast to the debates outlined above, the advertising discourse at the time of Castle in the Sky's release made no reference to the new studio. However, it did heavily emphasize Nausicaä of the Valley of the Wind as an authenticating 
comparison point for Miyazaki's newest film. More immediate for audiences, and redolent with its own success and meanings, Nausicä̈ of the Valley of the Wind was used almost in place of a 'pre-sold' product or image for Castle in the Sky (Austin 2002; Brooker 2012). An example of newspaper advertising copy for Castle in the Sky proclaims that, 'A masterpiece is born that surpasses the thrills and excitement of Nausicaä of the Valley of the Wind!' (Studio Ghibli 2002: 155) In this way, the contemporary advertising sought to create links between these two films, while genre and a sense of artistic 'mastery' are also broadcast as surpassing Miyazaki's previous attempt at feature filmmaking.

The hyperbolic advertising discourse seen here also suggests that Nausicaä of the Valley of the Wind was something to be overcome, to be surpassed, through the artist merits and populist spectacle of Castle in the Sky. Unlike Jonathan Grey's (2010) claims about older texts creating intertextual shadows that threaten to overwhelm newer films, here Nausicä̈ of the Valley of the Wind is less of a threat, and more of an associated benchmark used to reassure potential audiences about the quality of production on Castle in the Sky. I would argue therefore that the attempts to incorporate Nausicaä of the Valley of the Wind into the Ghibli canon retrospectively have been about more than securing the legitimacy of Nausicaä's presence within Ghibli's history. At the time of Castle in the Sky's release, when Studio Ghibli was yet to become a known animation brand, Nausicaä of the Valley of the Wind was, instead, used as a generic and aesthetic example of the high quality audiences could expect from Miyazaki's work, as well as providing a benchmark against which Castle in the Sky could be judged.

The ambiguity around Studio Ghibli's formation and Castle in the Sky's production was heightened by the founders' explanations of the studio's history. For example, in an interview with Kinema Junpo, Japan's foremost film magazine, Miyazaki explains that

The truth is that after Nausicä̈ of the Valley of the Wind I wasn't in shape to direct, and I had planned to try to make a proper adventure animation, staged in a provincial city in Japan. Things were not coming together and flowing for the animation, and truthfully, I would still be in the middle of making it now, but it has become a documentary film. But now, the director is Isao Takahata, who is the producer on Castle in the Sky. (1986: 46)

The film under discussion became Takahata's The Story of Yanagawa's Canals (Yanagawa horiwari monogatari, 1987). The documentary's existence partially explains the creation of 
Nibariki because Miyazaki had put his profits from the Nausicaä of the Valley of the Wind manga into Nibariki in order to create a budget for Takahata's film (Miyazaki 2009), before the formation of Studio Ghibli.

As Toshio Suzuki explains, Takahata's documentary ran short of funds despite the budget supplied by Nibariki. In Suzuki's version of the founding of Studio Ghibli, Takahata's documentary became the main motivation for the production of Castle in the Sky: 'Takahata needed money to make The Story of Yanagawa's Canals. When Miya-san [Miyazaki] asked me about it, I proposed that, "The way ahead is simple. Let's make another film.” This was the start of Laputa Castle in the Sky.' (2005: 88) Takahata, however, suggests a different history in his interview for the promotional magazine Roman Album in 1986, where he claims that 'we proposed the new production studio asking, if Tokuma shoten has the view that after this we are going to be making real animation epics, ought we not to make it a nurturing place that is self-reliant?' (140) In this version, as elsewhere (Fujitsu, 2004), Tokuma shoten becomes the spur behind both the creation of the studio, and a source of pressure regarding what kind of films Miyazaki and Takahata should make.

Takahata suggests that they could have easily gotten funding for a Nausicaä sequel (Nausicä̈ Part 2, or Naushika Pāto 2), but that Miyazaki’s insistence upon making a standalone film meant that, 'I was worried about whether we could do it on small production costs if it was a film for children. We had to make it as an epic amusement' (1986: 140). In this way, necessity dictated much of the production around Castle in the Sky, both in terms of needing to create a new studio where the work could be undertaken, and in regard of Tokuma shoten's pressure to create a film that would rival the success of their previous hit Nausica $\ddot{a}$ of the Valley of the Wind. In the accounts of the co-founders of Studio Ghibli, therefore, the impetus behind Studio Ghibli's genesis had more to do with economic necessity than art. Whether because they needed money to finish other projects, or because their financial backers were insisting upon bigger and bigger animated film successes, the founding of Studio Ghibli was tied to industrial imperatives, not just to the desire to make high quality animation.

\section{Miyazaki, intertextuality and the recycling of ideas in Castle in the Sky}

The result was a film that became highly intertextual. Like other forms of contemporary media, Japanese filmmaking is highly intertextual (Denison 2016), a tendency that developed early for animation. Marc Steinberg has shown that anime had already developed a 
sophisticated form of both intertextuality and paratextuality as early as the 1960s (2012). Although Castle in the Sky is routinely discussed in press coverage as a 'gensaku' or original work created by Miyazaki, it is also discussed as highly intertextual. Most obviously, Castle in the Sky's promotion clearly defined its generic identity, while allusions were made to European literature and Miyazaki's past work in animation in order to associate the new studio's film with perceived quality forms of children's literature and entertainment. This emphatic combination of generic language, recycling and borrowing is a sign of the complex systems of marketing present in 1980s Japan, as well as hinting at risk inherent in producing standalone films like Castle in the Sky. The games being played within the marketing of Castle in the Sky thereby reveal the potential difficulty in selling Miyazaki's artistic vision in the period of Japanese film history that preceded Studio Ghibli's well-known brand identity.

Miyazaki was clear about the generic identity for his new film, repeatedly referring to it as a 'bōken katsugeki', or action adventure film, throughout the promotional discourse created in the months leading up to Castle in the Sky's release. Even before that, in the original proposal for the film, Miyazaki calls it an 'intensely thrilling classic action film' (Miyazaki 2009: 252) and later he declares that 'The story unfolds like a roller-coaster ride, with love and friendship between the boy and girl developing on one level, and an action adventure focusing on the levitation crystal and trip to the castle in the sky taking place on another' (253). This highly generic set of descriptions is useful in uniting the disparate elements of the story, while giving the film a clear generic identity that was repeatedly linked back to the broader shōnen (boys') genre of anime by Miyazaki (Kinema Junpo 1986).

The action adventure genre aspect of Castle in the Sky is also connected back to Miyazaki's inclusions of intertextual borrowing. Borrowing from both the literary traditions of European and recycling character tropes and themes that Miyazaki had been experimenting with in his pre-Ghibli work, Castle in the Sky made its claim to 'epic amusement' through appeals to familiar, generic and yet inventive aesthetics intended to entice audiences. As Lamarre notes

It is not a question of straightforward continuity or direct influence. [...] Nonetheless, in Castle in the Sky, Miyazaki gathers those [previous] worlds into one epic world with a distinctively Miyazaki look and story arc. Castle in the Sky marks the emergence of a distinctive Miyazaki-Ghibli world and worldview, and in a stable and marketable form. (2009: 59) 
I would go further, and suggest that, in Castle in the Sky, we can see a compendium of Miyazaki's previous interests as an animator, and that, moreover, these interests played significant roles in the film's presentation to potential audiences.

Two facets to Miyazaki's intertextual referencing are particularly worthy of note: overt ones that were cited in the promotional materials surrounding the film's release; and covert ones that were a product of long-standing themes and interests. In relation to the latter, Lamarre makes careful note of the continuities between Castle in the Sky and earlier Miyazaki film and television productions. For example, Lamarre analyses how Future Boy Conan's (Mirai shōnen Konan, 1978) young female protagonist, Lana, mirrors Castle in the Sky's female heroine, Sheeta, both of whom are fighting against military forces trying to capture potentially destructive technologies (2009: 58). Other overlaps might also be suggested, for example, the fact that Miyazaki had worked as a key animator on Yasuo Ōtsuka's Gulliver's Space Travels (Garibā no uchū ryokō, also called Gulliver's Travels Beyond the Moon, 1965) when working at Tōei Animation. It is these repetitions that suggest Miyazaki was becoming a recognised animation auteur, not least thanks to his presentation as such in marketing materials. To put it another way, these repetitions can be thought of as linking Miyazaki's previous films and television shows to Castle in the Sky as way of authenticating the quality of its content, and demonstrating a generic consistency within the director's works.

Amongst the covert allusions to Miyazaki's own work, other more overt intertextual overlaps can be found. Miyazaki's pre-existing familiarity with Gulliver's Travels (1726) by Jonathan Swift, for example, became a central touchstone for discussions of intertextuality in Castle in the Sky. However, even Miyazaki's selection of Gulliver's Travels as a source text is shown to be part of more complex tapestry of intertextuality within the film's promotional coverage. In an Asahi Newspaper article, for instance, Miyazaki states that 'I thought we might make a work like Stevenson's Treasure Island. However, because it would be uninteresting to just use an island, I borrowed the idea of the floating castle of Laputa, which comes from Swift's Gulliver's Travels' (Asahi 1986). Miyazaki expands on his motivations in his interview for Kinema Junpo, recounting how:

I thought, why not make it something like Treasure Island? [...] and I thought it would be good to have an island floating in the sky [...] Certainly, I think it came out of Gulliver's Travels. In the proposal, when I wrote that it came from the third part of 
Gulliver's Travels, I was thinking that the older men who had not read it would probably think, 'ah, yes!' be persuaded. (1986: 43)

Miyazaki goes on to note that it was not until later that he learned of the unfortunate Portuguese language connotations of his chosen 'Laputa' title, which Swift had intended as an ironic name for his original castle.

The connection made above between Castle in the Sky and Swift and Robert Louis Stevenson's Treasure Island (1883) are important to the promotional for Castle in the Sky. On the one hand, Gulliver's Travels and Treasure Island are invoked as foreign literary authenticators for Miyazaki's fantasy action adventure film. On the other, they also connect Castle in the Sky to Miyazaki's previous work as an adaptor of foreign children's literature in animated television series. Most notable is the connection between Miyazaki's work with Takahata for the World Masterpiece Theatre animation series, which was comprised of adaptations like Akage no An (Anne of Green Gables, Isao Takahata, 1979), taken from Lucy Maud Montgomery's novel of the same name (for more, see: Hu 2010). Consequently, literary associations and adaptation work were a familiar part of Miyazaki's oeuvre for Japanese audiences, and therefore the continuing visibility of source texts like Treasure Island and Gulliver's Travels need to be understood as not just an appeal to educated audiences, but also as a reaffirmation of Miyazaki's growing critical reputation as an animation auteur. More significantly, though, in this case, they helped to off-set the risks inherent in making a 'gensaku' or original production, creating ostensible Ur-texts for audiences (for more on the importance of pre-sold or Ur-texts for audiences see: Austin 2002; Wyatt 1994).

Miyazaki's reputation as a popular animator was also significant within the promotion for Castle in the Sky. For example, Mainichi Newspaper confers high status upon Miyazaki, arguing that he is Japan's answer to Stephen Spielberg, and relating how Castle in the Sky was a U-turn in animation history intended to capture child and adult audiences alike (Mainichi 1986). By contrast, Animage magazine focuses more on Miyazaki's past, relating that 'Lupin and Clarisse. Conan and Lara. Miyazaki seems to have made these into legendary meetings, and he thinks "for sure, the meeting is the number one thing a director should put effort into"' (Animage 1986a: 62). These allusions to Miyazaki's work on Castle of Cagliostro and Future Boy Conan also suggest that his popular work for previous television and film shows was significant to the presentation of Castle in the Sky, particularly, it would 
seem, to the romance between the two central characters as they meet. These specific allusions to past Miyazaki works, combined with comparisons to Hollywood filmmakers and more covert analyses of Miyazaki's repetitions of themes and concepts across his television and film work, helps to suggest an image of Miyazaki as animation auteur. However, more pragmatically viewed, many of these allusions and repetitions are just as likely to have been the product of Miyazaki having less than two years to produce Castle in the Sky, and a whole career's worth of stifled and half-expressed ideas that he could recycle from the work he had done for other directors. Within the promotion for Castle in the Sky, therefore, there is a sense of a commercial auteur at work (Corrigan 1991), one who was aware of the value of repetition and promotion of his own past works as he attempted to create a new studio-based home for his animation style.

\section{Not just Ghibli, or not yet Ghibli? Ancillary and epiphenomenal production around Castle in the Sky}

In addition to the confusions over the status of Castle in the Sky in the history of Studio Ghibli, and to the myriad repetitions, references and allusions associated with it, the industrial context of the film's release also suggests that there was a good deal of experimentation taking place to bolster the reputation of Miyazaki's latest 'masterpiece.' Two of these experiments are worth exploring in detail because they directly impacted on the film's release. First, the release of two 'new' episodes from Miyazaki and Kyōsuke Mikuriya's animated television series Sherlock Hound (Meitantei Hōmuzu, or Famous Detective Holmes, 1984-1985) that were screened in cinemas along with Castle in the Sky. Second, a campaign for 'Laputa' soft drinks run by Ajinomoto. These two experiments offer insights into a counter-narrative to that of Miyazaki-as-auteur, again emphasising the split between art and industry at the heart of Ghibli productions and promotional surround. In the first instance, the use of Sherlock Hound shows that Miyazaki had yet to become an exclusively film-based auteur; while, the second example shows how Ajinomoto's attempts to create a real-world spectacle for its 'tie-up' campaign ${ }^{2}$ pulled the promotional focus away from Castle in the Sky and Miyazaki.

Sherlock Hound aired initially in 1984 on TV Asahi, and was a transnational coproduction between TMS and Italian broadcaster, RAI (Smith 2012). However, Sherlock Hound's production was complicated by 'a copyright dispute with Sir Arthur Conan Doyle's estate' (Team Ghiblink, n.d.) which may explain why some of the characters' names shift 
across the series, and why some of the episodes were re-released for cinematic exhibition with Nausicä̈ of the Valley of the Wind and Castle in the Sky where they acted as supplemental short films. The newspaper advertisements for Nausicä̈ of the Valley of the Wind indicate that its episodes were 'The Adventure of the Blue Carbuncle' (episode 5) and 'Treasure under the Sea' (episode 9), both of which were originally directed by Miyazaki (Studio Ghibli 2002: 124-139). For Castle in the Sky, two other Miyazaki-directed episodes, 'Mrs Hudson is Taken Hostage' (episode 4) and 'The White Cliffs of Dover' (episode 10) were presented as short films before Miyazaki's feature was shown.

The newspaper advertising for Nausicaä of the Valley of the Wind places greater emphasis on the presence of these episodes, with Sherlock Hound taking up about a third of the space in many advertisements (Studio Ghibli 2002: 124-135). However, the newspaper advertisements for Castle in the Sky tended to place the Sherlock Hound information at the bottom or in the corners of the advertisements. The diminishing size of the Sherlock Hound episodes is suggestive the rising popularity of Miyazaki’s feature films. Interestingly, too, the advertisements for Castle in the Sky call its episodes 'Zoku metantei Hōmuzu, ' literally meaning Famous Detective Holmes Continued, even though the original broadcast lists show that these were episodes taken from the middle of the original series. The Sherlock Hound shorts were, therefore, being treated as a series in their own right, despite the fact that audiences would have seen these episodes before. What these Sherlock Hound compendia add to the releases of Castle in the Sky and Nausica $\ddot{a}$ of the Valley of the Wind, is a pre-sold product repurposed for cinemas in the manner of popular summer anime 'roadshows.' Such roadshows regularly repurpose television animation for the cinema, and so were a fairly wellknown format even by the 1980s in Japan (Clements 2013; Clements and McCarthy 2006). The addition of Sherlock Hound episodes to cinematic exhibition of early Miyazaki films could therefore be seen as a mechanism to reduce risk, and in the case of Castle in the Sky, to add pre-tested products to an untested feature film.

For Castle in the Sky, the two episodes of Sherlock Hound were also used to expand the generic reach of the film. For example, an advertisement placed in Asahi Newspaper the day before Castle in the Sky's release displays the differences between the two films. The copy for Castle in the Sky declares that 'The Heart-warming Adventure Begins!' The strap line is then placed over a picture of protagonists, Pazu and Sheeta, in the air pirates' mechanical 'flaptor' machine, flying in front of the floating city-castle of Laputa. It explains that 'The young boy Pazu meets a mysterious girl who falls from the sky and they search for 
Laputa, beginning a journey that burns with courage and love... Go Pazu! Protect Sheeta...' (Studio Ghibli 2002: 160). Through this language and imagery the adventure and quest aspects of Castle in the Sky are unambiguously announced to audiences, as is the central focus on the male protagonist, something that contrasted to the female-centred story in Nausicä̈ of the Valley of the Wind. In the same advertisement, however, a smaller tagline reads, "An exciting romantic fantasy and love that surpasses "Nausicaa!"” promising audiences a balance of gendered interests (a boy protagonist, but romance; an adventure story, with a major female character and love). The taglines thereby work to balance generic associations and to eclipse Miyazaki's previous hit film. Accordingly, these descriptions of Castle in the Sky firmly place it within a set of genres as the successor to, and improvement upon, Miyazaki’s previous film.

Allied to the copy for Castle in the Sky, the advertisement contains the following statement about Sherlock Hound: 'An unbelievable big chase! Laughs so big it is absurd!' Here, the connection between chases and adventures may have been intended to conceptually unify the two sets of texts, but the emphasis on comedy also extends the generic reach of Castle in the Sky to include new potential audiences. In this way, the combination of Sherlock Hound and Castle in the Sky demonstrates a continuing release strategy in which the films of Hayao Miyazaki were allied with his work in television in order to maximize their potential reach in the Japanese marketplace. What they also show is that Miyazaki (and by extension Studio Ghibli) films were not yet a guaranteed draw for audiences. The recycling of Sherlock Hound into the exhibition of Castle in the Sky can therefore be read as a key means to off-set perceived lacks in Miyazaki's new feature film (comedy), while also reducing the risk inherent in creating an original and untested film.

Ajinotmoto's approach to supplementing and promoting Castle in the Sky went in a different direction. Toshio Suzuki has commented, years after the fact, that the 'Laputa' tieup (licensed product) campaign run by Ajinomoto was not particularly successful, even though it centred on the sale of a fruit-based soda in the middle of the hot Japanese summer (2005: 92-93, see also, Yoshioka, this collection). At the time, though, the campaign was extensive and high profile. It included multiple television commercials, large-scale prize draws and a competition to become a 'Laputa Reporter' in the Osaka area (Animage 1986a). The campaign received extensive coverage within Animage, where in addition to a making-of booklet on the production of the television commercials, Ajinomoto also took out multiple double-page spread advertisements (Animage 1986a and 1986b). However, Ajinomoto's deal 
with Studio Ghibli only allowed them to use Miyazaki's production sketches and the title logo for Castle in the Sky (Suzuki 2005). Ajinomoto responded by creating a series of live action of television commercials featuring a real-world model of Miyazaki's 'flaptor' design. The television campaign was initially focused on the Tokyo and Osaka metropolitan areas, and began airing from April $25^{\text {th }} 1986$, but it was further expanded following the film's release (Animage 1986b).

In August, the month of Castle in the Sky's release, the production of Ajinomoto's 'Laputa' soda campaign was covered in an extended booklet-length report in Animage. It explains that "The "Flaptor" is a type of aircraft that flaps its wings to fly through the open sky in this magnificent animated film' (Animage 1986b: 4), thereby introducing Ajinomoto's attempt to adapt Miyazaki's animated film into a live-action. In promoting their efforts, they announce:

Of course, while it may be true that this is a commercial for a tie-up product for anime film Laputa Castle in the Sky, which opens in August, the beauty does not come from remaking it [the film] as it is, as an anime film. It is constructed through live action special effects techniques. (Animage 1986b: 4)

This promotional coverage creates a hierarchical relationship between animation and liveaction production in Japan, suggesting that live action can reproduce, or even better, its animated counterparts. In this way, Ajinomoto's television commercial becomes, perhaps unintentionally, a rival for, instead of a complement to, or supplement to, Castle in the Sky.

This sense of competition is enhanced by the in-depth analysis of the production that follows in Animage's booklet. Some of those, like Hideo Hagiwara, the production designer on the commercials, attempt to complement Miyazaki; for example, saying that 'We paid attention to putting out the "antique image" which was there in Miyazaki's images,' when making his life-sized model of the Flaptor (Animage 1986b: 6). However, the director, Masatake Satomi, overtly compares his version and the forthcoming film. Satomi states that

On this job, the success of the moving wings was what I was most worried about, and the depth of field came out pretty well, and I think it turned out well. In the Laputa anime I have a lot of interest in seeing how the Flaptor flies, I'm looking forward to it. (9) 
The remainder of the booklet focuses on the Flaptor model itself, including its length, width and weight, as well as providing a comparison of the mocked-up control panel and Miyazaki's original sketches for the machine. In this way, the coverage links the live-action production back to things Miyazaki was already becoming known for: namely, his machines. However, in emphasising the difficulty in producing the movements required to make the Flaptor fly, and by positioning live action spectacle and the real over Miyazaki's animation, Ajinomoto's commercial production team intimates that the real is more difficult, and therefore more worthy. In this way, the discourse around the commercial pulls focus away from the animated film and towards Ajinomoto's adaptation.

This emphasis on spectacle is such that other aspects of the commercial, including the characters' names (the actors are cited as Dennis and Diana, with no surnames supplied) are left out of the coverage in favour of emphasising the real-world challenge of producing Miyazaki's flying machine. The logic comes from both spectacle and expense. In the June 1986 issue of Animage (63) it was reported that the model had cost Ajinomoto 10million yen to manufacture, which was a significant investment by the tie-up producer on top of the expense involved in the filming process, which required new compositing equipment, bluescreen and camera cranes among other expenses. The fact that the promotional booklet for the television commercials (there were four versions of the ad in total, recut from the master footage), emphasizes the more spectacular aspects of the production process is perhaps understandable in this context. Spectacle is also drawn out of the voice-over narration for the commercials, which was recorded by the key voice actors from Nausicä̈ of the Valley of the Wind. The brochure attempts to surprise readers by telling them that 'Incidentally, Sumi Shimamoto (who play Nausicaä) and Yoji Matsumoto (who played Asbel) have been put in. What do you think?' (1986b: 4) In these ways, Ajinomoto's commercials competed with Miyazaki's new film, while spectacularly re-adapting aspects of his work into a live action context.

These peripheral experiments in marketing and exhibition around Castle in the Sky offer evidence that the industrial machinery of Studio Ghibli had yet to coalesce. Ajinomoto's campaign ran before Castle in the Sky's release, creating visual competition for Miyazaki's film, rather than simply re-using imagery from it to sell the Ajinomoto drinks product. Likewise, the episodes of Sherlock Hound were used to frame the viewing experience and advertising for Castle in the Sky, pulling attention away from the feature film even as the episodes were used to expand its generic meanings. 


\section{Conclusion}

Examined through its discursive promotional surround then, Castle in the Sky may have technically been Studio Ghibli's first film, but the way it was framed at the time does not suggest a break between this 1986 film and the earlier Nausicaä of the Valley of the Wind. Rather, the promotion and exhibition for Castle in the Sky repeated the seemingly successful practices used for Miyazaki's Nausicaä of the Valley of the Wind, and even the tie-up advertisers worked to make connections between both the 1984 and 1986 films. Furthermore, by the time Studio Ghibli was created, Miyazaki was already a significant animator, and one who was building an established style of filmmaking that could be recognised across production patterns in both his television and film productions. Having brought many of the key production staff across from Nausicaä of the Valley of the Wind to Castle in the Sky, this continuity in aesthetics was further exaggerated. For these reasons, Miyazaki's Castle in the Sky, despite being the first film created by Studio Ghibli, might be better thought of as more of a continuation, or consolidation, of his existing approach to filmmaking.

However, Castle in the Sky remains a significant moment of experimentation and risktaking for Miyazaki and Studio Ghibli. While it would not be the last time the Studio Ghibli released a double-bill, it was the last time Miyazaki's television work was repurposed for exhibition with his films. In addition, Suzuki changed his approach to tie-ups and licensing following the economic failure of Ajinomoto's expensive 'Laputa' soda campaign (2005, see Carter, and Yoshioka, this collection). The campaign ended up delivering a product with little connection to the film, to the extent that Ajinomoto struggled to sell the links between its citrus-fruit drink and Castle in the Sky. Ajinomoto's product information states that the Laputa drink 'is about as refreshing as the story, full of adventure and romance, and it will moisten the throats of a lot of people' while the company's tie-up advertisements temporarily rebranded Ajinomoto as 'Kazenomoto'. This new name implies the brand confusion riddling the Ajinomoto campaign, with the 'Kaze' of Kazenomoto being borrowed from the first word in the Japanese title of Nausicä̈ of the Valley of the Wind. Studio Ghibli's lack of either oversight or control regarding these changes suggests that the company was not yet able to exert the kinds of associative brand power that it would later come to wield (Denison 2015).

Likewise, although the prize draws Ajinomoto ran for Castle in the Sky contained goods branded with Miyazaki's original sketches for the film, they were not otherwise cognitively associated with its content, especially not when it came to the grand prize, a 
Toshiba home entertainment system, branded as a 'Laputa Version' system for the purposes of the prize draw (Animage 1986a: 46-47). In these ways, Castle in Sky's status is further confused and spread too thinly, becoming unthinkingly commercialized in a way that Suzuki would not repeat after Studio Ghibli became a more stable corporate entity.

This is perhaps the most significant point to be drawn out of the debates around whether or not Castle in the Sky is the 'first' Studio Ghibli film or not. Up until 1990, when Suzuki was able to convince Tokuma shoten that Studio Ghibli could be reimagined as a constantly staffed, permanent animation studio (Suzuki 2005; McCarthy 1999), Studio Ghibli remained a nascent, sporadic industrial construct. Fujitsu recounts that initially, 'To reduce the risk to the company, they decided on a basic policy of gathering staff to make each production, and then dissolving the group when finished' (2004: 207). Even in 1986, though, stability was Miyazaki’s aim. In his Kinema Junpo interview, Miyazaki claims that Studio Ghibli was created when 'we made a team by collecting scattered people together' and he goes on to say that 'if you are just paying for piecework, then you can't really call them your staff' (46). Later in the same interview Miyazaki goes on to outline his hopes for his studio:

Personally, I think about having the kind of place where the people I want to work with are here and have permanent jobs, even if I have to personally take in outside work and have no cooler in my house all summer. (Kinema Junpo, 1986: 47)

This is where the tension resides - the Studio Ghibli that would rise to prominence in the Japanese film industry was yet to be a reality in 1986, and its most famous animator's ambitions had yet to be realised. In an industrial sense, then, the debates around which film was the 'first' Studio Ghibli work might be easily extended into the years following Castle in Sky, into the 1990s and the construction of the first purpose-built Studio Ghibli offices and permanent staff.

Likewise, the tensions inherent in the definitions of Studio Ghibli's brand might be extended beyond art and industry into the contexts of the promotion and dissemination of their films. Examples like the partnerships with Topcraft, Ajinomoto and Tokuma shoten all indicate that Ghibli's corporate identity in this early period was fluid. Further, with the lack of permanent staff, Studio Ghibli was, in this period at least, only really discernible through its productions, forcing industry into the heart of aesthetic considerations of branding and studio identity. Before Studio Ghibli became what we know it as today, then, it was a far 
more contingent entity, reliant on the economic might and aesthetic skills of other institutions.

Moreover, Castle in the Sky's success was far from certain, and the repackaging of previously successful television hits demonstrates how much trepidation there was around releasing original animated films in a period led by the successes of animation on television (Clements 2013). In the experiments around Castle in the Sky's release and in its allusions to a wide range of intertextual materials and epiphenomenal supporting texts, we can see how essential a contextual understanding of Japanese film production is to a full understanding of the significance of Miyazaki and his nascent Studio Ghibli. Castle in the Sky, therefore, offers us a corrective lens through which the emergence of Studio Ghibli can be viewed, and reveals how crucial it is to understand brands as historically, contextually situated phenomena that are always-in-process. As Takahata, Miyazaki and Suzuki worked to create their studio, Castle in the Sky became their first attempt to draw together the threads of production, promotion and distribution that would later dominate the Japanese animation industry under the guise of Studio Ghibli.

Acknowledgements: I would like to thank the Great Britain Sasakawa Foundation for their generous support for this research. All translations are my own, unless otherwise indicated in the Bibliography.

\section{Notes}

${ }^{1}$ It is worth noting that this label also distributes other pre-Ghibli works like Miyazaki's Rupan Sansei: Kariosutoro no Shiro (Lupin III: Castle of Cagliostro, 1979), but does not include it within their studio chronology. In fact, Castle of Cagliostro is distanced from the main Ghibli distribution label by being repackaged as a 'Special', and stamped with a 'TMS Tokyo Movie Product' stamp that qualifies its status, and closeness, to the Ghibli brand. By contrast, incorporating Nausicaä of the Valley of the Wind fully into the Jiburi ga Ippai DVD label, confirms its canonicity.

2 Tie-up is the term commonly used in Japan to describe licensed tie-ins. In this instance, Suzuki had arranged for Ajinomoto to produce goods, a juice soda that would be linked to Castle in the Sky through sketches from the production and an advertising campaign.

\section{Bibliography}


Animage (1985), 'Pirate Ship Tiger Moth,' [Kaizokusen Tigāmosugou], Animage 86.8, n.p. Animage (1986a), 'Castle in the Sky: Morning, A Young Girl Opens her Eyes in Pazu's Home,' [Tenkū no shiro Lapyuta: Asa, Pazū no ie de shōjo wa mezameta...], Animage 96.6, pp. 46-47 and 62-65.

Animage (1986b), 'Report on the Filming of the Laputa Commercial,' [Lapyuta CF satsuei repo], Animage 98.8, pp. 3-12.

Asahi (1986) 'Castle in the Sky the New Film from Director Hayao Miyazaki,' ['Miyazaki Hayao kantoku ga shinsaku Tenkū no shiro Lapyuta'], Asahi Newspaper 29 July, p. 11.

Austin, T. (2002), Hollywood, Hype and Audiences: Selling and Watching Popular Film in the 1990s, Manchester: Manchester University Press.

Brooker, W. (2012), Hunting the Dark Knight: Twenty-first Century Batman, London: IB Tauris.

Clements, J. and H. McCarthy (2006), The Anime Encyclopedia, Revised and Expanded Edition, Berkeley, CA: Stonebridge Press.

Clements, J. (2013), Anime: A History, London: BFI Publishing.

Corrigan, T. (1991), A Cinema Without Walls: Movies and Culture after Vietnam, New Brunswick, NJ: Rutgers University Press.

Denison, R. (2015), Anime: A Critical Introduction, London: Bloomsbury.

- (2016), 'Franchising and Film in Japan: Transmedia Production and the Changing Roles of Film in Contemporary Japanese Media Cultures,' Cinema Journal 55.2, pp. 67-88.

Fujitsu, R. (2004), 'A Studio Ghibli Walk,' [Sutajio Jiburi no ayumi,] Eureka 12, pp. 205217.

Grey, J. (2010), Show Sold Separately: Promos, Spoilers, and Other Media Paratexts, New York: New York University Press.

Hesmondhalgh, David (2007), The Cultural Industries, Second Edition, London: Sage.

Hu, T.Y.G. (2010), Frames of Anime: Culture and Image-Building, Hong Kong: Hong Kong University Press. 
Kanō, S. (2006), The Complete Hayao Miyazaki, [Miyazaki Hayao zensho], Tokyo: Film Art.

Klinger, B. (1997) 'Film History Terminable and Interminable: Recovering the Past in Reception Studies,' Screen 38.2: 107-128.

Lamarre, T. (2009), The Anime Machine: A Media Theory of Animation, Minneapolis: University of Minnesota Press.

Mainichi (1986), 'We Hear from Director Hayao Miyazaki of Castle in the Sky: An Anime U-Turn to Bestow Dreams on Children,' ['Tenkū no shire Lapyuta no Miyazaki Hayao kantoku ni kiku: Kodomo ni yume wo ataeru anime ni U-tān'], Mainichi Newspaper 6 August, sec.2, p.7.

McCarthy, H. (1999) Hayao Miyazaki: Master of Japanese Animation, Berkeley, CA: Stonebridge Press.

Miyazaki H. (2009), Trans. Beth Cary and Frederk L. Schodt. Starting Point 1979-1996. San Francisco: Viz Media.

Nomura M. (1986), 'Castle in the Sky: Interview with Director Hayao Miyazaki.' [Tenkū no shiro Laputa: Miyazaki Hayao kantoku intabyū.] Kinema Junpo 941, pp. 42-49.

Smith, I. R. (2012), 'Sherlock Hound and the Transnational,' Alluvium 1.3 https://www.alluvium-journal.org/2012/08/01/sherlock-hound-and-the-transnational/. Accessed 18 August 2016.

Steinberg, M. (2012), Anime's Media Mix: Franchising Toys and Characters in Japan, Minneapolis: University of Minnesota Press.

Studio Ghibli (2002), Have you Seen the 'Newspaper Advertisements' for Nausicaü? [Naushika no 'shimbun kōkoku' tte mita koto arimasuka?] Tokyo: Tokuma shoten and Studio Ghibli.

Studio Ghibli (n.d.), 'Studio Ghibli Chronology' [Sutajio Jiburi nenhyō], Sutajio Jiburi, http://www.ghibli.jp/30profile/000159.html\#more. Accessed 01 September 2016.

Suzuki, T. (2005), My Film Hobby, [Eiga dōraku], Tokyo: Pia.

— (2011) Ghibli's Philosophy, [Jiburi no tetsugaku,] Tokyo: Iwanami publishing. 
Takahata I. (1986) 'Producer Isao Takahata: I had Enjoyable Thoughts on Music Design and the Theme Song,' Roman Album Castle in the Sky [Tenkū no shiro Lapyuta] 1986 [Republished 2005], pp. 140-141.

Team Ghiblink (n.d.), 'Kaze no Tani no Naushika: Frequently Asked Questions,' The Hayao MIYAZAKI Web, http://www.nausicaa.net/miyazaki/nausicaa/faq.html\#studio. Accessed 23 August 2016.

Wyatt, J. (1994), High Concept: Movies and Marketing in Hollywood, Austin: University of Texas Press. 


\title{
Marketing Anime to a Global Audience: A Paratextual Analysis of Promotional Materials from Spirited Away
}

Laz Carter, School of Oriental and African Studies

\begin{abstract}
This article will concentrate specifically on the marketing materials utilized in the Japanese and American markets for Spirited Away. That is to say, it takes a deeper look at the paratextual deployment of film posters and theatrical trailers. By comparing the different linguistic versions of both posters and trailers, this article highlights areas of difference and thus extrapolates the key selling points which are accentuated for both the domestic and global markets of Studio Ghibli films.
\end{abstract}

Keywords: Globalization, anime, marketing, Studio Ghibli, Hayao Miyazaki 


\section{Marketing Anime to a Global Audience: A Paratextual Analysis of Promotional Materials from Spirited Away}

Lawrence Carter, School of Oriental and African Studies

Whilst a number of scholarly works have been penned on the topic of Studio Ghibli's meanings, few have reached a satisfactory degree of specificity with regards to its brand identity. Indeed, a frustrating number of works relating to the animation studio are preoccupied with simply delineating the narratives of the texts (Drazen 2003: 257-279; Odell and Le Blanc 2010: 46-139). Analyses of Studio Ghibli have the potential to move beyond textual into contextual matters and, therefore, I focus in detail on 'paratextual' (Gray 2010) concerns herein, which is to say those items relating to film promotion. Jonathan Gray defines the paratext as content such as 'posters, videogames, podcasts, reviews, or merchandise' and argues that they 'are not simply add-ons, spinoffs, and also-rans: they create texts, they manage them, and they fill them with many of the meanings that we associate with them' (Gray 2010: 6). Furthermore, beyond simply strengthening a connection to potential consumers, paratextuality can be used to actually create audiences; Lisa Kernan comments that 'audiences are implicitly defined by promotional discourses' (2009: 3). Viewed in such a light, there is even more reason to focus on promotional paratextuality as the implied commercial demographic of a text itself is constructed beforehand through its marketing materials.

Building upon the work of Rayna Denison, especially 'The Global Markets for Anime: Miyazaki Hayao's Spirited Away (2001)' (2006; see also Denison 2015), this analysis will concentrate specifically on the promotional materials utilized in the Japanese and American markets for Spirited Away (Sen to Chihiro no kamikakushi, Hayao Miyazaki, 2001). Following on from Denison's findings, this article takes a deeper look at the paratextual marketing materials utilized in the promotion of the film, in particular the deployment of film posters and theatrical trailers. By examining the specificities of select paratexts in great detail, this article aims to highlight which brand names and promotional strategies are accentuated in a given market or medium and thus connect these marketing manoeuvres with an approximate targeted demographic. Moreover, when these paratextual particularities are collated together in a single case study, one is thereby able to postulate a framework which describes the overarching power structures that govern the corporate relationship between Studio Ghibli and Walt Disney Studios. 
The methodological approach I take in probing paratextuality has been influenced by Keith Johnston's Coming Soon: Film Trailers and the Selling of Hollywood Technology, which espouses the concept of 'unified analysis [which] places [emphasis] on [both] scrutinizing the individual trailer text, and building a network of the unique historical influences that surrounded its production' (2009: 155). Johnston employs a unified analysis framework in order to 'understand each text in its historically specific moment' (2009: 90), which indicates that his goal is to utilize paratextual examination to uncover a socio-historic zeitgeist. Kernan's approach is similarly entrenched in historical analysis, as her methodology is centred upon 'ideological critique within a social-historical framework' (2009: 5). This article similarly attempts to link various paratexts contemporary to Spirted Away's releases in two contrasting marketplaces in order to observe how promotional strategies shift over time and space to accommodate (re-)production cultures and consumption patterns. That is to say, my approach, which one might term 'campaign analysis', looks across multiple paratexts not for their individual impact or influence upon a film's reception, or a particular society, but in order to track the trajectory of the marketing campaign itself: to comment upon the promotional policies put in place by industrial professionals and the effects these actions have upon the 'implicitly defined' consumer. I argue that by utilising the technique of campaign analysis one is better able to demonstrate which facets occur simply because they happen to work well within a given marketing medium and those which are applied uniformly across the paratexts, indicating an agenda accentuated by the advertisers. I contend that such an approach has the potential to be applicable for deployment throughout media and film studies and that this article may be beneficial to these endeavours by laying the groundwork for further research.

I selected Spirited Away for this paratextual analysis for three reasons. Firstly, it follows on from the groundwork established by Denison in her aforementioned article. Secondly, the film remains a critical turning point in Miyazaki's work wherein, despite the fact that his films were already immensely popular within Japan, the Western exhibition of Studio Ghibli films shifted dramatically from the cramped screenings in arthouse cinemas to more mainstream releases, in addition to garnering several accolades, not least of all the 2003 Academy Award for Best Animated Feature. Thirdly, the more contemporary films which follow Spirited Away are mired in more complex associations, including the involvement of Disney subsidiaries like Touchstone Pictures, as well as an increasing emphasis on alternative paratexts, such as numerous official websites and DVD covers. As such, I have chosen to 
focus solely on Spirited Away, yet even this selection is far too broad due to the sheer amount of Spirited Away's promotional material. Indeed, Denison notes that 'there were nine additional theatrical trailers and ten television advertisements produced just for the Japanese market' (2007: 312). I have chosen to focus solely on film posters and theatrical trailers and even then I have been presented with a wealth of content to analyse as multiple versions of posters and trailers were produced for Spirited Away even within a given linguistic context. In total I shall be examining four paratexts in detail: a Japanese poster, an American poster, a Japanese trailer and an American trailer. I have opted to focus on the paratext which appeared most prominently and frequently in the promotion of Spirited Away in each context. Thus, what follows is not to intended to act as a complete account of the promotional strategies for Spirited Away; instead, this article serves as a starting point for future studies with the understanding that there exists plenty of scope for further examinations of a wide range of Studio Ghibli’s paratextual ephemera.

This campaign analysis will show that the promotional strategies behind Spirited Away in both the domestic and global marketplaces rely heavily upon the concept of the brand name of the auteur, or as LaMarre describes it, 'an artist or author effect' (LaMarre, 2009: 87). Timothy Corrigan goes on to qualify 'auteurism as a way of viewing and receiving movies, rather than as a mode of production' and that, specifically in terms of promotional strategies, 'auteurist marketing of movies [...] through the reverberations of directorial names across titles [...guarantees] a relationship between audience and movie [through] a kind of brand-name vision whose contextual meanings are already determined' (1990: 44). Through these postulations, Corrigan contends that the auteur is implicated in the paratext as much as the text itself and that the deployment of an auteur brand name in a promotional campaign can play a crucial role in forging a bond between the producer and the consumer.

In the context of Spirited Away, the obvious site of authorship is that of the director, Hayao Miyazaki, who LaMarre describes as

an auteur in the sense that he puts his stamp on every aspect of production (writing, directing, animating) [...] there really is a Miyazaki style, a Miyazaki look and feel and treatment, and we recognize his films as Miyazaki films, we see in them his vision' (2009: 87).

The language LaMarre uses is one of optics and aesthetics, indicating that Miyazaki's auteur impact is located in the visuality of his creations, yet this emphasis overlooks the power of 
his commodified brand name in the promotional campaign. Such is the power of this branding that Miyazaki might be described as an 'auteur-star' (Corrigan 1990: 48); that is, an auteur 'situated along an extratextual path, in which [... they are] meaningful primarily as promotion' (Corrigan 1990: 48-9). Considered in this light, this article shall engage campaign analysis to focus on how the Hayao Miyazaki brand name is deployed throughout the marketing materials of Spirited Away.

Yet a case could also be made to consider Studio Ghibli as an 'author function' (Foucault 1984: 107) in that the animation company acts as a commodified brand name in the promotional paratext, or, as Jerome Christensen describes the concept, 'a person who is not actual but who nonetheless qualifies for the status of the intending author: the corporate studio itself' (2012: 13). In the case of the Japanese domestic context and Studio Ghibli's oeuvre, LaMarre notes, 'Ghibli films [...] address viewers in a certain way and present the world in a certain way. They thus imply a worldview that contributes to the constitution of a Ghibli world' (2009: 87). Moving forward with this understanding, it is the position of this article that, in addition to the visuality of Miyazaki's auteurism, the 'corporate studio' of Ghibli espouses a textual 'worldview' that has been successfully deployed as a brand name in promotional paratexts.

However, as alluded to above, within the global, Anglophone market for Spirited Away, a third agency complicates these two brand names: the localizing force of Disney. Eriko Ogihara-Schuck describes the US promotional campaign as a process of 'deliberate Disneyfication' (2014: 88), a process wherein a corporate agency is involved in 'changing an entity into something basic and artificial' (Matusitz and Palermo 2014: 100). It is the position of this article that the Western marketing campaign for Spirited Away is characterized by the Disneyfication of the Oriental origins of the film and that the American (re-)marketing campaign condenses and simplifies content to produce more accessible global paratexts.

Working on the basis that the auteur brand name of Miyazaki, and those of the corporate studios of Ghibli and Disney, each actively take on the role of the auteur and act as a nexus connecting a textual canon, it is worthwhile focusing on the interactions amongst this 'layered brand' (Denison 2015: 120) to establish the power dynamics in the domestic and global marketplaces. The following campaign analysis shall pay particular attention to these three brand names as well as their intrinsic relationship to their respective native languages, and plot their deployment throughout the promotional paratexts of Spirited Away. 


\section{Poster analysis: Language, exoticism and Disneyfication}

The first paratexts this article shall analyse in detail are the film posters, as still-image marketing often includes the broad trends of a wider promotional campaign. For the sake of clarity, it is worth specifying that I shall be analysing the Japanese and American posters that feature Spirited Away's protagonist, Chihiro, as a central figure - the very same designs examined by Eriko Ogihara-Shuck in her fascinating comparison focused on animism (2014: 89-90). In the case of Spirited Away, the first disparity between the two contrasting film posters used in the domestic market of Japan and the globalizing market of America that becomes immediately apparent is the eliding of Japanese 'linguistic signs transmitted visually' (Katsuno and Maret, 2004: 82); most notably, the title has been altered from 'Sen to Chihiro no kamikakushi' ('the spiriting away of Sen and Chihiro') to 'Spirited Away'. Ogihara-Schuck writes of these titles that

[u]nlike the Japanese term, the English phrase does not necessarily carry a supernatural and religious connotation, as it literally means being taken away or kidnapped [...] yet, as the title of a film that is populated by "spirits," the phrase “spirited away" attains a supernatural connotation. (2014: 88)

She goes on to note that in the Japanese poster, the phrase 'kamikakushi in the title is the only indicator of otherworldliness' (2014: 88) whilst 'on the other hand, the Disney [design] makes animism more evident $[\ldots]$ the American version newly inserts the image of a spirit at the bottom right' (2014: 91). In order to achieve the effect that the Japanese poster realises solely through the inclusion of 'kami' (meaning god or spirit) in its title, the American design requires further contextualization through incorporating explicitly spiritual characters. This suggests that the otherworldly 'narrative image' (Neale, 2000: 160) of spiritualism is so intrinsically important to both the Japanese and American campaigns that it must be emphasized in both paratexts, however inefficiently.

Yet there is still an observable difference to the naming conventions. Roland Barthes utilizes the terms 'anchorage and relay' (1977: 38, emphasis in original) to denote those linguistic signs which, respectively, merely describe an image and those which combine with an image to create deeper meaning. Using this perspective, one could describe the American title as providing anchorage to the image by explicitly spelling out the film's narrative, 
whereas the Japanese title acts more as a relay in that it combines with the 'catch-copy' (Yoneoka, 2005: 37) and ghostly figures in order to create an overall impression of a film inspired by Japan's Shintō spiritualism. This movement from relay to anchorage between the domestic and US campaigns neatly outlines the overarching processes of Disneyfication and simplification which characterises the US promotional strategy.

There is another meaning lost in the title, which relates to the name of the protagonist; the same kanji character is utilized to create both 'Sen' and part of 'Chihiro'. Despite the fact that the two names are to be read differently, with 'Sen' becoming 'Chi' due to the presence of the accompanying character comprising 'hiro', one cannot help but notice that, when the film title is written down in its original linguistic context, the Japanese title is able to hint at a dynamic of conflict and duality occurring within the protagonist's identity which the Anglophone Spirited Away fails to convey.

There are other linguistic signs transmitted visually in the original Japanese poster such as the catch copy reading 'tonneru no muko ha, fushigi no machi deshita' ('On the other side of the tunnel, was a mysterious town'); the 'sei arimasu' ('there is life') on a sign in the background; or the amount 'jyüni' written on the bathhouse token - which are completely omitted from the American design. Rather than replace such visual linguistic signs with English language equivalents, Disney chose to simply expunge the signifiers. As Kubo Masakazu, a producer of the Pokémon animated series, remarks: it is 'easy to produce international versions by erasing Japanese language signs as much as possible' (quoted in Iwabuchi, 2004: 68).

To a given extent, one can understand this Anglicization process as simply a necessary step to translate and (re-)market Spirited Away to Western audiences. And yet the Disney design does attempt to include Japanese linguistic signifiers by including a stylized hanko (an official name stamp) rendering of the Japanese language kanji 'Sen' at the very top of the paratext as well as the Japanese hiragana script reading ' $m e$ ' visible in a shop window. The only thing that the Sen and the me have in common when compared to the three expunged signifiers analysed above is that they are both comprised of a single, relatively simple, symbol, rather than comprised of a string of more complex Japanese language kana and kanji. This suggests that whilst one broadly familiar with Japanese language and culture might be immediately able to at least partially recognise both Sen and me as Japanese ideograms and thus deduce Spirited Away originates from Japan (Denison 2007: 318), a 
typical member of the Western audience might not necessarily recognise Sen and me as being Japanese signifiers at all and so for these consumers such signs instead become exotic 'nuances and jokes [that] become transcribed into little more than further evidence of the film's Oriental origins' (Denison 2007: 318). Once more, one is able to observe the consequences of Disneyfication: through adhering simplified linguistic references without the appropriate knowledge and context, the American poster exoticizes the text. Building upon Edward Said's discussion of Orientalism (1979), Sheridan Prasso comments that the phenomenon can actually prove profitable, writing that the "“Oriental" style is not really Asian. It is Western - a reflected image of what westerners think Asia looks like. And it sells' (2006: 391). This marketability of Orientalism is a tool deployed repeatedly by Disney throughout the American campaign for Spirited Away.

In addition to marketing the film as exotic through linguistic Orientalism, the American campaign also places a greater emphasis upon the deployment of brand names. In the Japanese poster, the brand-names are scattered across the entire image. The Studio Ghibli brand name and logo are hidden away in the top left corner; other entities involved in the production, including Disney, are referenced in passing along the bottom; six star names those of Rumi Hiiragi, Miyu Irino, Mari Natsuki, Takashi Naitō, Yasuko Sawaguchi and Bunta Sugawara - are listed in small font down the left-hand side. Indeed, the only brand name which draws the eye is that of Hayao Miyazaki, which is rendered in a striking red and yellow colour scheme and positioned directly above the title. Moreover, the qualifier 'kantoku sakuhin' - loosely equivalent to 'a film by' - emphasizes the director's authorial claim over the text. If one accepts that the main focus of the Japanese design can be said to be the persona of Hayao Miyazaki, then one can go on to argue that this is in itself indicative of the types of audience it is designed to attract. As Finola Kerrigan notes in relation to poster design, "if the director is given prominence then the film may be more stylistically or artistically driven' (2010: 133). Thus, one might argue that the domestic design is focused upon the artistic attributes of the animator-auteur over other brand names.

By comparison, the American poster contains less text and no star names at all. This is, in part, because Disney had opted to select a relatively unknown cast where arguably the most famous star name belonged to a rising star of the time, Daveigh Chase (see Denison 2008b). However, I argue that in the Western design a greater significance lies in the placement and positioning of the brand-names surrounding the film's title, especially when compared to the more cluttered Japanese poster. Disney's cleaner, more streamlined version 
is best described by Justin Wyatt's notion of the 'high concept' paratext, which is 'basically simple in its composition' (2006: 129), wherein the aim is to engender 'a very close match between the film's marketing campaign and the actual content of the film' (2006: 117). This 'high concept' style is particularly evident in the Disney poster, as very little information is overlaid upon the original filmic frame. The neat, centralized text does serve to highlight critical information: the three primary brand-names comprising the layered brand - Disney, Studio Ghibli and Hayao Miyazaki - are positioned above the title logo 'Spirited Away' and act to introduce the text to the potential US audience through an appreciation of the production process. By providing equal foregrounding to both the Japanese and Western brand names responsible for the Anglophone version of the film, the American poster is able to position the Spirited Away within a wider canon of popular animation products. That is to say, by associating Spirited Away with the previous oeuvres of both Ghibli and Disney animation stables which have garnered popular followings on their respective sides of the Atlantic - one cannot help but link Spirited Away with their combined commercial successes, as well as to begin to re-position the film as an interstitial site betwixt the two studios.

Once again, mirroring the Japanese design's larger font and red colour scheme, Hayao Miyazaki is given a greater prominence than any other brand name on the American poster. Here, one can track the first evidence of a secondary promotional strategy to rival that of Disneyfication: the reliance upon the commerciality of the 'transnational auteur' (Lee 2008: 217). Whilst the promotional strategy of Disneyfication has been to simplify and elide Japanese origins, adhere additional anchorage signifiers and sell the exoticized Orient to the Western customer, the promotional strategy of the 'transnational auteur' is focused upon the high-brow, independent, arthouse market. In order to bolster this appeal, the Hayao Miyazaki auteur brand-name is complemented by ancillary text located under the film title, which works to connect Spirited Away with a variety of high profile film festivals and awards. Nikki Lee notes that ' $[\mathrm{w}]$ hen it passes through transnational sites of reception, such as international film festivals, the locality of a film often becomes displaced as it is endowed with new layers of meaning and significance' (2008: 212). These 'new layers of meaning' are a critical facet of the contemporary feature film; as Janet Harbord comments: 'the marketing function of the festival is the nexus of apparently different cultures, of the multinational and national, of commerce and art' (2002: 70). The references to the brand names of the San Francisco Film Festival, the Berlin International Film Festival and the Nippon Academy Awards on the American Spirited Away poster act to inflect the film, giving it an identity as a serious artistic 
endeavour. By attaching these accolades to the poster paratext, Disney is able to legitimize the text as an arthouse film worthy of further critical acclaim in the USA.

Thus far, the Japanese marketing strategy has been to focus on the auteur brand name of Hayao Miyazaki - a figure well-known to the domestic audience - and otherwise follow a mainstream 'daihitto' (big hit) approach similar to the successful promotion of Princess Mononoke (Mononokehime, Hayao Miyazaki, 1997, see Denison 2008a). Yet in the American marketplace, one can appreciate how, whilst the Disneyfication promotional strategy serves to introduce Spirited Away to the popular, mainstream Western audience, the transnational auteur promotional strategy simultaneously legitimizes the animation for critical communities in the USA and beyond.

\section{Trailer analysis: Campaign consolidation and shifting brand names}

The construction of the theatrical trailers mirrors the Japanese and the American poster campaigns, in that the Japanese trailer ${ }^{1}$ focuses on auteur brand names as well as the narrative image of the film, whereas the American trailer ${ }^{2}$ both contextualizes the animation through Disneyfication for the benefit of a broad mainstream Anglophonic audience whilst simultaneously legitimizing it as an academic text by focusing on the transnational auteur brand name of Hayao Miyazaki. By comparing the two trailers, one is able to extrapolate the contrasting nature of the anime market in both marketplaces.

In isolation, the Japanese trailer appears relatively unremarkable. Perhaps the most noteworthy factor is that more brand names are utilized, such as that of composer Joe Hisaishi, and that they are each given similar, yet proportionally little, screen-time: the Hayao Miyazaki brand name appears for only slightly longer than Joe Hisaishi's or various other star and brand names. The Japanese title card does act to both reiterate the Hayao Miyazaki brand name, as well as the brand names of other potential authors, including Ghibli and Disney. It should be noted here that, as pointed out earlier by Denison, there are a number of trailers which were screened in the domestic market. Indeed, there are a handful of trailers that are not dissimilar from the primary trailer I have chosen to study, which are cut to differing lengths, and yet each still principally outlines the narrative image of Spirited Away as well as a range of the primary characters, or, as Annett describes them, 'kyara' (2014: 182, emphasis in original). That is to say that, regardless of the precise paratext chosen, the same promotional strategies that were evident in the domestic still-image campaign - a preference for auteur brand names and narrative images - have remained consistent into the Japanese 
moving-image marketing materials. This continuity in domestic promotional strategies is unsurprising; as noted above, Spirited Away was a mainstream, daihitto success in Japan and the promotion did not need to deviate from established marketing techniques in order to present and contextualize the film for its original intended audiences.

By contrast, the American trailer is an excellent case study of paratextual (re)branding for global consumers. The very first image of the paratext, which is crucial to any trailer as it often 'addresses the audience and provides information about the film' (Kerrigan 2010: 143), is of the Disney brand name contextualizing the images that follow for an Anglophone audience. Even though Disney chose not to utilize their renowned production logo, the arcing firework graphic used throughout the Spirited Away trailer is able to echo this famous image and acts as an indicator symbolically representing the influence of Disneyfication for the remainder of the paratext. It is significant that the next image introduces the Ghibli brand name, not through the well-known production logo of Totoro upon a blue background, but instead through the lens of this Disney firework graphic. This is Disneyfication in action; Japanese logos and brand names are omitted and become homogenized by the added artifice of the firework graphic that echoes the Disney studio's own logo.

A further re-contextualizing phenomenon takes place through the use of the Disneyfication firework graphic: an overt exoticization of the Japanese language that highlights Chihiro's 'judgment', 'courage' and 'loyalty'. Whilst at first one might assume that the film's Oriental origins are no longer being denied by allowing the onscreen depiction of the kanji characters for 'ketsudan', 'yūki' and 'chüsei', a reconsidered examination might counter that the Anglophonic anchorage translations of 'judgment', 'courage' and 'loyalty' are literally transposed on top of these Japanese signifiers. Moreover, the entire encounter occurs amidst the Disneyfication firework graphic, thus symbolically representing both the paratext and the text itself as 'just', 'courageous' and 'loyal' adaptations of the original animation. When we are finally introduced to the American title card for Spirited Away we are once again presented with a firework graphic, which, having earlier been established in terms of a Japanese backdrop and a foregrounded Anglophone translation, comes to fully acclimatize the audience to the concept of the Spirited Away film text as Anglophone entertainment with an Oriental flavour. 
At the same time, perhaps surprisingly, the Disneyfication firework graphic introduces the intertitles for the Berlin International Film Festival and the San Francisco Film Festival which act as transnational auteur inflections. As such, these secondary associations are seen to grant critical, award-worthy 'calibre' (Kerrigan 2010: 145) to the Western animation giant rather than the Japanese originating studio. However, these inflections are nonetheless given an unusual amount of screen time for a trailer, and the transnational auteur brand name of Hayao Miyazaki himself escapes the Disneyfication firework graphic and actually receives his own colourful typeface.

Looking solely at the visuals of the paratext, it would initially seem that the balance of power has tipped in favour of the promotional strategy of Disneyfication, rather than the transnational auteur approach. Yet to complete this paratextual analysis, one must not only pay attention to visual cues but also audiovisual ones. As alluded to above, the Japanese trailer contains only short excerpts from two scenes and no narration whatsoever - doubtless a deliberate decision which allows the focus of the trailer to rest upon the narrative image and certain kyara - whereas the American trailer is centred around a voice-over that drives the paratext through a litany of brand names, inflections and anchorage. What follows is a transcript of the 'deep male voice' (Kerrigan 2010: 143) narration from the American trailer emphasized to highlight certain issues: emboldened text indicates a brand-name deployment; underlined text represents an ancillary inflection or association; and italicized text portrays an anchorage phenomenon which I term 'audiovisual synchronicity', which is to say the situation wherein narrated 'verbal signs transmitted acoustically' (Katsuno and Maret 2004: 82) align with the on-screen linguistic signs transmitted visually:

Walt Disney Studios presents a Studio Ghibli film from master filmmaker Hayao Miyazaki. In worlds seen and unseen, where spirits are transformed and sorcerers rule, one girl's future depends on her judgement, her courage, her loyalty, and remembering one thing above all else ... Walt Disney Studios presents a Studio Ghibli film. Experience a magical movie phenomenon embraced by all the world. This fall, prepare to be Spirited Away

There are three key points which bolster the transnational auteur promotional strategy evident in this transcription. Firstly, what becomes immediately apparent is that both the Disney and Ghibli brand names are repeated in identical phraseology and via audiovisually synchronous anchorage. This suggests that there is a tendency towards reinforcing these 
brand names as part of a layered brand, because they have been selected as the primary selling points for the global marketplace. Secondly, two additional signifiers are present, which may be thought of as 'inflections' as they imbue additional signification into authorial brand names: a description of Hayao Miyazaki as a 'master filmmaker' and a depiction of the theatrical release schedule as 'a magical movie phenomenon embraced by all the world'. These inflections both work to attract more independent, critical consumers which may be more familiar with world cinema. Thirdly, in addition to establishing a layered brand and appealing to the arthouse audience through the transnational auteur approach, it should be noted that audiovisually synchronous anchorage is also deployed atop the exoticized Disneyfication of Chihiro's judgment, courage and loyalty, indicating that this tool for combining linguistic systems is not employed solely for the benefit of a single promotional strategy.

\section{Conclusion}

Although existing in-depth paratextual analysis allows one to glean insights on a case-by-case basis, it is only when one can plot recurring themes across multiple paratexts that progress can be made. Paratextual campaign analysis, as demonstrated through this case study of Spirited Away, is a valuable resource which has the potential to add weight to future academic research in the field. As more campaigns are fully analysed, comparisons and contrasts may be more easily drawn betwixt corporate studios and consumption patterns. I postulate that further campaign analysis is necessary, not just of Studio Ghibli's oeuvre, but also wider film cultures, in order to truly understand how global phenomena are consumed in each individual marketplace as they traverse the globe.

Throughout this particular campaign analysis I have argued that the Japanese campaign promotional strategies have relied upon the domestic audience for anime daihitto appreciating complex duality within the Japanese language, remaining consistently familiar with auteur brand names and being primarily interested in narrative images and the representation of kyara. Conversely, the American paratextual materials indicate two distinct promotional strategies: one characterized by Disneyfication and a desire to render references to the film's Oriental origins as merely exotic nuances and jokes for the benefit of the Western mainstream demographic, and another driven by the inflection of transnational auteur brand names in order to appeal to an arthouse, world cinema market. Whilst one can distinguish between these two promotional strategies and target audiences, it is worth noting 
that specific marketing devices - such as a 'high profile' poster design and 'audiovisually synchronous anchorage' - can be deployed to bolster either strategy and that one has to look closely to ascertain which strategy is profiting from a given decision.

However, it should be noted that there is one aspect of marketing which both campaigns and all four of these paratexts do have in common: the accentuation of Hayao Miyazaki as transnational auteur above all other brand names. The Miyazaki transnational auteur brand name is consistently deployed throughout both campaigns with a striking red colour scheme and often inflected with critical acclaim through film festival awards as well as being reinforced through audiovisually synchronous anchorage. This tendency to focus strongly upon the Miyazaki brand name extends beyond Spirited Away, and the American trailers for later Studio Ghibli films like Howl's Moving Castle (Hauru no ugoku shiro, Hayao Miyazaki, 2004), Ponyo on the Cliff by the Sea (Gake no ue no Ponyo, Hayao Miyazaki, 2008) or The Wind Rises (Kaze Tachinu, Hayao Miyazaki, 2013) are littered with similar 'master filmmaker' inflections (Denison 2015: 120) and audiovisually synchronous anchorage. As such, I argue that the brand name of Hayao Miyazaki is the foundation upon which the (re-)marketed promotional strategies of his films are built.

And yet, even if the deployment of Hayao Miyazaki the brand name is crucial in selling Ghibli films, that does not necessarily mean that Hayao Miyazaki the filmmaker wields the most power over the promotional strategies undertaken. LaMarre defines ' $[\mathrm{t}] \mathrm{he}$ dynamics of the Miyazaki auteur effect and the Ghibli-brand world' (2009: 87) as a hierarchy of authorship where the director's influence is subservient to the studio. He goes on to write that 'the Miyazaki effect - Miyazaki as auteur - emerges within a theater of operations known as Studio Ghibli, as it strives to secure a perimeter for staging its animated worlds and worldview' (2009: 87). That is to say that whilst Hayao Miyazaki the animator reigns supreme over textual concerns, the commodified Hayao Miyazaki brand name is, in practice, little more than one of many 'artful patterns of distribution and commercialization' (2009: 87). In the domestic marketplace, Studio Ghibli and the producers behind the scenes - which admittedly prominently includes Hayao Miyazaki but also a number of other influential individuals such as Toshio Suzuki (see Denison 2015: 127-31) - make the critical decisions regarding promotional strategy. But this chain of command does not end there: in the global marketplace it is Disney who calls the shots and thus it is Ghibli's turn to be commodified as yet another brand name to be utilized within marketing materials. In this model, one can 
imagine a linear structure of hierarchy wherein those entities towards the bottom are prime candidates for (re-)branding by those agencies situated at the top.

Crucially, it is my argument that this Russian doll configuration of hegemony and power relations defined the (re-)marketing of Studio Ghibli films at the time of Spirited Away's release, but that, at the time of writing, especially noting the present pause in Studio Ghibli's feature film production, the relationship has evolved and can now be better understood as 'a commingling of Studio Ghibli and Disney's brand meanings' (Denison 2015: 120). Only time will tell whether this system will endure on past this post-Miyazaki period, but I posit that if trends continue along this current path then the future holds the promise of a much more equal global arena in which promotional strategies may be enacted.

\section{Notes}

${ }^{1}$ See The Studio Ghibli Collection 2 Disc Region 2 DVD distributed by Optimum Releases.

${ }^{2}$ See The Studio Ghibli Collection 2 Disc Region 2 DVD distributed by Optimum Releases.

\section{References}

Annett, S. (2014), Anime Fan Communities: Transcultural Flows and Frictions, Basingstoke and New York: Palgrave Macmillan.

Barthes, R. (1977), Image - Music - Text, trans. by S.Heath, New York: Hill and Wang.

Christensen, J. (2012), America's Corporate Art: The Studio Authorship of Hollywood Motion Pictures (1929 - 2001), California: Stanford University Press.

Corrigan, T. (1990), 'The Commerce of Auteurism: A Voice without Authority, New German Critique, 49:1, pp. 43-57.

Denison, R. (2007), 'The Global Markets for Anime: Miyazaki Hayao's Spirited Away (2001)' in A. Phillips and J. Stringer (eds.), Japanese Cinema: Texts and Contexts, London and New York: Routledge, pp. 308-21.

— (2008a), 'The Language of the Blockbuster: Promotion, Princess Mononoke and the Daihitto in Japanese Film Culture' in L. Hunt and L. Wing-Fai (eds.), East Asian 
Cinemas: Exploring Transnational Connections on Film, London and New York: I.B. Tauris, pp. 103-22.

— (2008b), 'Star-Spangled Ghibli: Star Voices in the American Versions of Hayao Miyazaki’s Films', Animation: An Interdisciplinary Journal, 3:2, pp. 129-46.

— (2015), Anime: A Critical Introduction, Bloomsbury: London.

Drazen, P. (2003), Anime Explosion! The What? Why? \& Wow! Of Japanese Animation, California: Stone Bridge Press.

Dyer, R. (1986), Heavenly Bodies: Film Stars and Society, London: BFI Publishing.

Foucault, M. (1984), 'What is an Author?' in P. Rabinow (ed.), The Foucault Reader, New York: Pantheon Books, pp. 101-20.

Gray, J. (2010), Show Sold Separately: Promos, Spoilers, and Other Media Paratexts, London and New York: New York University Press.

Harbord, J. (2002), Film Cultures, London: Sage.

Iwabuchi, K. (2004), 'How “Japanese” is Pokémon?’ in J. Tobin (ed.), Pikachu's Global Adventure: The Rise and Fall of Pokémon, Durham and London: Duke University Press, pp. 53-79.

Katsuno, H. and J. Maret (2004), 'Localizing the Pokémon TV Series for the American Market', in J. Tobin (ed.), Pikachu's Global Adventure: The Rise and Fall of Pokémon, Durham and London: Duke University Press, pp. 80-107.

Kernan, L. (2009), Coming Attractions: Reading American Movie Trailers, Austin: University of Texas Press.

Kerrigan, F. (2010), Film Marketing, Oxford: Elsevier.

LaMarre, T. (2009), The Anime Machine: A Media Theory of Animation, Minneapolis: University of Minnesota Press.

Lee, N. (2008), 'Salute to Mr. Vengeance!: The Making of a Transnational Auteur Park Chan-wook', in L.Hunt and L. Wing-Fai (eds.), East Asian Cinemas: Exploring Transnational Connections on Film, London and New York: I.B. Tauris, pp. 203-20. 
Matusitz, J. and L. Palermo (2014), 'The Disneyfication of the World: A Globalisation Perspective', Journal of Organisational Transformation \& Social Change, 11:2: pp. 91-107.

Miyazaki, Hayao (2001), Spirited Away / Sen to Chihiro no kamikakushi, Tokyo: Studio Ghibli.

— (2004), Howl's Moving Castle / Hauru no ugoku shiro, Tokyo: Studio Ghibli.

— (2008), Ponyo on the Cliff by the Sea / Gake no ue no Ponyo, Tokyo: Studio Ghibli.

— (2013), The Wind Rises / Kaze Tachinu, Tokyo: Studio Ghibli.

Neale, S. (2000), 'Questions of Genre', in R. Stam and T. Miller (eds.), Film and Theory: An Anthology, Malden: Blackwell Publishers, pp. 157-178.

Odell, C. and M. Le Blanc (2009), Studio Ghibli: The Films of Hayao Miyazaki and Isao Takahata, Hertfordshire: Kamera Books.

Ogihara-Schuck, E. (2014), Miyazaki's Animism Abroad: The Reception of Japanese Religious Themes by American and German Audiences, North Carolina: McFarland \& Company.

Prasso, S. (2006), The Asian Mystique: Dragon Ladies, Geisha Girls, \& Our Fantasies of the Exotic Orient, New York: Public Affairs.

Said, E. (1979), Orientalism, New York: Vintage Books.

Wyatt, J. (2006), High Concept: Movies and Marketing in Hollywood, $5^{\text {th }}$ edition, Austin: University of Texas Press.

Yoneoka, J. (2005), 'The Striking Similarity between Korean and Japanese English Vocabulary', Asian Englishes, 8:1, pp. 26-47. 


\title{
Can Faithfulness to the Original Text Betray the Target Public? The Adaptations of Mononokehime (Princess Mononoke) in Italy
}

Daniela Pizzuto, School of Foreign Languages and Literatures, Interpreting and Translation, University of Bologna (Italy)

\begin{abstract}
Over the past few years audiovisual translation in 'dubbing countries' has been experiencing a significant shift from the traditional domesticating approach to a foreignizing approach that focuses more on faithfulness toward the source text rather than to the target readership. The Italian rendition of anime is a case in point: while appreciated by an increasing number of viewers, both serial and stand-alone anime have either suffered a limited distribution or a highly homogenising adaptation, in many cases through the employment of English as vehicular language.

The first Italian dubbed version of the popular Studio Ghibli masterpiece Princess Mononoke (Mononokehime, Hayao Miyazaki, 1996) is a clear example of the latter. The version distributed by Buena Vista International in 2000 as Princess Mononoke was adapted from the North American version, which included radical modifications aimed at providing a context with which the spectators would be more familiar. A second version, distributed by Lucky Red in 2014 under the title Principessa Mononoke, was re-adapted from the original Japanese script in order to improve fidelity to the original, and was re-dubbed with a new voice cast. However, numerous viewers criticized the unintelligibility of most of the dialogue. This article analyses the differences between the two versions and investigates whether the visibility of the translator can be seen as an obstacle for the understanding and enjoyment of films for the target viewership.
\end{abstract}

Keywords: Mononokehime, Principessa Mononoke, adaptation, retranslation, indirect translation, translator's invisibility, translatability. 


\section{Can Faithfulness to the Original Text Betray the Target Public? The Adaptations of Mononokehime (Princess Mononoke) in Italy}

Daniela Pizzuto, School of Foreign Languages and Literatures, Interpreting and Translation, University of Bologna (Italy)

Popular masterpiece Mononokehime (Princess Mononoke, Hayao Miyazaki, 1997) was released in the Italian market first as Princess Mononoke in 2000, as an adaptation from the North American version, and later as Principessa Mononoke in 2014, in a brand new adaptation. Both are far from perfect, but while the former suffers the consequences of being an indirect translation, the latter - despite offering a more philologically correct and direct translation of the script - still does not enjoy the status of 'great translation' (Berman, in Tahir Gürçağlar 2011) as hypothesized for retranslations. As a matter of fact, viewers lamented the unintelligibility of its dialogue, and the weirdness of some linguistic choices. The present article therefore analyses the two differently adapted versions of the film from a translation studies perspective, in order to ascertain whether too much visibility for the translator, despite what has been advocated for by Venuti (2008), may actually be a hindrance to the comprehension of the message.

\section{Italy and anime: love at first sight}

Italy was one of the first countries in Europe to import cartoons and full-length animated films from Japan and anime's success was immediate, to the extent it could be considered as a sort of love at first sight:

Anime and manga have contributed to shape the audiovisual background of many Italian children and teenagers, thanks also to the weird show schedule on TV. ${ }^{1}$ Arriving in Europe during the second half of the 1970s, a first wave of Japanese cartoons set the basis for a new aesthetic sensitivity. (Pellitteri 2008: 7)

After a long pause between the mid-1980s and the early 1990s, during which the programming of cartoons on Italian TV suffered an abrupt arrest, a second and probably stronger wave re-established the distribution and popularity of Japanese animation. There is also nostalgia towards the anime of the past and their TV opening and ending theme songs, especially amongst people in their thirties who used to be children at the time of the first wave (Pellitteri 2008: 7). 
In such a sociocultural environment, it is easy to assess the success of films by Studio Ghibli, which have been loved both by children and adults alike. Despite their popularity on television, animation films in Italy tend to suffer at the box office, while they collect their highest returns in the home video market (Tieri 2008), which might be the reason why they are usually exhibited in cinemas for just a few days. Mononokehime was one of the first animated films to be distributed at the beginning of the second wave of anime in Italy, and it was immediately loved by the public, smitten by its tale of love and hatred and the eternal conflict between progress and nature. What the public did not know at that time was that the story they had seen in cinemas was not quite what Hayao Miyazaki had directed.

\section{The tale of a prince and a princess, and a complicated genesis}

Set in a long ago era 'when gods and spirits still walked the earth' (Townsend 1999), Mononokehime tells the story of Ashitaka, the young prince of the Emishi tribe, who is forced to leave his people after being cursed by a dying wild boar god. Banished from his homeland and sent to find the Great Forest Spirit in a quest to save his own life, Ashitaka finds the people of Tataraba (Irontown), governed by the strong and proud Lady Eboshi; and San, the titular princess of ghosts, a human girl abandoned as an infant by her family and raised by wolf gods. Irontown is where the iron ball found in the body of the dying wild boar was produced and it was likely the reason why the boar god turned into a demon and blindly attacked people. San is doing everything in her capacity to kill Eboshi, whom she holds responsible for the destruction of the forest. Ashitaka finds himself stuck in a hard fight between two strong-willed women and the eternal conflict between the preservation of nature and the hardships of progress.

Mononokehime was bought by Buena Vista International, in 1996, a Disney subsidiary. Due to the violent content of the film and the unclear definition of the good/evil opposition, Disney chose to release the film through Miramax, another of its subsidiary companies known for distributing independent and foreign films. The script was translated by Steve Alpert, Haruyo Moriyoshi and Ian MacDougall, and turned into dialogue through the adaptation of novelist Neil Gaiman. By his own admission 'a lot of it was just taking it and trying to get it to flow as dialogue' (Gaiman, in Townsend 1999) because

Most anime dialogue that I've seen [...] doesn't sound like dialogue that people would ever say. And what I wanted to do was try and (a) sneak information in, while (b) giving natural-sounding dialogue, that (c) kept as much as possible, 
of either what the Japanese said or what they meant. Occasionally, you'd wind up completely changing something in order to make it work. (Gaiman, in Townsend 1999)

Of course, adapting a film is something that goes beyond the mere translation of dialogue, as Paolinelli and Di Fortunato argue:

When translating the lines for the actors, the adaptor cannot avoid taking into consideration all the necessary elements that form the narrative structure of the scene and of the whole film. That must be accomplished by examining a series of elements that go beyond the mere words used in the dialogues. [...]

[The adaptor] must immerse themselves into the language, understand what is the 'language' of the film, which communicative strategies were chosen by the characters, which variety of language - what in linguistics is known as 'register' - is used by every character in every situation, and then choose the right variety, and the 'parallel register' to use in the target language.

The adaptor should be able to ascertain the different communicative levels: the one existing among the characters - which could identify their ethnic, social and geographical background - and that between the characters and the public - which concerns the linguistic competence of the public itself - and, after an accurate analysis, should be able to convey all of that in target language. (Paolinelli and Di Fortunato 2005: 2)

Gaiman's adaptation received high praise by critics and fans, to the point of believing that he and director Jack Fletcher had 'set a new standard' (Gaiman, in Townsend 1999) in the field in the US, but that does not mean it is immune from imperfections and problematic translation strategies. Gaiman himself admits having changed part of the dialogue because it would not have been funny if translated literally and that it was not his intention to simply 'recreate the Japanese experience on the screen' (Gaiman, in Townsend 1999), thus focusing more on fluency than accuracy. While such an approach is not wrong per se, it is suggestive of a long-standing aggressively monolingual attitude, typical of a dominant culture, which is often seen in the US market (Venuti 2008).

\section{A first (indirect) adaptation: Princess Mononoke}


As Miramax held distribution rights in Italy after 1996, Mononokehime was not adapted directly from the original Japanese script, but from the already released North American version. This could be viewed as a way to profit from an already well-received product and to limit the translation expenses for a film with a low expected return at the box office. In fact, indirect translations, the practice of translating from a pre-existing translation in a vehicular language, used to be common in the past, especially between distant languages, because of the unavailability of professional translators from less diffused languages and the lower costs of production (Pieta and Assis Rosa 2013). However, indirect translations are not devoid of risks, as they heavily rely on the quality of the mediated text: as the translator cannot be aware of mistakes or censored text, and therefore is not able to recognize or correct them, such mistakes were commonly transferred to new versions as well. Which is why translators now use them 'only when absolutely necessary' (UNESCO 1976).

The first Italian version of Mononokehime was translated by Rodolfo Cappellini and released in 2000 through Buena Vista International. The influence of the North American version is strong, especially regarding the translation of single items and nouns. In the following analysis some of the most significant cases will be highlighted and discussed. While in the original film San is either addressed by her given name or by the appellative mononoke (literally things that are mysterious, used to identify some spirits of Japanese folklore), in the US version she is referred to as the wolf girl, which was then directly translated into la ragazza lupo in the Italian version. As San is mostly seen with her mother Moro and her wolf brothers, this could be considered as an attempt to domesticate a term and a concept from the source culture that the team of adaptors considered too complicated or foreign for the target public. San's nickname, mononoke, was therefore connected to what was on screen (a girl raised by wolves), linking her to the literary tradition of feral children, among which the most famous examples are Tarzan in Tarzan of the Apes (Rice Burroughs 1912), or Mowgli in The Jungle Book (Kipling 1894) in literature, or Romulus and Remus in the myth of Rome's foundation.

Ashitaka is sometimes referred to as straniero in the Italian version by Buena Vista International, which is a calque of the term employed in the US release of Princess Mononoke. This case is particularly interesting for two reasons: (1) straniero is not the usual translation for stranger, as its closest translation would be foreigner (thus, in Italian the focus is more on the fact that Ashitaka comes from another land, rather than he is someone no-one 
knows); and, (2) in the Japanese film no-one ever calls Ashitaka gaikokujin (foreigner) or ihōjin (stranger). Rather, he is either called by his given name or danna (sir).

A peculiar case of translation also surrounds Shishigami no mori, adapted as forbidden forest in the North American version of Mononokehime and consequently as foresta proibita in the 2000 Italian release. The forest is actually not forbidden at all, as the Japanese name simply means forest of the God of Beasts. As the people of Tataraba are wary of the god and the spirits living in his forest, they tend to look scared and agitated when they speak about it - which is probably why the adaptors chose to add the appellative forbidden to what was simply a sacred forest. In a similar fashion Deidarabocchi, the nocturnal aspect of the Shishigami (the forest god), is rendered as Colui che cammina nella notte (literally He who walks through the night), as a translation of the American Nightcrawler. Both adaptations thus preferred to focus more to the shape of the night version of the god rather than its function, which made the translations highly evocative, but lacking in connection to the original character name. Finally, the appellative Shishigami is rendered in Italian either as Spirito della Foresta (Spirit of the Forest) and dio cervo (deer god), depending on what was on screen. The American version favoured only the first because, as Neil Gaiman himself explained, "Deer God" seems kind of small and limiting, whereas "Great Spirit of the forest" seems to be huge and inclusive' (Gaiman, in Townsend 1999). In these examples, the attempts to give local meaning to what is seen on screen causes increasing breaks from the way important characters and settings were described in the original Japanese production. While these help to explain and localize aspects of the film, they also create distance between the experience of audiences in Japan and those watching the 2000 release of Princess Mononoke in Italy.

\section{A new hope: Mononokehime's acquisition by Lucky Red}

After the reduction of about 70 per cent of its staff in 2009, Walt Disney International sold Miramax to Filmyard Holding, an investment group (Nakashima 2010). By the time that happened, Lucky Red had already bought the distribution rights for Disney films in Italy. When it came to the newly acquired Studio Ghibli works, Lucky Red intended to release new Studio Ghibli films alongside the old ones that had not been released yet (for example, Tonari no Totoro/My Neighbour Totoro, Hayao Miyazaki, 1988), in addition to re-releasing film already distributed, but in revised editions (including Sen to Chihiro no kamikakushi/Spirited Away, Hayao Miyazaki, 2001 and Haoru no ugoku shiro/Howl's Moving Castle, Hayao 
Miyazaki, 2004). Lucky Red planned to re-translate, re-adapt and re-dub such films directly from the Japanese scripts, with a considerable amount of money invested in their realization and distribution. For example, Alessandra Tieri, Press Office Manager of Lucky Red, confirms:

Of course, the success of Spirited Away has opened the doors of the Ghibli world to a wider public, which is unquestionably something that a good distributor would not ignore. The idea of buying the entire catalogue of titles was by no means a sudden decision, as we slowly got to it after the release of Howl's Moving Castle. That was an extraordinary experience for all of us. [...] Without realising it, suddenly we were completely immersed in the world of Hayao Miyazaki. And well, we decided to never get out of it... (Tieri 2008; my translation)

The script for Principessa Mononoke was translated from Japanese by Giorgio Sato Nardoni, while Gualtiero Cannarsi was in charge of the adaptation and the direction of dubbing by Lucky Red. Dubbing is a very complex and expensive form of audiovisual translation, as it requires 'the re-recording of the original voice track in the target language using dubbing actors' voices' (Pérez González 2011: 17) and it also necessitates 'a complex juggling of semantic content, cadence of language and technical prosody [...] while bowing to the prosaic constraints of the medium itself' (Whitman-Linsen, in Pérez González 2011: 17). Consequently, translation is just the first stage of the dubbing process, followed by the adaptation of the translated text, which takes into consideration the need for lip-synchronicity and the length of lines voiced by the actors. Once the script is ready, then the re-voicing of the dialogue track by professional actors can take place, usually under the supervision of a dubbing director and a sound engineer. 'The involvement of so many professionals in the dubbing process explains why this form of audiovisual translation is up to fifteen times more expensive than subtitling' (Lukyen et al., in Pérez González 2011: 17).

For the abovementioned reasons, retranslation ${ }^{2}$ is not as frequent in audiovisual translation as it is in literature - where it is actually regarded as a positive phenomenon - and thus it is quite clear why it was so important for Lucky Red to produce a satisfying adaptation. Reasons for retranslating a text may include 'the need to update or modernize the language of a translation, the publication of a revised or expanded source text, and the discovery of mistakes or misinterpretations in the first translation’ (Tahir Gürçağlar 2011: 
235; see also Toury 1999). Given the aforementioned issues within the US adaptation, it is not surprising that the public expected Lucky Red to create dialogue more equivalent to that of the original film, which could potentially reproduce the same experience as the Japanese viewership. The Lucky Red version indeed features revised and corrected dialogue and moved away from the US version, for example, presenting a more accurate translation of most characters' names. The next sections will provide a deep analysis of some of the most significant changes in the new adaptation.

\section{A more focussed adaptation: From Mononokehime to Principessa Mononoke and discourses around retranslation}

Despite the fact that at the moment there is not any published work available about the procedures of the Lucky Red adaptation of Mononokehime, the intensive research and work put into the retranslation is well documented in the official Italian Internet forum for Studio Ghibli's films (see the thread Mononokehime - ineditamente in italiano). Adaptor Gualtiero Cannarsi himself is particularly active and passionate on this website, explaining his thought processes and justifying his personal choices, in the name of validating the effort he put into his work. This is especially significant due to the alleged obscurity of some of Mononokehime's cultural references even for Japanese people. Miyazaki has confirmed Mononokehime to be a difficult movie, but also offers a generational critique arguing that 'many of the elements in the film were commonly known about Japan among those of my generation' (Miyazaki 2000: 188). Responding to this discourse of obscurity, Cannarsi's forum posts tend to be extensive and verbose, especially when people disagree with his opinions, and as he likes to remark 'I could go on for days, since, as it might come across pretty clearly, I've extensively researched on the matter.' (Cannarsi 2014; my translation).

The first major change was the title. Lucky Red replaced Princess Mononoke (2000) with Principessa Mononoke (2014), and while the change appears minimal, the translation of hime (princess) into its literal equivalent principessa in Italian makes it a less obscure title than the previous one, which comprised words in two different foreign languages. An even closer equivalent might have included a translation of the term mononoke as spettri (ghosts), as the latter is used throughout the Lucky Red version. While titles tend to be chosen by distributors rather than adaptors, there might be various reasons why the title was not changed into La Principessa degli Spettri. On one hand, keeping the term mononoke was a way to maintain a link to the previous adaptation and to a product with which the public was 
already familiar. On the other hand, the term spettri might have frightened the children away, because it implies that there might be frightening ghosts surrounding one of the main characters. While leaving mononoke untouched in the title of the US version was evocative, it was not exactly clear for audiences, who were forced to take it at face value and work out by themselves the meaning of the expression. However, some viewers had grown attached to the word, since,

to a certain extent, it's easy and natural to experience strangeness when seeing a known product in a new translation, as we tend to be faithful to the status quo and the previous translation, regardless of the trueness and correctness of that version. (Lefevere and Bassnett 1990)

Audiences in Italy were particularly vocal in showing their displeasure directly to the adaptor on an Internet thread on the official Italian forum dedicated to Studio Ghibli works. To one of said complaints, adaptor Cannarsi replied:

The absolute necessity of doing it [i.e., translating the term mononoke] is due to the fact that 'mononoke' is not, and never was, San's name, except in the phantasmagoria of the previous adaptation in Italian.

The fact that you consider that a correct term to identify San, as if it were a proper name for her, is evidence of how much damage that invented 'translation' has caused. [...] It still is just a *noun*, not a proper noun. (Cannarsi 2014; my translation)

Here, the battles over nuances in localization are revealed, with the adaptor asserting both his position of knowledge and authority within the Italian context.

In Lucky Red's version of Mononokehime the wolf gods (yamainu or mountain dogs) likewise take on new descriptive names, appearing as cani selvatici (wild dogs) in place of lupi (wolves) in the first Italian version. Moro and her offspring were simply known as wolves in the US version, as they are depicted as giant wolves: with their hard eyes, pointed ears and scary jaws and fangs, they share a common representational ancestry with the wolves of European fairy tales. However, the term used in the Japanese script is not okami (wolf) but yamainu (mountain dog), because, as Cannarsi explains: 
The infamous 'mountain dogs' [...] are what in Italian are called 'wild dogs'. As Japan is a mainly mountainous territory, Japanese people consider what is not 'urban' or 'domestic' as 'mountainous' and not 'wild'. [...] Actually, what we nowadays call 'Japanese wolf', now extinct, used to be a beast of small size. But they weren't called 'ookami' (wolves), as it seems [...] that the Japanese language hadn't distinguished the subspecies 'canis lupus' yet, therefore 'wolves' were simply identified as 'wild dogs' (yamainu, 'mountain dogs'). (Cannarsi 2014)

The public seems to have been resistant to the new term, causing Cannarsi to provide this history of alternative terminology, though in this case their attachment can be attributed to the strong influence of the visual, rather than to an emotional attachment to the previous translation.

It was not just characters that were renamed by Lucky Red, but also the iron smelting community, which changed from the Japanese Tataraba into la fucina (the bellows) in place of la Fortezza (the Fortress). Known as the Irontown in the US version and as la Fortezza in the first Italian edition, the name Tataraba refers to the place ( $b a$ ) where the bellows (tatara) are located. While not equivalent to the original Japanese noun, both terms worked quite well as substitutions, as they focused more on the function of the city in one case and on its shape on the other, and were therefore unlikely to cause confusion.

The re-translation went further though, with Lucky Red 'correcting' the final scene so that it more closely mirrored the original Japanese version of Mononokehime, thus erasing the far-fetched ecologically-friendly message of the first Italian version. Here, after her arm was bitten off by the head of wolf-goddess Moro, Eboshi speaks to her fellow villagers about the irony of being hurt by the god she had warned others about, while at the same time being saved by the one of the wolves she had wanted to kill:

\section{$\mathrm{MH}^{3} \quad$ Watashi wa yamainu no se de hakobare iki no kotteshimatta.}

(In the end I could survive because I was carried on a wild dog's back)

PM00 Oggi ho capito che la foresta è sacra e nessuno ha il diritto di profanarla.

(Today I've come to understand that the forest is sacred and no-one has the right to profane it.) 
Lucky Red's adaptation offers then a message closer in meaning to that of the Japanese film:

PM14 Io ho finito per sopravvivere trasportata in groppa a un cane selvatico.

(I ended up surviving because I was carried on a wild dog's back.)

In this way, Lucky Red's adaptation sought difference from the first international release, while courting fan appreciation by a return to the original Japanese language text.

After the final denouement, the monk Jiko-bo remarks on the stupidity of the human race with an ironic comment:

\section{MH Iyaa-maitta maitta. Baka ni wa katen.}

(I give up, I give up. You can’t win against fools.)

The translator/adaptor of the first Italian version by Miramax apparently decided to focus more on what was visible on screen (Jiko-bo laughing in the background, while nature is blossoming again all over the mountain), rather than on the actual dialogue:

PM00 A quanto pare, la natura stavolta ha avuto la meglio.

(Apparently nature had the upper hand this time.)

Lucky Red's new translation, though, brings the original line and message back:

PM14 M'arrendo, m'arrendo! Non li vinci, gli stupidi!

(I give up, I give up! Fools, you can’t win against them.)

Through such retranslation work, Principessa Mononoke is produced to close the linguistic distance between Studio Ghibli's original release in Japan, and the Italian anime market. In doing so, however, the retranslators of the text risked over-emphasising the original language, making the film less intelligible overall.

\section{Principessa Mononoke: All that glisters is not gold}

The few examples listed in the previous section show how the new version was carefully translated, and how much effort and research Cannarsi employed to produce the closest adaptation possible - but then, the closest possible does not necessarily equal to the best in 
absolute terms. Berman (1985), for example, considers the practice of translating a vernacular language into another vernacular something that should be avoided, as:

A vernacular clings tightly to its soil and completely resists any direct translating into another vernacular. Translation can occur only between "cultivated" languages. An exoticization that turns the foreign from abroad into the foreign at home winds up merely ridiculing the original. (Berman 1985; emphasis in the original)

While the closer adherence to the 'spirit of the original film' is definitely appreciable, as well as the diversification in register and the variety in the way characters speak to each other, the existence of a real public on the other side of the screen is crucial to translators. The public at the movies cannot stop and rewind the scene if a line of dialogue is particularly rushed, complicated, or translated more in a word-for-word fashion rather than sense-for-sense. Some of the most interesting cases of problematic adaptations will be discussed in this section.

First, we might consider points at which the translation is correct, but not appropriate to context: in particular, that is the case of words such as otome (young girl) and danna, and the translation of the appellative Shishigami. In the first case, the Japanese otome is translated as pulzella (maiden, maid) by Lucky Red. Otome is commonly used to refer to a young girl, normally before the age of puberty, or to a virgin: there is an intrinsic reference to purity, or to someone whose integrity has yet to be spoiled. Semantically speaking, pulzella holds the same meaning and connotations as otome, but while otome is used in modern Japanese as part of everyday speech, pulzella is an archaic term, usually attributed to Joan D'Arc, The Maid of Orléans (la pulzella di Orléans in Italian). Nowadays the use of the term pulzella is strictly confined to historical settings. Likewise, danna (mister), is translated as messere (milord). Danna is a respectful Japanese title to address a patron, an unknown person of higher status, while messere is an old respectful title in Italian for somebody of higher status or nobility. Taken together, the Italian terms belong to medieval language and they are socioculturally well-defined, much more so than the Japanese terms used. While it is true that the Muromachi period (1336-1573) of Mononokehime is contemporaneous with the European Medieval age, it is not philologically correct to match terms from one time to the other. 
Similarly, although the use of Dio Bestia by Lucky Red to replace Shishigami might look similar to the abovementioned examples, there is a crucial cultural difference. Given the Catholic tradition in which the Italian culture is deeply rooted, the employment of any expression referring to God has to be treated with extreme care, as it has the potential to give rise to problematic situations. Indeed, while the translation of the appellative is formally correct, as the Japanese shishi means bestia (beast) and kami (voiced as gami) means Dio (God) in Italian, placing the two terms together in this fashion creates two problematic situations for the majority Catholic Italian audience. On the one hand, there is the not insignificant issue of infringing the Second Commandment: "Thou shalt not take the name of the Lord God in vain"; on the other hand, the association of the words for God and beast creates a potentially seriously offensive blasphemy (for which, for example, TV celebrities have even been evicted from programmes in Italy). ${ }^{4}$ Such expressions are usually condemned by a wide majority of the Italian population, especially in the South and in the North of Italy. Furthermore, for people living in regions with a less religious background (Tuscany, EmiliaRomagna, Veneto and Marche), in which such expressions are historically rooted, the use of Dio Bestia can, conversely, become humorous - throwing people at the theatres in fits of laughter. In either case, it is easy to understand how both reactions - personal offence or laughter - are equally undesirable to the film's adaptor.

Realia, or untranslatable, culturally-specific concepts, are another challenge in translation, especially when they involve two majorly different languages and cultures. Such is the case with Hanasaka-jiji rendered as 'nonnetto Hanasaka' in the sentence 'Shishigami wa Hanasaka-jiji idattanda' (Il Dio Bestia era come il nonnetto Hanasaka!, The God Beast was like old grandpa Hanasaka!). Spoken by Irontown warrior Gonza, the dialogue refers to a traditional Japanese tale about the old man Hanasaka who made flowers grow and cherry trees blossom by sprinkling ashes over them. In the same way, indeed, the Deidarabocchi brings back life to the mountain after San and Ashitaka return his head to him. Unlike other Japanese folktales, which may be known to the Italian public, this one is obscure in Italy. Therefore, saying that Shishigami is like the old man Hanasaka is unlikely to add meaning for Italian viewers.

Formality and informality, physical and personal distance, and personal status are expressed in Japanese with a range of linguistic devices, from the use of specific pronouns for speakers, to the use of honorific language, and of gendered language (see Makino, Tsutsui, 1989; and Iwasaki, 2006). These too are difficult to effectively translate into Italian. Given 
their history and geographical distribution it is no surprise that Italian and Japanese are two very different languages in this regard: while Italian is a Romance language, evolved from Vulgar Latin and deeply linked to those of the same family (among which Spanish, French, Portuguese and Romanian), Japanese is considered a language isolate, whose relation to other language groups is still debated. Their distance is based on a series of key elements, such as: (1) the lexical structure; (2) the grammar typology; and (3) a different semantic-grammatical Gestalt, reflecting the way the sociocultural environment and relations affect the way the discourse is organized (Soravia 2011: 86). ${ }^{5}$

In what follows, the analysis focuses on some key examples that highlight specific linguistic challenges of translation according to the differences between Italian and Japanese. For example:

MH: Suzumare! Suzumaritamae! Sazokashi na no aru yama no nushi to miuketa ga naze sono you ni araburo no ka?

PM14: Placati. Ti chiedo di placarti. Se ti ho scorto quale un certamente illustre nume delle montagne, perché ti dai alla furia in tal modo?

(Please lessen your fury! I beg of you, please lessen your fury! If I have properly and rightfully recognized thy as a certainly illustrious protective deity of the mountains, why do you yield to fury in this way?)

This long sentence is pronounced by Ashitaka, while he is frantically trying to stop the enraged boar god Nago from attacking his village, and he pleads for the god's clemency even while firing arrows at him. The scene is very intense and Ashitaka speaks agitatedly in a loud voice, which has led Cannarsi to state that:

Actually that passage was very arduous. It is the same in Japanese, to be honest [...], but, alas, the text is always less comprehensible in Italian than in Japanese, because of the linguistic characteristics of the two different languages. (Cannarsi 2014, my emphasis)

The validity of Cannarsi's claim can be contested from a linguistics perspective - no language is less comprehensible than another in objective terms, as 'all cognitive experience and its classification is conveyable in any existing language', therefore reinforcing the idea that 'there is no untranslatability between any pair of languages' (Jakobson, in Venuti 2004: 
139-140). Also, it should be noted that the responsibility for the intelligibility of a line of dialogue lies with the translator first, and the adaptor second, not on the languages involved in the process.

Cannarsi uses the difficulty in translation to shift blame away from his own practice. However, the line in Italian is too complicated and long: it combines the use of words of higher register (placati, scorto, tal) with elements typical of written speech (quale in place of come) and a noun compound modified on the left side rather than on the right (certamente illustre nume delle montagne). Moreover, the excessive length of the line forces Ashitaka's dubbing actor to rush his words. The result is a barely intelligible line, supported only by the visual elements on screen, which put the viewers in the uncomfortable situation of being unable to discern the meaning of the scene. The translation of such a varied language was definitely a challenge for the adaptor, who decided to employ literal translation extensively. The resulting target text, while philologically correct, tends to be marked and inappropriately connoted, thus making comprehension for the Italian audience more complicated than necessary.

\section{A problematic principessa: Linguistic difficulties and mistakes in Principessa Mononoke}

Given the diversity of the two languages involved and the different standard structures, following the original structure of Japanese is almost bound to result in calques and awkwardly phrased sentences. That is the case of the rendition of personal indexical terms and pronouns of Japanese, as they are so different from those employed in Italian: it is particularly difficult not make them sound artificial and forced in translation. In many cases, the pronouns in Principessa Mononoke are translated inaccurately, or in a way that does not correspond to the intentions implied in the original sentences. For example, translating ano hito or sono hito with quella persona rather than he or she appears artificial in Italian, while using questo qua or questi qua for the Japanese koitsu or koitsura can be perceived as arrogant, and the use of noialtri and voialtri for oretachi and omaetachi borders on regionalism.

MH: Rei wo ittoke

PM14: Porgetegli ringraziamenti!

(Give him thanks!) 
MH: Ato de rei wo ittoke.

PM14: Dopo vorrei rendergli grazie.

(Afterwards I would like to give thanks.)

$R e i$, in the example above, means thanks, and it is used when one of the two participants is grateful for something the other has done for them. The two examples above do not feature the standard Italian verb ringraziare (to thank) but the formal porgere ringraziamenti and the literate rendere grazie: the former is usually found in formal or commercial letters, as a closing formula, while the latter is heard in parts of the Catholic mass, thus implying the sense 'thanks be to God.' The two lines are both pronounced by Eboshi: in the first case to the people of Irontown to welcome Ashitaka when he brought Kōroku back, and in the second to Gonza, who goes to find Ashitaka after he saved Eboshi's life. In this way, it is implied that Ashitaka deserves a higher reverence than the other characters, which is not the case in the film's narrative.

A different case is that of grammar mistakes, which at first might appear as personal interpretations of the source text. Sometimes they could be justified by a particular situation in the source text (for example, when a foreign character does not speak the language very well), or because of a more commonly used form (for instance, the use of indicative present instead of subjunctive in Italian). Sometimes, though, a grammar mistake in translation is just that - a mistake. For example:

MH: Watashi wa jibun de koko e kita.

PM14: Sono arrivato qui da me stesso.

(I've come here by me myself)

Here, the Japanese jibun corresponds to the reflexive pronoun myself in English: its use in the line above forces the adaptor to bring about the idea of reflexivity in Italian as well. The problem is that the adjective stesso can be paired only to a subject pronoun (io, $t u)$ and not to an object pronoun $(m e, t e)$ as in this case. While not the most unsettling mistake, it still causes disturbance in an otherwise well-rendered dialogue.

Similarly, the following example shows two sentences in the past form: 
MH: Sono mae ni kita toki ni wa koko ni mosorenari no mura ga attanoda ga naa.

PM14: L'ultima volta che ero venuto, anche qui c'era un discreto villaggio.

(The last time I came, here as well there was a decent village.)

Japanese only has one form of the past, so the order of the actions is expressed through the use of prepositions and lexis. On the other hand, Italian has a strict sequence of tense that has to be respected in order for the sentence to make sense and show the correct series of actions. Any mistake in the sequence is bound to cause problems for audiences trying to understand the dialogue. In this particular case, both the dominant (anche qui c'era un discreto villaggio) and the dependent clause (l'ultima volta che ero venuto) are in the imperfect past tense, thus describing actions with undefined coordinates. However, the action described in the dependant clause is not undefined but clearly set in a specific time (the last time I came) and therefore should be expressed in a finished tense, such as the indicative present (sono). Such mistakes have the potential to disrupt viewing, so although they are minor mistakes, their impact can be disproportionately large.

Finally, as remarked upon before, the language of the Lucky Red adaptation tends to be formal or marked. It is interesting to show some of the most recurrent cases because of the way they mark the whole retranslation production. For example: invero in place of invece (instead), immane instead of enorme (enormous), buggerati for ingannati (tricked), celati for nascosti (hidden). In some cases, the words chosen are even archaic of disused. Among the more obvious examples are: imperitura in place of immortale (immortal), frammezzo in place of tralfra (between), puranco in place of pure (also). Although most of the cases analysed would not hinder the comprehension of the film in isolation, the continual use of formal or marked structures and words, as well as grammar imperfections and uncommon translation choices, makes the experience of the Italian audience more challenging than necessary, and seemingly still distant from the experience of the Japanese-speaking viewers of the original

\section{Mononokehime.}

\section{Conclusion; Or, 'Fools, you can't win against them!'}

As shown throughout the article, the work and research done by Gualtiero Cannarsi for Lucky Red's new adaptation of Mononokehime was remarkable. As a matter of fact, by comparison to the first Italian version in 2000, which was affected by problems connected to the procedures of indirect translation, the Lucky Red edition is more philologically accurate 
and attempts to maintain the same spirit and content of the Japanese film, as advocated for by potential Italian viewers online as the news of a second adaptation spread.

Nonetheless, while much more source-oriented than the first Italian translation, the Lucky Red adaptation is sometimes too faithful to the original, to the point that it can sound strange and foreign even for the Italian public. In a sense Cannarsi abuses Venuti's idea of the need for a more visible translator, to the point of making his work too visible. Among the problematic translation choices highlighted, the most evident is that of his adherence to a word-for-word translation strategy. The result is a constantly marked syntax that makes it difficult for the Italian audience members to follow the dialogue properly. Also, the attitude displayed by the adaptor on the Italian fan forum dedicated to Studio Ghibli has not made the approach to the new version any easier to understand for audiences. Indeed, one of the more amusing outcomes of this repeated translation process has been growing resentment within the Italian viewership. The blog Gli sconcertanti adattamenti italiani dei film Ghibli (The disconcerting adaptations of Ghibli films), for example, is comprised of critiques wherein the blog owners screencap scenes from the various Studio Ghibli films adding the correspondent line of dialogue as caption, in the fashion of joking Internet memes.

By contrast, if it were an adapted literary text, Principessa Mononoke would likely be considered as a good final draft before the final revision, or, to paraphrase Antoine Berman, the first step towards a great translation. The combination of visual and written materials reifies the problematic adaptation practices surrounding both Princess Mononoke and Principessa Mononoke with neither able to smoothly marry Italian dialogue to the Japanese visuals. Since it is very unlikely for the film to be re-adapted and re-dubbed for a third time because of the high demands in terms of costs and work involved - Principessa Mononoke is to be considered the final Italian version of Mononokehime. For the reasons highlighted in this article, such a circumstance cannot help but leave the Italian viewership slightly disappointed, if not feeling betrayed, at the missed opportunity to fully experience a Japanese animation masterpiece filtered and refined for the experience of Italy's filmgoing public.

\section{Notes}

${ }^{1}$ All translations of Italian materials are my own, unless otherwise stated. I use Mononokehime to refer to the Japanese version of Hayao Miyazaki's text, with Princess Mononoke use to describe the first translation released in Italy, rather than to the US-English 
version. These included, for example, the first (and only) TV screening of the film Kaze no Tani no Nausicaa/Nausicaä of the Valley of the Wind (Hayao Miyazaki, 1983) in four parts in 1987 on RAI 1 (http://www.antoniogenna.net/doppiaggio/film/nausicaa.htm - last accessed: 22/07/16). (my note, not included in the original quotation)

${ }^{2}$ The term 'retranslation' usually denotes the act of translation of a text that has previously been translated into the same language, or the retranslated text itself. Sometimes it is also used to refer to a text that is translated through a vehicular language, what is otherwise called an 'indirect', 'intermediate' or 'relay' translation (Tahir Gürçağlar 2011: 233).

${ }^{3} \mathrm{MH}$ stands here for the Japanese version, Mononokehime, PM00 for the Buena Vista International release based on the US Princess Mononoke, and PM14 for Lucky Red's retranslation.

${ }^{4}$ The most recent case is that of the employee responsible for the open captions during the live New Year's Show on national TV, who let a message with blasphemous language pass and was consequently fired a few days later (http://www.ilfattoquotidiano.it/2016/01/01/raiil-2016-inizia-male-bestemmia-in-diretta-e-conto-alla-rovescia-in-anticipo/2344294/ - last accessed 22/07/16).

${ }^{5}$ Japanese is mainly a SOV language, as every sentence starts with the topic noun or noun phrase and ends in a verb, an adjective or a form of the copula (Makino, Tsustui, 1989), while Italian is mainly a SVO language, where the object tends to be placed in the final position (Berruto, 2006). Moreover, the word order principle in Japanese is the modifier precedes what is modified, as the function of the modifier is to specify the meaning of the modified word (Makino, Tsustui, 1989), making it a language that 'builds the sentence on the left' (pre-determinant), while Italian 'builds the sentence on the right' (post-determinant), as the modifier follows what is modified (Berruto, 2006).

\section{References}

Berman, A. (1985), 'Translation and the Trials of the Foreign', in L. Venuti (ed.), The Translation Studies Reader (trans. L. Venuti), New York and London: Routledge.

Berruto, G. (2006), Corso Elementare di Linguistica Generale, Torino: UTET Università.

Cannarsi, G. (2014), 'Studio Ghibli forum', Studio Ghibli.Org http://www.studioghibli.org/forum/viewtopic.php?f=21\&t=3766. Accessed 22 July 2016. 
Cine Front, Cine Furuntosha (1997 [2014]), 'The elemental power of the forest also lives within the hearts of human beings. On directing Princess Mononoke' in H. Miyazaki, Turning Point 1997-2008, San Francisco: Viz Media.

Genna, A. (2014-2015), 'Nausicaä della Valle del Vento', http://www.antoniogenna.net/ doppiaggio/film/nausicaa.htm. Accessed22 July 2016.

Gli sconcertanti adattamenti italiani dei film Ghibli (2015), 'Mononokehime', https://studiogualty.wordpress.com. Accessed 23 July 2016.

Il Fatto Quotidiano (2016), 'Rai, il 2016 inizia male: bestemmia in diretta e conto alla rovescia in anticipo', http://www.ilfattoquotidiano.it/2016/01/01/rai-il-2016-inizia-malebestemmia-in-diretta-e-conto-alla-rovescia-in-anticipo/2344294/. Accessed 22 July 2016.

Iwasaki, S. (2006), Japanese, Amsterdam: John Benjamins Publishing Company.

Jakobson, R. (1959[2004]), 'On Linguistic Aspects of Translation', in L.Venuti, (ed.), The Translation Studies Reader, New York and London: Routledge.

Kipling, R. (1894), The Jungle Book. United Kingdom.

Lefevere A. and S. Bassnett (1990), 'Introduction: Proust's Grandmother and the Thousand and One Nights. The "Cultural Turn" in Translation Studies', Translation, History and Culture, London and New York: Pinter.

Makino, S. and M. Tsutsui (1989), A Dictionary of Basic Japanese Grammar, Tokyo: Japan Times.

Miyazaki, Hayao (1997), Mononokehime/ Princess Mononoke, Japan.

MOFA Ministry of Foreign Affairs of Japan, 'Hanasaka Jiisan', http://webjapan.org/kidsweb/folk/hanasaka/hanasaka01.html. Accessed 20 July 2016.

Nakashima R. (2010), 'Disney completes \$663M sale of Miramax’, https://web.archive.org/web/20110629044428/http://finance.yahoo.com/news/Disneycompletes-663M-sale-of-apf-1909918456.html?x=0. Accessed 23 July 2016.

Nikkei Voice (2013), 'Spirited Away: the films of Studio Ghibli', http://nikkeivoice.ca/spirited-away-the-films-of-studio-ghibli/2/. Accessed 27 September 2016. 
Paolinelli, M. and E. Di Fortunato (2005), Tradurre per il Doppiaggio. La Trasposizione Linguistica dell'Audiovisivo: Teoria e Pratica di un'Arte Imperfetta, Milano: Editore Ulderico Hoepli.

Pellitteri, M. (2008), Il Drago e la Saetta. Modelli, Strategie e Identità dell'Immaginario Giapponese, Latina: Tunué.

Pérez González, L. (2011), ‘Audiovisual Translation’, in M. Baker and G. Saldanha (eds.) Routledge Encyclopaedia of Translation Studies, New York and London: Routledge.

Pieta, H. and A. Assis Rosa (2013), 'Indirect translation: exploratory panel on the state-ofthe-art and future research avenues', 7th EST Congress, Germersheim, Germany, 29/081/09/2013, http://www.fb06.uni-mainz.de/est/51.php. Accessed 27 September 2016.

Rice Burroughs, E. (1912), Tarzan of the Apes. United States.

Ebert, R. (2000 [2014]), 'Traditional Japanese aestheticism in Princess Mononoke: An interview by Roger Ebert, Interview at Park Hyatt, Toronto, September 19, 1999', in H. Miyazaki, Turning Point 1997-2008. San Francisco: Viz Media.

Serianni, L. (2010), Grammatica Italiana. Italiano Comune e Lingua Letteraria, Novara: De Agostini Scuola SpA.

Soravia, G. (2011), 'Dalla parte del discente: le lingue "lontane"', in T. Takeshita (ed.), Nihon-JP: Insegnamento della Lingua Giapponese e Studi Giapponesi. Didattica e Nuove Tecnologie. Bologna: CLUEB.

Tahir Gürçağlar, Ş. (2011), ‘Audiovisual Translation', in M. Baker and G. Saldanha (eds.) Routledge Encyclopaedia of Translation Studies, New York and London: Routledge.

Townsend E. (1999), 'Neil Gaiman. The Sandman scribe on anime and Miyazaki (exclusive interview)', http://purpleplanetmedia.com/eye/inte/ngaiman.php. Accessed 21 July 2016.

— (1999), 'Princess Mononoke. Nature is presented in both its glory and fury in Hayao Miyazaki's epic', http://purpleplanetmedia.com/eye/film/mononoke.php. Accessed 21 July $\underline{2016 .}$. 
UNESCO (1976), 'Records of the General Conference. Nineteenth Session', Nairobi, Kenya, 26 October to 30 November 1976, Resolutions, http://unesdoc.unesco.org/images/0011/001140/114038E.pdf. Accessed 22 July 2016.

Venuti, L. (2008), The Translator's Invisibility: A History of Translation, 2nd Edition, London: Routledge.

Yamato S.R.L. (2008), 'Lo Studio Ghibli pronto per lo sbarco in Italia. Intervista ad Alessandra Tieri di Lucky Red', http://www.yamatovideo.it/focuson_int.asp?idEntita=401. Accessed: 25 July 2016 


\title{
The 'Totoro Meme' and the Politics of Transfandom Pleasure
}

Lori Morimoto, Independent Scholar

\begin{abstract}
This paper is an exploration of the 'Totoro meme' against the backdrop of the Japanese government 'Cool Japan' soft power initiative. In the Totoro meme, Japanese and nonJapanese fans alike appropriate the now-iconic image of Satsuki, Mei and an umbrella-toting Totoro at a bus stop, from Hayao Miyazaki’s 1988 film, My Neighbor Totoro (Tonari no Totoro), to their own fannish ends, creating fan art that inserts favourite characters from other media into the scene in ways that not infrequently have a doubled semiotic resonance. Considered from the perspective of 'Cool Japan', the online pervasiveness of this meme seems to affirm its goal of mobilizing the transnational appeal of, in this case, anime to Japanese economic ends. Yet, I argue in this essay that this meme is actually characteristic of the global appropriation not of a broad 'Japanese anime style', per se, but a specific, and affectively appealing, 'Ghibli style'; one that is fully part of non-Japanese fans' own popular cultural repertoires. In its cross-border merging of globally circulating Studio Ghibli aesthetics with other fan-favorite media, I contend that the Totoro meme and its associated fanworks are in fact wholly congruent with, and representative of, what Matt Hills has termed 'trans-fandom' (Greco 2015), contemporary practices of 'navigating across and combining and fusing fandoms' (159). In this sense, rather than affirming 'Cool Japan' (and its associated costs to Japanese taxpayers), the Totoro meme is a potent reminder of the difficulties of harnessing fan passions to political ends.
\end{abstract}

Keywords: My Neighbor Totoro, intertextuality, transfandom, transcultural fandom, memes 


\section{The 'Totoro Meme' and the Politics of Transfandom Pleasure}

Lori Morimoto, Independent Scholar

The setting is a rainy night-time bus stop somewhere deep in the Japanese countryside. Three figures stand in the shadow of a rusty sign, one carried on the back of another, and one silent and massive next to the other two. In My Neighbour Totoro (Tonari no Totoro, Hayao Miyazaki, 1988), these three are young Mei, her older sister Satsuki, and Totoro himself, looming over the pair with a leaf on his head to (ineffectively) protect him from the rain. Originally featured on Japanese promotional materials for the film, within online fan circles this scene has attained singular resonance through memetic fan art that substitutes characters from other, unrelated media for those of Satsuki and Totoro (Mei is optional). This 'Totoro meme' is believed to have begun with a 2007 work by Oceanic artist sachsen depicting a rifle-toting Satsuki standing next to a horrifically bloodied, gaping-mawed Totoro (CSloth 2013). It is difficult to say with any certainty what specifically it was about this image that caused it to resonate with people around the world and from many walks of fandom (although its jarring juxtaposition of the film's pastel nostalgia with the grotesqueness of this work certainly lingers), but its iconicity is such that, as one commenter on the website knowyourmeme.com observes, 'from what I've seen the only artwork that's been spoofed more times is Nighthawks by Edward Hopper' (Evil-Tree 2014).

As described by Limor Shifman, memes are first and foremost 'pieces of cultural information that pass along from person to person, but gradually scale into a shared social phenomenon' (2014: 18, emphasis in the original), fertilized in the increasingly transcultural convergence of not just media, but online fan spaces as well (Jenkins 2006). As shared social phenomena, memes are fundamentally intertextual (Shifman 2014: 2) in ways that mirror 'transfandom' (Hills 2015), nodal fan articulations of often-unrelated media whose affective resonance depends largely on the recognition of intertextual affinities. Like memes, transfandom works and spaces 'constitute shared spheres of cultural knowledge' (Shifman 2014: 173), or experiential 'third spaces' (Williams 2015: 79) in which 'multiple fandoms, texts, and meanings' (Booth 2016: 17) commingle and recombine in ways that, when successful, provoke what Roland Barthes (1975) adamantly calls the 'bliss' (21) of intertextual recognition.

It is this bliss - the 'unspeakable' (Barthes 1975: 21) pleasures of intertextual recognition engendered in this meme through transfannish articulation - that is at the crux of 
the Totoro meme's significance within both online fandoms and a globalized mediascape more broadly (Appadurai 1990: 330). The range of fannish variations brought to bear on this one scene through the meme embodies and exemplifies media circulation within the nexus of 'nonlinear, incoherent, and impermanent' (Cho 2014: 45) online fan spaces such as Tumblr and Twitter, where transfandom articulation proliferates. Unlike the dedicated boards, groups, and communities that have heretofore characterized much of online fandom, Tumblr is a multi-fandom melange of real-time activity in which fans often (although not always) meander from one fandom to another to another, collecting traces of each in a way that is less linear than rhizomatic. In this sense, we might understand the Totoro meme as nodal, a liminal stopping point within the 'flow of content across multiple media platforms... and the migratory behavior of media audiences' that characterizes cultural convergence (Jenkins 2006: 2).

At the same time, the Totoro meme makes visible the affective economies at work in the production and consumption of intertextual pleasure - and it is pleasurable. One generalizable quality of this meme is the sheer excitement that greets it in its various iterations: 'XD I AM IN LOVE WITH THIS!!!!!!!!!! PERFECT MIX!!!!' (Five Nights at Freddy's mashup, Jaimeenator123 2013); 'OMG f*cking BEST crossover EVER!!!' (Five Nights at Freddy's mashup, RyuTamashi 2014); 'I'm going to die of cuteness.

AAAAAAAAAAAAAAAAAAAACK. Totoro was one of my favorites, because he was so fat and huggable. And Gengar, who was my favorite Pokemon. He's so mischievous and fat. Thanksthanksthanksthanksthanks' (Pokemon mashup, subzerogengar 2012). Notably, exuberance here is expressed at least partly through evaluation: words like 'perfect' and 'best', and specific examples of transfandom affinities, suggest that the success of these memes, and of transfandom generally, is predicated at least in part by artist and viewers' intersubjective interpretation of 'affinity.' That is, any ability to provoke such responses requires that artist and viewers possess a popular cultural repertoire diverse enough both to recognize not only the media being remixed, but also those specific, if subjective, affinities that engender Barthes's unspeakable bliss.

Indeed, the unspeakability of transfandom pleasure is symptomatic of its affective resonance. Writing in the context of cinema, Morten Nielsen argues that montage, the linear joining of two images, 
reveals a flow of difference within and across the individual images that provokes radical changes in perspectives through the sensation of the momentary 'tertium quid' (third thing) that emerges through the correlation of distinct movements (e.g., cinematic sequences). (2013: 41)

This tertium quid, originally theorized by Soviet filmmaker Sergei Eisenstein, refers to an intangible 'third thing' that arises from the clash of otherwise unrelated images. Famous within his own work for demonstrating this is a scene from the film Strike! (Eisenstein, 1925) in which shots of people running and soldiers with bayonetted rifles are intercut with shots of a cow being slaughtered; here, of course, Eisenstein's 'third thing' is the recognition - the immediate awareness - that innocent people are being slaughtered like animals by the Cossacks. As 'sensation' this third thing is something less consciously understood than felt; it comes into being experientially as something quite literally unspeakable. Translated to transfandom, the tertium quid is one way of grasping the mechanics of transfandom memes, but particularly how viewers experience their intertexuality as pleasure.

In this way, both artist and (affected) viewer signal through creation/consumption of the meme that shared fandom literacy from which a sense of cultural kinship is born. As Shifman notes, to participate in a meme is to claim membership in an affinity-based culture (2014: 169) through the demonstration of both the specific knowledges and/or cultural authenticity that, in turn, generate subcultural capital for participants (Thornton 1995; Nissenbaum and Shifman 2015). Thus, we might think of the pleasures of intertextual recognition produced through the Totoro meme as being inextricably linked to a value system outside the gift economy through which English language fandoms are typically discussed (Chin 2010), one that trades almost exclusively in affect.

It is this affective economy that foregrounds, here in the context of the Totoro meme, what I am tentatively calling a politics of transfandom. If transfandom arises from the kinds of 'nonlinear, atemporal rhizomal exchange of affect and sensation' (Cho 2014: 47) that characterize online fan spaces such as Tumblr, so too have both social media and increased fan-producer overlap troubled what historically was conceived of by media producers, fans, and academics alike as a clear, often oppositional, fan/producer binary (Hills 2010). This, in turn, has raised questions within fan studies about the intersection of media production and affective fan labour, particularly the extent to which such labour may constitute exploitation where corporations benefit from it (Milner 2009; Scholz 2012; Stanfill and Condis 2014; 
Jones 2014). To the extent that such research centres on how media producers may capitalize on fannish love, transfandom's affective economy begs the question of how synergistic media conglomerates might (re)produce the intertextual pleasures of transfandom articulation in ways that may masquerade as, or actually be, fannish.

By way of exploring first how the Totoro meme creates transfandom intertextuality, and what proceeds from it, this essay will first explore several contributions to the Totoro meme, with attention to the ways artists communicate intertextual affinities within their work, as well as how both they and viewers alike signal their membership in certain fan communities through their successful mobilization. The pleasures of intertextual recognition in these works, I argue, are critical in understanding the semiotic significance of the Totoro meme itself; equally, it is this perspective that enables us to consider the role pleasure plays in transfandom works that exceed the already fluid bounds of fandom. It is here that I turn my attention to specific intersections of transfandom pleasure and media industry through both the Totoro meme, as well as discussion of the Studio Ghibli film Nausicaä of the Valley of the Wind (Kaze no tani no Naushika, Hayao Miyazaki, 1984) and its argued transfannish affinities with Star Wars: The Force Awakens (Abrams, 2015). While unrelated to the Totoro meme itself, I argue that the pleasures which emerge from the grassroots convergence of the bus stop scene and other fannish texts within the textually (and transculturally) fluid fan sites of Tumblr, deviantART, and Japan's pixiv reveal the extent to which Studio Ghibli films, writ large, are something of a global popular cultural touchstone that is deeply implicated in the increasing borderlessness of our current media moment.

\section{The Totoro meme}

Although I first saw My Neighbor Totoro in 1989 while living in Japan, I can scarcely remember a popular cultural landscape without it. In Japan itself, the film was only a modest success in its first theatrical run (Eiren 2006), but it topped both critical and audience top ten lists for 1988 (Kinema jumpō-sha 1989) creating a demand for Totoro-related merchandise that would eventually culminate in Studio Ghibli's Donguri Republic chain of stores (Studio Ghibli 1995). By the time I was a parent of two toddlers some twenty years after that first viewing, My Neighbor Totoro was a fixture on online parenting lists of age-appropriate viewing for young children, alongside such films as The Snowman (Diane Jackson and Jimmy T. Murakami, 1982) and Toy Story (John Lasseter, 1995). That is, what began as a local, then regional phenomenon had, by the turn of the century, become a fixture on the 
global popular cultural landscape; so much so that the Totoro meme is broadly legible even to those who have not seen the film: 'I love these [meme variations], except that they remind me I still haven't gotten around to watching this movie $=($ ' (MZero 2014).

Nonetheless, the Totoro meme seems to have particular semiotic resonance where it foregrounds recognizable points of affinity between both the image (if not the film itself) and the texts it is articulated with. 'Luke, Yoda and Chewbacca?' (2014) is a contribution to the meme by Argentinian fan artist Amisgaudi, who describes it in both English and Spanish as 'merg[ing] two things that I love, Star Wars and Totoro' (Amisgaudi 2014). Here, both narrative and visual affinities are invoked to clever ends in the juxtaposition of Star Wars and My Neighbour Totoro, with Yoda and Luke Skywalker standing in for Mei and Satsuki, respectively, and the iconic umbrella of the Totoro scene hovering over Luke and Yoda through the Force. Affinity here thus sits at the intersection of the iconic image of Satsuki carrying Mei on her back, and that of the equally iconic image of Luke carrying Yoda on his back. Interestingly, Totoro here is something of a transfannish hybrid: the character remains, but outfitted in Chewbacca's iconic ammunition belt. Given both Totoro's and Chewbacca's size relative to the other characters, here too the artist invokes a visual affinity. But in true fandom fashion, the decision to hybridize Chewbacca is not universally applauded, with one commenter on the piece arguing, 'Should have been Chewbakka [sic] instead of Totoro, methinks. Most of the parodies I've seen try to stay in tact [sic] universe/setting-wise and just follow the concept of the famous scene' (KeinZantezuken 2014). Regardless, most commentary on the piece overwhelmingly echoes what another commenter writes, 'So cute! The best crossover ever!' (SvalaW 2014). 


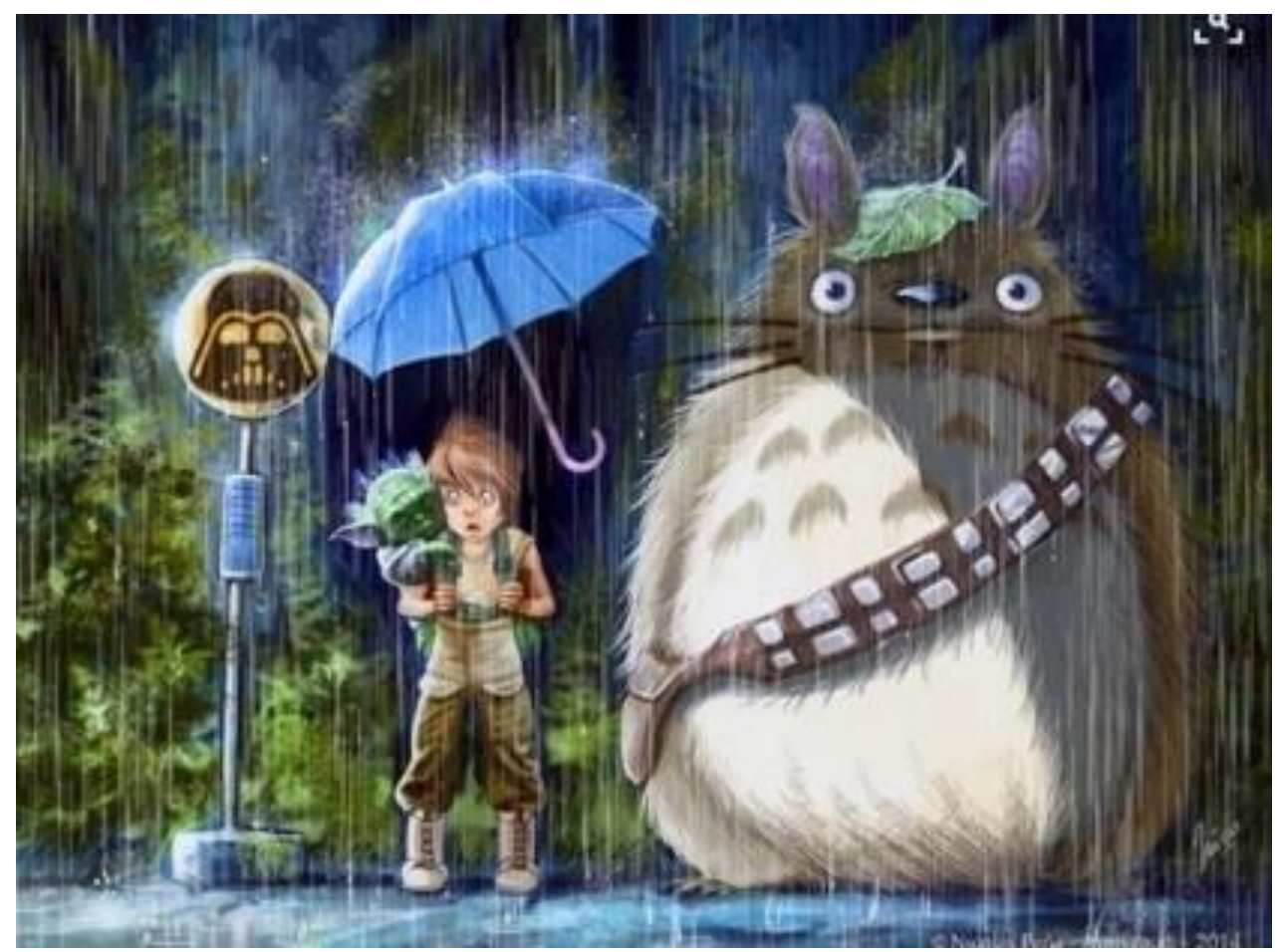

Figure 1: 'Luke, Yoda and Chewbacca?' (2014) by Argentinian fan artist Amisgaudi

Where a commenter seems unfamiliar with both Totoro and the meme itself, there is a jarring disconnect from other commentary on the piece:

I love the Western feel of the work, considering Totoro is supposedly an anime classic; I need to watch it, considering Hayao Miyazaki made it! Of course, this is something imaginable as a Western cartoon production, a Star Wars and Miyazaki crossover; I like how you break the two boundaries and suggest the idea of a Pixar movie based on an anime, something I wish could be done for a series like Avatar or DBZ. That's to say I like the concept. (Shad73 2014)

Both this comment and the above Chewbacca one illustrate how broader questions of cultural membership assert themselves in spaces of ancillary fan participation in the meme. Broadly speaking, Internet memes 'constitute a cultural base that marks a commenter as part of [a commenting] community, a form of cultural capital that is required in order to assert a legitimate voice' (Nissenbaum and Shifman 2015: 15). In detailing the specific ways Amisgaudi's contribution fails to correspond to the unwritten and intrinsically unstable rules of the Totoro meme (Nissenbaum and Shifman 2015), the first commenter asserts thus their own 'correct' knowledge of the meme, as a means of claiming 'superior status and authority while simultaneously providing reminders of common cultural affinity' (Nissenbaum and 
Shifman 2015: 16). Similarly, albeit to different ends, the longer comment stakes a claim to a different kind of membership. Unfamiliar with both My Neighbor Totoro and presumably the meme itself, this person instead implies membership in a more elevated 'animephilic' culture, signified through his identification of My Neighbor Totoro as a 'classic' of Japanese animation, Hayao Miyazaki as an animator of repute, and references to non-Ghibli Japanese and American anime.

The mildly argumentative tone of the Chewbacca comment is, in fact, something of an anomaly within deviantART fan art communities. Nele Noppe (2013) observes that on social networking sites such as deviantART and Japan's pixiv, where fan art proliferates, the unspoken community rules of fandoms (both English language and Japanese, in this case) carry over to commenting etiquette, which privileges 'a perceived equality among community members' as one 'key idea for many Japanese- and English-speaking communities' (151). The conflict characteristic of meme-centred commentaries on such sites as 4chan (Nissenbaum and Shifman 2015) clash with more supportive and enthusiastic fan discourse on deviantART, foregrounding among other things, the highly subjective nature of online communities. Together with the 'animephilic' comment above, the diversity of comments on this iteration of the meme foregrounds the subjective nature of transfandom interpretation. At the same time, it illustrates how the meme becomes a stopping point on transfandom journeys that may take entirely different paths.

Where this Star Wars contribution reflects its visual and narrative affinities with $M y$ Neighbour Totoro, others find affinities in shared character traits. Like the transfannish Chewbacca above, in 'My Neighbour, Hulk' (2012), by Canadian fan artist Samoubica, it is the Hulk's size, relative to a small, bewildered, and childlike Captain America (cleverly depicted holding his shield over his head in place of the iconic umbrella) where we can locate his affinity with the character of Totoro. In the same way, American Tumblr user Ron Chan's (2013) contribution to the meme, which he calls 'My Neighbour Titan! Or maybe Attack on Totoro', substitutes a giant, gruesome Titan from the Hajime Isayama anime, Attack on Titan (Shingeki no kyojin, 2013-), for Totoro, and Survey Corps leader Zoë Hange for Satsuki, again relying primarily on size difference to affectively link the two texts. Additionally, however, they also substitute for Totoro characters that are at least as intimidating, incomprehensible, and non-verbal as Totoro himself. While intimidation in these contributions ranges from charmingly gruff to frankly terrifying, such points of affinity also seem to accord these meme iterations a fan culturally specific resonance, as expressed in 
exclamations of 'YES PERFECT' (ArtmasterRich 2012), 'perfectperfectperfectperfectperfect' (mistresstrista 2012), 'This is perfect!' (clawman2000 2012), and 'Absolutely brilliant ahahaha best crossover I've seen so far' (MyMadMadMadMadWorld 2012). Indeed, the apparent transfannish naturalness of the Hulk/Totoro mashup is such that one commenter writes, 'oooo... I did a Hulkoro piece around the same time [as this]. Must have been that whole Avengers frame mind [sic]' (artildawn 2013), attributing the Avengers variant of the meme to a kind of transnational popular cultural zeitgeist.

If such contributions to the Totoro meme illustrate how affinities between $M y$ Neighbor Totoro and other media texts are mobilized by fans in the creation of subjectively satisfying transfandom works, those that remix it with the BBC's Sherlock further demonstrate the kinds of fan cultural fluency required to make the meme fully legible and, as such, affectively resonant. 'My Neighbor Sherlock' (2014), by Italian fan artist Elisabetta Borseti, substitutes Sherlock Holmes for Totoro, complete with iconic leaf, while John Watson, standing unhappily bent and burdened with heavy shopping bags under an umbrella, is substituted for Satsuki. Rather than relying on these characters' visual affinities (Sherlock is certainly taller than John, but nowhere near the size of Totoro relative to Satsuki) this work deftly suggests an affinity at the level of Satsuki/Totoro and John/Sherlock's interpersonal relationships. Both are defined in part by Sherlock/Totoro's taciturnity and mysteriousness, and the frustrations they provoke in John/Satsuki as they are subjected to the perceived whims of the other. Borseti captures the intangible (and unspeakable) feel of the relationships between John/Satsuki and Sherlock/Totoro in ways that exceed either their visual or narrative characteristics. Similarly, Mei here is more idea than character, communicated, rather than depicted, through John's posture; an invisible weight recognizable primarily to those fans familiar with Sherlock and, in particular, Martin Freeman's interpretation of the longsuffering John Watson. 


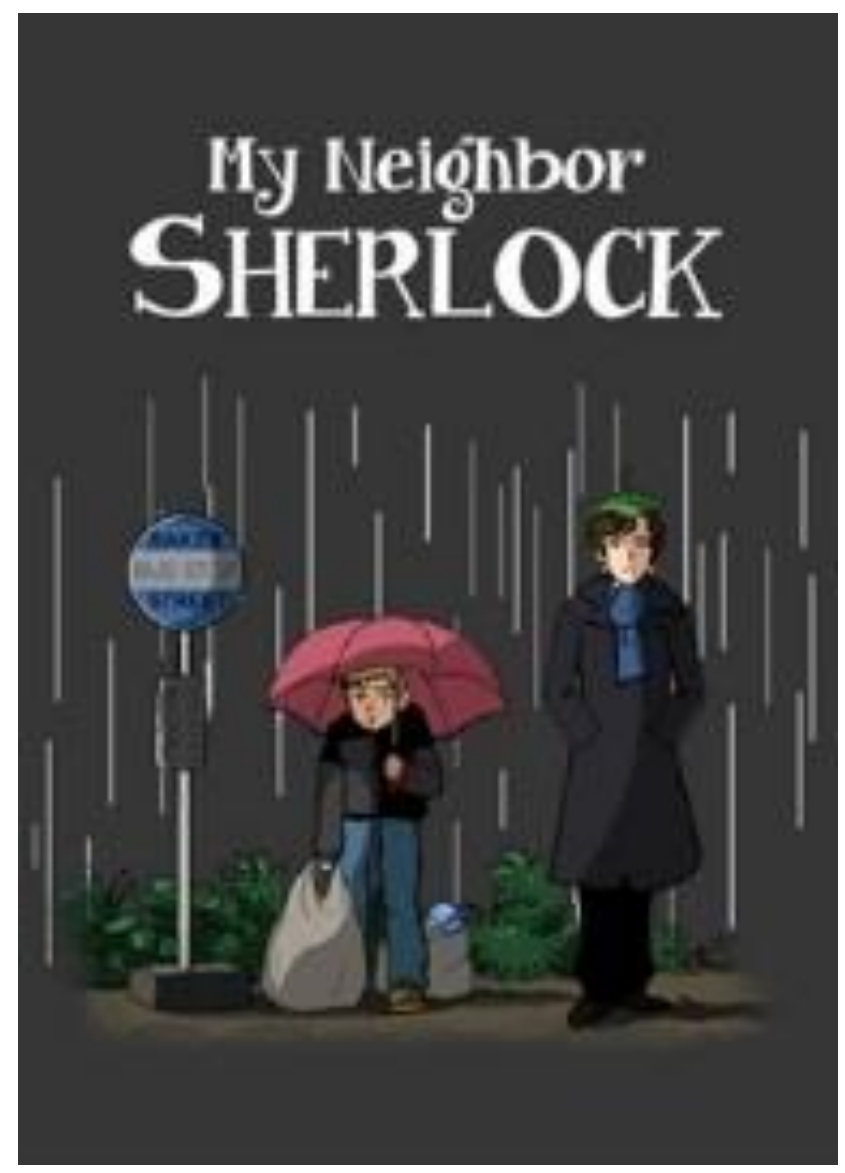

Figure 2: 'My Neighbor Sherlock' by Elisabetta Borseti

Two German and Japanese versions of the meme feature Totoro as himself. Here, he is semiotically affiliated with Sherlock's brother, Mycroft Holmes, through the umbrella each character carries in his own story. Art by Japanese fan Hatobairo (year unknown) ${ }^{1}$ shows Totoro not only holding the umbrella above his head, but also sporting a Mycroftian necktie patterned with small umbrellas. He stands next to a child version of Sherlock who is carrying an even younger version of John, outfitted in Mei's raincoat and galoshes, on his back. In 'Kidlock: My Neighbour Totoro' (2013), by German fan artist puddinge, Totoro similarly stands at the bus stop with a black umbrella in hand, this time next to a young Mycroft Holmes who is also holding a black umbrella over his head and carrying a sleeping Sherlock, again in raincoat and galoshes, on his back. The umbrellas in both of these works are semiotically complex, suggesting rather than depicting affinity between Sherlock and My Neighbor Totoro. Here, full legibility, and thus intertextual recognition, is most accessible to those fans aware that, in the film, Satsuki subsequently lends her (red) umbrella to Totoro, giving him a canonical reason for holding it in these works. Similarly, John is recognizable in 'Kidlock: My Neighbour Totoro' primarily to those fans who are familiar enough with 
Sherlock to recognize the black and white striped sweater, worn here by the smallest of the Totoro family, as one of John's season one jumpers. Indeed, this small detail turns out to be a singular point of intertextual delight for some commenters: 'Oh my Oz YES! Also totally dig the tiny totoro in John's jumper' (Caustic-Phangirl 2015); 'I especially love little john spirit in it's stripey jumper' (skins2007 2013), to which the artist replies, 'Glad to see somebody noticed it!' (puddinge 2013).

In all, these iterations of the Totoro meme demonstrate what Alexander Cho describes in the context of Tumblr as 'reverb,' a 'function of repetition' (2015: 53, emphasis in the original) that constitutes 'a way of apprehending that is not beholden to straightforward formulas of signification' (ibid: 51). In each of the above memes there are clear points of affinity, recognizable mainly through the intersubjective interpretation of texts by both artist and viewers. Pleasure results, as with any intertext; but inasmuch as it occurs within a fannish space and gets caught up in fandom value systems that depend on not just experiencing, but demonstrating the esoteric knowledge involved in understanding a given iteration of the meme, it is here worth turning our attention to this intersection of pleasure and value, and what it means for fandoms generally.

\section{The politics of transfandom pleasure}

There are two common refrains in comments on contributions to the Totoro meme. The first is an acknowledgement of where the commenter 'first' found the art - oftentimes not on the artist's own Tumblr or deviantART page. Facebook, Tumblr, Twitter, and online articles about Totoro, the meme, fan art of the remix media, and so on are familiar culprits that, together, demonstrate both the wide-ranging ways people encounter the meme and their uncontrollability. What begins in a single post can, and often does, become something entirely different, consumed in a context wholly outside the artist's own locus. This raises issues of ownership, copyright, and so on that are rather opaque in the context of transnationally circulating fan art, and particularly so when actual commerce enters the equation. The second common refrain found in comments on various iterations of the Totoro meme is that the artist 'should' offer a t-shirt of the work for fans to buy. The creator of the 'Hulkoro' piece is exhorted by several commenters to make it available for purchase as a tshirt, with one linking to the website Qwertee, where people vote on which designs to produce on t-shirts, insisting, 'I'm sure, [sic] it would get 1000 [sic] of votes!' (Tanuki72 2012). Similarly, a commenter on a Totoro/Pokemon contribution to the meme comments, 
'Can I throw money at you for this??? : DDDD' (TerraRed 2013), to which the artist replies, 'Uh yeah I'll take money if your [sic] just throwing it around! But also, you can throw it here and get a print of the piece' (mscorley 2013), followed by a link to inprnt.com.

Indeed, several meme contributors pre-empt such questions by making the artwork available from the beginning. Chan, a professional cartoonist in his own right, anticipates demand by offering his Titan version of the meme for sale at his Society6.com store, where it can be bought as a t-shirt, stationery, prints, rug, and mug (Chan 2013). Elisabetta Borseti also makes her 'My Neighbor Sherlock' art available as a t-shirt through Bēhance.com. Indeed, both online and offline, particularly in fan convention spaces, such sales are not uncommon, despite the emphasis in both transformative fandoms and fan studies alike on the gift economies of fandom. But they 'problematize [...] the market/nonmarket dichotomy' (Jones 2014: 4.1) of the gift economy to the extent that, as Sal Humphries argues, we might be better served by

consider[ing] the hybrid market environments where there is no such clear distinction between the social and commercial economies - where instead they co-exist in the same space, and where some people occupy different positions over time within the same markets. It's possible to identify people who both give away and sell their content. (2008: 2, emphasis in the original)

In the same way that the Totoro meme is a transfandom hybrid that cannot be defined solely in terms of one or another media object, so too is this hybrid market neither solely commercial nor fannish. In this sense, we can think of Chan himself as embodying the dual subjectivities of fan and professional artist - an ideal participant in the hybrid marketplace.

But what happens when the dividing line between media producer and fan artist blurs? One 2015 Big Hero 6 iteration of the Totoro meme posted to Tumblr is by South Korean artist Sang-Jin Kim (CosmoAnimato 2014). It features, like some of the contributions above, both visual and character affinities that affectively link the two media together. Here, balloonish robot Baymax is substituted for Totoro, paralleling both the characters' size and their almost childlike attempts to navigate a human world. Indeed, as one online article showcasing Kim's piece observes

[Baymax is] big, huggable and has a warm heart (metaphorically speaking). But as we list all these lovable traits, it's a little hard not to think about another popular animated 
character. Sure he's decades older, but Studio Ghibli's Totoro certainly holds many of the same qualities found in Baymax. (Navales 2015)

What sets this version of the meme apart is Kim himself, who was the character design supervisor for Big Hero 6 (credited as Jin Kim) (Fitzgibbons 2015). If transfandom gestures towards the growing borderlessness of media consumption and intensifying overlap between discrete fandoms, this borderlessness is equally reflected in the widespread blurring of heretofore solid boundaries separating the spheres of fandom and production, as well as fan and producer subjectivities. Within fan studies scholarship, concerns about fandom monetization, on the one hand, and the inevitability of increasingly blurred fan-producer interactions and identities, on the other, are site of intense debate (Chin and Hills 2008; Russo 2009; Larsen and Zubernis 2011; Williams 2010; Chin 2013; Scott 2014). In his Tumblr post, Kim describes the piece as 'my tribute to great [sic] Hayao Miyazaki and Studio Ghibli' (CosmoAnimato 2014), a fannish utterance that equally might signal Kim's professional indebtedness to Miyazaki and the film of Studio Ghibli. The Baymax version of the meme was posted to Kim's personal Tumblr three days before Big Hero 6 was released (CosmoAnimato 2014); so, is it fan art, advertising, or some amalgam of both suited not only to the hybrid marketplace, but also to transfandom?

\section{Transfandom, Hollywood and Studio Ghibli beyond the Totoro meme}

In an article on the Baymax version of the Totoro meme, Brendan Fitzgibbons writes, 'It's so easy to see Hayao Miyazaki and Studio Ghibli's influence spill over into modern mainstream popular culture' (2015). What happens, then, when the mainstream popular culture it spills into is a Hollywood blockbuster? The first Star Wars (Lucas, 1977) film famously drew from Akira Kurosawa's The Hidden Fortress (Kakushi toride no san akunin, 1960), which featured an incognito princess on the run accompanied by two peasants. Lucas, as one of several 'New Hollywood' filmmakers in the 1970s, had attended film school prior to becoming a filmmaker himself, and it was in this auteurist environment that he was first exposed to Kurosawa's films (Kaminski 2012: 83). Its mainstream success notwithstanding, Star Wars' indebtedness to The Hidden Fortress was thus less fannish than cinephilic (ibid: 89).

In contrast, J.J. Abrams, the director of Star Wars: The Force Awakens (Abrams, 2015) has openly brought an unabashed fannishness to his own resurrection of (or contribution to) the Star Wars franchise. As Scott Dadish writes in the preface to a 2015 interview with Abrams 
It's clear that in addition to being one of the most gifted movie directors in the world, somehow the heir apparent to both Steven Spielberg and George Lucas, Abrams is also a superfan. That puts him in a precarious situation. He has inherited the one megafranchise to rule them all. Sure, this won't be the first time Abrams resurrects a beloved Enterprise. But [...] this is the saga. It's one of the things that invented modern superfandom. [...] He loves those movies as much as you or any of your laserbrained friends do. But when he first met those movies he was just an apprentice. Now he must become the master. (Dadish 2015: n.p.)

Dadish's own use of fannish signifiers is in many ways emblematic of the very real concerns about corporate capitalization of fandom, a clumsy attempt to hail readers as fellow (geek) fans rather than paying consumers or subscribers. Abrams himself, however, is a more complicated figure. As Michael Duffy writes, there is

a seemingly more accepted movement in contemporary media-making culture depicting fans as developing from childhood dreamers to consumers to creators of fan-worthy material. Writer, producer, and director J.J. Abrams is a great example; he has never been shy about his fandom for the Star Wars films and franchise [...] and this circular personal-professional cycle of growth and regeneration of fandom into work has truly come full circle, with Abrams committed to co-writing and directing a new Star Wars film set for release in 2015. (2014: 9)

In the context of Studio Ghibli and the Totoro meme, it is fans' insistence on visual connections between The Force Awakens and Ghibli's Nausicaä of the Valley of the Wind (Kaze no tani no Naushika, Hayao Miyazaki, 1984) that throws this hybrid fan-producer subjectivity into relief. As early as October 2015, two months prior to the release of The Force Awakens, Tumblr user ghibli-collector posted a collage of shots from one of the The Force Awakens trailers that garnered 141 'notes' (i.e., likes and reblogs onto other Tumblr blogs), juxtaposing them against several Nausicä̈ stills: Rey walking across the desert, staff in hand, versus Nausicaä gazing out into the desert, also with staff in hand; Rey swathed in scarves and wearing goggles as she scavenges for scrap metal and electronics versus Nausicaä, equally well-covered with goggles resting on her head; the murky depths of an abandoned Imperial Star Destroyer, lit only by the rays of the sun as they shine through holes in the deteriorating metal above versus an underground garden lit only by the rays of the sun shining through holes in the topsoil above. 
One month later, YouTube fan vidder issac_sea created a mashup video that similarly and skillfully juxtaposed film clips from Nausicaä in the bottom half of the frame with the full The Force Awakens trailer playing in the top half, further foregrounding the extent to which The Force Awakens clearly seemed to bare a more-than-passing similarity to Nausicä̈. While some fans used the comments section of this video to excoriate Abrams' Star Wars on the basis of its appropriation of superior material (part of an anti-fandom discourse already several years old by this point), others applauded the issac_sea's clever insights. On Reddit, where the video was also posted, one fan acknowledged the similarities between The Force Awakens and Nausicä̈, writing,

I have had Nausicaa on DVD for over 10 years and still have not seen it. I have been waiting for the right time. My daughter and me have watched most of the Ghibli film [sic] suitable for kids under 8 years (which she currently is) since she was 2 years. I have promised her that we will go see Star Wars at the Cinema, but I guess now is the time to see Nausicaa with her first. (Grums 2015)

What is particularly striking here is the unquestioned ease with which this fan seems to accept that, given The Force Awakens' apparent citations of Nausicä̈, viewing Nausica $\ddot{a}$ prior to The Force Awakens will augment, rather than diminish, his and his daughter's experience of seeing the latter film. Both films are perceived here to be in transfandom conversation with one another, the one a lens through which to better, or differently, enjoy the other in ways that are analogous to the transfandom pleasures of such fanworks as the Totoro meme.

Yet, not only have theatrical screenings of The Force Awakens grossed a nearly unprecedented $\$ 2$ billion worldwide (boxofficemojo.com 2016), but what we might posit as a kind of corporatized transfandom expressed through its citations of the characters and settings of Nausicä̈ is entirely congruent with Disney's synergy-centred model of transmedia marketing; one that has been in effect, to varying degrees, since the late 1950s (Kottke 2015). Originally intended to capitalise on Disney's media content across a variety of products and services, including feature films, television, publishing, music, theme parks and so on, today this synergistic model is equally discernible in Disney's high-profile studio acquisitions of the past decade (ibid.).

\section{Conclusion}


To return, then, to the discussion at the beginning of this article, if 'Tertium Quid is the emergent property that is created through the synergy of two or more' (Bell and Fenske 2004: 6 , emphasis in the original) things, exemplified as much in the intertextual pleasure produced by the Totoro meme as that generated in the big budget mashup of Star Wars and Studio Ghibli's Nausicä̈, does it also lend itself to the kinds of corporate synergy Disney has been exploiting for decades? Is Abrams, as a fan, effectively (or affectively) the same as those meme artists who sell their work as T-shirts and other goods, particularly inasmuch as The Force Awakens' (apparent) citations of Nausicä̈ in its own coming-of-age story about a plucky young girl on the cusp of womanhood produce little-to-no clear economic rewards? Or is there a more intangible value to tapping into the pleasures of transfandom articulation, particularly with such media texts as Nausicä̈ and, in particular, My Neighbor Totoro, that are so ubiquitous and recognizable as to bring a certain semiotic stability in their memetic refashioning by Ghibli fans worldwide?

\section{Notes}

\footnotetext{
${ }^{1}$ This art originated on the art hosting site pixiv; however, the artist's account has since been deleted; reposts of the artwork on Tumblr are currently one of the only ways to access it. The artist's Japanese nationality is presumed, but not confirmed. http://ladyavenal.tumblr.com/post/46744517965
}

\section{Bibliography}

Abrams, J.J. (2015), Star Wars: The Force Awakens, Los Angeles: Lucasfilm/Bad Robot.

Amisgaudi (2014), 'Luke, Yoda and Chewbacca?', April, http://amisgaudi.deviantart.com/art/Luke-Yoda-and-Chewbacca-4449. Accessed 26 September 2015.

Annett, S. (2015), Anime Fan Communities: Transcultural Flows and Frictions, New York: Palgrave Macmillan. 
Appadurai, A. (1990), 'Disjuncture and Difference in the Global Cultural Economy', Theory, Culture and Society 7.2/3, pp. 295-310.

artildawn (2013), comment, http://samoubica.deviantart.com/art/My-Neighbour-Hulk308819419?offset=0\#comments. Accessed 29 September 2016.

ArtmasterRich (2012), comment, http://samoubica.deviantart.com/art/My-Neighbour-Hulk308819419?offset=25\#comments. Accessed 29 September 2016.

Attack on Titan/Shingeki no kyojin (2013-), Tokyo: Wit Studio.

Barthes, R. (1975), The Pleasure of the Text, New York: Hill and Wang.

BBC Worldwide (2014), Annual Review 2013-2014, London: British Broadcasting Corporation.

Bell, J.G. and Fenske, R.R. (2004), 'Dialogue and Systems Thinking: Building a Bridge for the Practitioner' (unpublished), http://web.pdx.edu/ rfenske/Academic_Summary_files/Final\%20paper\%20\%20dialogue\%20and\%20systems.pdf. Accessed 30 September 2016.

Booth, P. (2016), Crossing Fandoms: SuperWhoLock and the Contemporary Fan Audience, London: Palgrave Macmillan UK.

Borseti, E. (2014), 'My Neighbor Sherlock', 3 October, https://www.behance.net/gallery/20232185/My-Neighbor-Sherlock-Fan-tshirt. Accessed 26 September 2016.

Caustic-Phangirl (2015), comment, http://puddinge.deviantart.com/art/Kidlock-Myneighbour-Totoro-347921461. Accessed 27 September 2016.

Chan, R. (2013), 'My Neighbor Titan! Or maybe Attack on Totoro?' Ron Chan, http://rondanchan.tumblr.com/post/59580327727/my-neighbor-titan-or-maybe-attack-ontotoro-it. Accessed 24 September 2015.

Chin, B. (2010), 'From Textual Poachers to Textual Gifters: Exploring Fan Community and Celebrity in the Field of Fan Cultural Production', Ph.D. Thesis, Cardiff: Cardiff University. Chin, B. and M. Hills (2008), 'Restricted Confessions? Blogging, Subcultural Celebrity and the Management of Producer-Fan Proximity', Social Semiotics 2, pp. 253-272. 
Cho, Al. (2015), 'Queer Reverb: Tumblr, Affect, Time', in K. Hillis, S. Paasonen, M. Petit (eds.), Networked Affect, Cambridge, MA: The MIT Press, pp. 43-58.

clawman2200 (2012), comment, http://samoubica.deviantart.com/art/My-Neighbour-Hulk308819419?offset=25\#comments. Accessed 29 September 2016.

CosmoAnimato (2014), 'This is my tribute to great Hayao Miyazaki and Studio Ghibli', http://cosmoanimato.tumblr.com/tagged/hayao_miyazaki. Accessed 24 September 2015.

Csloth (2014), 'Totoro Bus Stop Parodies', Know Your Meme, http://knowyourmeme.com/memes/totoro-bus-stop-parodies. Accessed 14 August 2016.

Dadich, S. (2015), 'Lucky VII: An Interview', Wired, December, http://www.wired.com/2015/11/star-wars-force-awakens-jj-abrams-interview/. Accessed 14 August 2016.

Duffy, M.S. (2014), 'Book Review: Cult Collectors: Nostalgia, Fandom and Collecting Popular Culture, by Lincoln Geraghty', Transformative Works and Cultures 16, doi:10.3983/twc.2014.0584.

Eiren, (Motion Pictures Association of Japan) (2016), 1988 nen haikyū shūnyū sakuhin/1988 Film Revenues, http://www.eiren.org/toukei/1988.html. Accessed 30 September 2016.

Eisenstein, S. (1925), Strike!, Moscow: Goskino/Proletkult.

Evil-Tree (2013), comment, Know Your Meme, http://knowyourmeme.com/memes/totorobus-stop-parodies. Accessed 29 September 2016.

Fitzgibbons, B. (2015), 'Disney artist draws beautiful Big Hero 6 tribute to Studio Ghibli', Dramafever, 13 January, https://www.dramafever.com/news/disney-artist-draws-beautifulbig-hero-6-tribute-to-studio-ghibli-/\%7B\%5B\%7Bnotification.object.url\%7D\%5D\%7D. Accessed 30 September 2016.

ghibli-collector (2015), 'Star Wars: The Force Awakens Trailer (2015) X Nausicaa', October, http://ghibli-collector.tumblr.com/post/131572877496/star-wars-the-force-awakens-trailer2015-x. Accessed 13 August 2016. 
Grums (2016), Ghibli forum comment, January, https://www.reddit.com/r/ghibli/comments/3z9mtw/nausicaa_the_force_awakens_trailers_sid e_by_side/.Accessed 14 August 2016.

Hall, D. and C. Williams (2014), Big Hero 6, Los Angeles: Walt Disney Pictures. Hatobairo (year unknown), 'Sherlock/Ghibli', http://dumbledorathexplora.tumblr.com/post/45759990211/鳩羽紫原稿中-sherlockghibli. Accessed 26 September 2015.

Henry, E.C. (2016), 'Was Rey Inspired By Nausicaa', 29 May, https://www.youtube.com/watch?v=1rRmGYiK6g8. Accessed 14 August 2016.

Hills, M. (2015), 'Fandom as an Object and the Objects of Fandom, Interview with Clarice Greco', Matrize 9.1, pp. 147-163.

- (2010), Triumph of a Time Lord: Regenerating Doctor Who in the Twenty-first Century, London: I.B. Taurus.

— (2002), 'Transcultural Otaku: Japanese Representations of Fandom and Representations of Japan in Anime/Manga Fan Cultures', Proceedings of MiT2, Massachusetts Institute of Technology, Cambridge, MA, http://cmsw.mit.edu/mit2/Abstracts/MattHillspaper.pdf. Accessed 13 August 2016.

Humphreys, S. (2008), 'The Challenges of Intellectual Property for Users of Social Networking Sites: A Case Study of Ravelry', Proceedings of Mind Trek, Tampere, Finland, http://eprints.qut.edu.au/14858/1/14858.pdf. Accessed 28 September 2016.

issac_sea (2015), 'Nausicaa: The Force Awakens Mashup/Side by Side', 6 November, https://www.youtube.com/watch?v=AvDrQtMIAxU. Accessed 14 August 2016.

Jackson, D. (1982), The Snowman, London: TVC London.

Jaimeenator123 (2015), comment, http://forte-girl7.deviantart.com/art/FNAF-My-NeighbourFreddy-GIF-477286908. Accessed 29 September 2016.

Jenkins, H. (2006), Convergence Culture: Where Old and New Media Collide, New York: New York University Press. 
Jones, B. (2014), 'Fifty Shades of Exploitation: Fan Labor and Fifty Shades of Grey', Transformative Works and Cultures 15, http://dx.doi.org/10.3983/twc.2014.0501. Accessed 28 September 2016.

Kaminski, M. (2012), 'Under the Influence of Akira Kurosawa: The Visual Style of George Lucas', in Brode, D., L. Deyneka (eds.), Myth Media, and Culture in Star Wars: An Anthology, Plymouth: Scarecrow Press, pp. 83-100.

Kim, S.J. (2014), 'This is my tribute to great Hayao Miyazaki and Studio Ghibli', 4 November, http://cosmoanimato.tumblr.com/post/101774246277/this-is-my-tribute-to-greathayao-miyazaki-and. Accessed 26 September 2015.

Kinema jumpō-sha (1989), '1988 nendo besuto ten happyō kessan tokubetsu-go/Special Year-End Issue: The Best Tens of 1988', Kinema jumpō/Movie Times, 15 February.

Kottke, J. (2015), 'Walt Disney’s Corporate Strategy Chart', Kottke.org, http://kottke.org/15/06/walt-disneys-corporate-strategy-chart. Accessed 29 September 2016. Kurosawa, A. (1958), The Hidden Fortress/Kakushi toride no san akunin, Tokyo: Toho Studios.

Larsen, K. and L. Zubernis (2011), Fandom at the Crossroads: Celebration, Shame and Fan/Producer Relationships, Newcastle: Cambridge Scholars Publishing.

Lasseter, J. (1995), Toy Story, Los Angeles: Walt Disney Pictures/Pixar Animation Studios. Lucas, G. (1977), Star Wars, Los Angeles: $20^{\text {th }}$ Century Fox.

McGray, D. (2002), 'Japan’s Gross National Cool', Foreign Policy 130, pp. 44-54.

McMillan, G. (2014), 'Marvel vs. "Star Wars,” Twitter-Style', The Hollywood Reporter, 23 January, http://www.hollywoodreporter.com/heat-vision/marvel-star-wars-twitter-style673635. Accessed 15 August 2016.

Milner, R. (2009), 'Working for the Text: Fan Labour and the New Organization', International Journal of Cultural Studies, 12.5, pp. 491-508.

mistresstrista (2012), Comment, http://samoubica.deviantart.com/art/My-Neighbour-Hulk308819419?offset=25\#comments. 
Miyazaki, H. (1998), My Neighbor Totoro/Tonari no Totoro, Japan: Studio Ghibli.

— (1984), Nausicaä of the Valley of the Wind/Kaze no tani no Naushika, Tokyo: Topcraft.

mscorley (2012), 'My Neighbor Gengar', http://mscorley.deviantart.com/art/My-NeighborGengar-282373433. Accessed 24 September 2015.

MyMadMadMadMadWorld (2012), comment, http://samoubica.deviantart.com/art/MyNeighbour-Hulk-308819419?offset=75\#comments. Accessed 29 September 2016.

Mzero (2014), comment, Know Your Meme, http://knowyourmeme.com/memes/totoro-busstop-parodies. Accessed 14 August 2016.

Navales, E. (2015), 'Disney Artist Combines "My Neighbor Totoro" with "Big Hero 6", Kore Asian Media, 15 January, http://kore.am/image-of-the-day-disneyartist-combines-myneighbor-totoro-with-big-hero-6/. Accessed 13 August 2016.

Nielsen, M. (2013), 'Temporal Aesthetics: On Deleuzian Montage in Anthropology', in C. Suhr, R. Willerslev (eds.), Transcultural Montage, New York: Berghahn Books, pp. 40-57.

Nissenbaum, A. and L. Shifman, (2015), 'Internet Memes as Contested Cultural Capital: the case of 4chan's /b/ board, New Media \& Society, doi:10.1177/1461444815609313.

Noppe, N. (2013), 'DeviantART and Pixiv', in Berndt, J., Kümmerling-Meibauer, B. (eds.), Manga's Cultural Crossroads, New York: Routledge, pp. 143-159.

puddinge (2013), 'Kidlock: My neighbour Totoro', http://puddinge.deviantart.com/art/Kidlock-My-neighbour-Totoro-347921461. Accessed 26 September 2015.

Russo, J.L. (2009), 'User-Penetrated Content: Fan Video in the Age of Convergence', Cinema Journal 48.4, pp. 125-130.

RyuTamashi (2014), comment, http://forte-girl7.deviantart.com/art/FNAF-My-NeighbourFreddy-GIF-477286908?offset=100\#comments. Accessed September 262016.

Samoubica (2012), 'My Neighbour, Hulk', June, http://samoubica.deviantart.com/art/MyNeighbour-Hulk-308819419. Accessed 26 September 2015. 
saschen (2008), 'TonarinoTotoro-Bus Stop', June, http://sachsen.deviantart.com/art/TonariNoTotoro-Bus-Stop-57754491. Accessed 26 September 2015.

Scholz, T. (ed.) (2013), Digital Labor: the Internet as Playground and Factory, New York, Routledge.

Scott, S. (2014), 'The Moral Economy of Crowdfunding and the Transformative Capacity of Fan-ancing', New Media \& Society 17.2, pp. 167-182.

Shad73 (2015), comment, http://amisgaudi.deviantart.com/art/Luke-Yoda-and-Chewbacca444921593. Accessed 28 September 2016.

Sherlock (2010-), Wales: BBC Wales/Hartswood Films/WGBH.

Shifman, L. (2014), Memes in Digital Culture, Cambridge, MA: The MIT Press.

Skins2007 (2013), comment, http://puddinge.deviantart.com/art/Kidlock-My-neighbourTotoro-347921461. Accessed 29 September 2016.

Stanfill, M. and M. Condis (2014). 'Fandom and/as Labor' [editorial], Transformative Works and Cultures 15. doi: 10.3983/twc.2014.0593.

Studio Ghibli (1995), Totoro ga ippai - Totoro 1988-1995 (Totoro Merchandise Catalogue 1988-1995), Tokyo: Studio Ghibli.

subzerogengar (2012), comment, http://mscorley.deviantart.com/art/My-Neighbor-Gengar282373433? offset=75\#comments. Accessed 29 September 2016.

SvalaW (2014), comment, http://amisgaudi.deviantart.com/art/Luke-Yoda-andChewbacca444921593. Accessed 28 September 2016.

Tanuki72 (2012), comment, http://samoubica.deviantart.com/art/My-Neighbour-Hulk308819419?offset=0\#comments. Accessed 29 September 2016.

TerraRed (2013), comment, http://mscorley.deviantart.com/art/My-Neighbor-Gengar282373433. Accessed 30 September 2016.

Thornton, S. (1995), Club Cultures: Music, Media and Subcultural Capital, London: Polity Press. 
Williams, R. (2015), Post-Object Fandom: Television, Identity and Self-Narrative, London: Bloomsbury. 


\title{
Bridge Builders, World Makers: Transcultural Studio Ghibli Fan Crafting
}

\author{
James Rendell, Cardiff University
}

\begin{abstract}
Whilst global hits such as Pokémon utilized what Marc Steinberg calls anime's media mix (2012: 142), implementing a multiple-platform narrative world in an attempt to synergize/converge a franchise, what are we to do when one finds a dearth of official merchandise available to transnational audiences? What are the reasons or politics for such a decision that seems to run contra to a long socio-cultural history of such media ecology? Equally as important, what do fans do when their championed fan objects offer a relatively restricted media palette?
\end{abstract}

This article looks at how Studio Ghibli has, to a degree, negotiated and/or rejected the traditional 'anime media mix'. This is not to say that Ghibli is void of media mixing, rather, via online communities, one has seen a growing presence of fan-crafts whereby audiences are making their own Ghibli objects. In doing so, these transcultural fan-made Ghibli objects extend fan ideologies linked to the studio, expanding on what Susan Napier terms 'MiyazakiWorld' (2006: 49; 2007: 193). Much like Miyazaki's philosophy, this is not entirely rejecting industry, but offering creative alternatives. The fan-as-producer of Ghibli objects is doing so through convivial construction. Thus, the essay offers new insights into global audience practices and affective meaning-making around Ghibli that goes beyond the films themselves.

Keywords: Fandom, craft, social media, online, transcultural, transnational 


\section{Bridge Builders, World Makers: Transcultural Studio Ghibli Fan Crating}

James Rendell, Cardiff University

Since the beginning of the twentieth century, Japan has long created toys of popular manga characters (Cross 2006: xv-Xvi), subsequently becoming a central component of television anime with the introduction of Tetsuwan Atomu (Astro Boy) in 1963 (see Schodt 2007: 5). This triangulation of manga, anime and merchandise is now the primary business model for the Japanese media industries that Marc Steinberg calls anime's 'media mix' (2012). Much like Henry Jenkins' convergence cultures (2006),

[t]he anime media mix within popular discourse refers to two intersecting phenomena: the translation or deployment of a single work, character or narrative world across numerous mediums or platforms [...] and the synergetic use of multiple media works to sell other such works within the same franchise or group (Steinberg 2012: 142).

Within the media mix, character branding has become a central nodal point of synergy (Steinberg: 190), being extensively utilized in the twenty-first century exemplified in the global hit Pokémon (Kelts 2006: 90-1), thus shaping transcultural fan collecting practices (Tobin 2004: 3; Napier 2007: 129-31). Likewise, such approaches that incorporate merchandise into their business models are also popular in Western animation (Gray 2008: 80; Bédard 2015; Seroff 2012), and wider media franchises (Johnson 2013; Lawrence 2006). Whilst not guaranteeing success (Aldred 2014; Condry 2013: 72-3; Tobin 2004: 7-8), this has proven a lucrative model in Japan and abroad (Bainbridge and Norris 2008: 3; Cooper-Chen 2010: 24; Steinberg 2012: 158).

However, whilst such textual synergy may be dominant it is not ubiquitous or monolithic. In the case of Studio Ghibli and Hayao Miyazaki it is a more tentative and ambiguous relationship. Firstly, Miyazaki is openly not a fan of anime (Miyazaki 2009: 20), referring to his own work as animation, inscribing a cultural value more akin to the arts. He attacks the industry for the plasticity of aesthetics (43-5), churning out of quantity over quality (123-4), in favour of profit (25-6), and focusing on selling toys, hindering the quality of animators $(47,127)$. One might note that Ghibli hardly features, if at all, in Steinberg's writing on anime's media mix.

Moreover, Miyazaki's eco-politics and philosophies have structured Studio Ghibli as a business (Baseel 2015; Miyazaki 2009: 173). Both the studio's production houses and the 
Ghibli museum located in Mitaka present the company as different from the wider anime industry, stressing green politics as a core corporate value whilst reinforcing brand identity (Denison 2010: 550; Lamarre 2009: 97). Miyazaki himself has noted he is not against technology or capitalism per se, rather, he argues that technology should be used to support nature, not destroy it (2009: 46), favouring the bicycle not the bomb. Such ideologies have been taken up by transcultural Ghibli fans in their online critical discussions. Examining the Miyazaki Mailing List, Susan Napier illustrates how this transcultural fandom engages in what she terms 'MiyazakiWorld, an overt ideological agenda encompassing environmentalism, humanism, and what might be called "Ghibli (or Miyazaki) family values," and a concern with presenting works of a psychological and moral complexity" (2006: 49). These fans engage with Ghibli through the ideologies read within the films and through their championing of Miyazaki as an auteur.

Secondly, despite acquiring distribution rights for theatrical release, Ghibli refused to sell merchandising rights to Disney (Kelts 2006: 54). This has allowed Ghibli to create 'a vacuum in merchandising around [...][its] films in the United States' (Denison 2011: 223), and, as this article illustrates, beyond. However, this is not to say Ghibli is completely detached from transmedia practices (Condry 2013: 150; Lamarre 2009: 96-7). Studio Ghibli is hugely popular in Japan (Davis and Yeh 2008: 79-83; Osmond 2008: 14), seen as a form of mainstream media within the native space (Denison 2008). Likewise, the studio's globally iconic films offer, alongside quality storytelling, a strong sense of character branding (Steinberg 2012: 187-8; Condry 2013: 61-2) that is likely to have aesthetic appeal especially when made into toys (Allison 2004: 35-6). Furthermore, whilst the Ghibli Museum offers the ludic experience of going 'into' the studio's history, influences, and creative processes (Cooper-Chen 2010: 32; Denison 2015: 126), it also offers a gift shop full of exclusive merchandise, resulting in a space full of eager buyers. Yet, symbolic pilgrimages for transcultural fans to the museum require substantial economic capital (Napier 2007: 149-50). Likewise, official products that do make it to the West can also be a large expense for fans (Kendall 2014; Lynch 2014; Kay 2014), as can the subsequent hardware needed to consume such texts. ${ }^{1}$

This transnational gulf, I argue, has opened up a space that encourages transcultural fans to create Ghibli crafts (Hills 2011: 58). Furthermore, such creative practices are congruent with Miyazaki's own ideologies of low-level creative processes that are not injurious to the natural environment. Thus, this article builds on Napier's MiyazakiWorld by 
not only looking at fans' political engagement with the studio at a textual level, but through partaking in fan-crafting as a deeply personal practice in the creation of Ghibli objects (Blakey and Mitchell 2013: 174). To do so, this article considers how craft studies can be applied to fan studies. As Hills comments, in comparison to other established fan practices, 'the fan craft of modding [modifying] and creating one-offs as well as generating photographs/videos of toys, has not been studied enough' (2009). Moving away from Napier's model, this research not only considers the political potential of crafting but how the process of making also fosters other forms of (non-political) affective fan-engagement.

This is not to say fans completely reject buying merchandise: several North American participants explained how the alternative chain store Hot Topic has recently begun selling Ghibli ancillary products (see also Granshaw 2015), further problematizing the studio's previous stance on global merchandising whilst perhaps suggesting the route the company might be taking now its two main contributors have retired from making films. Rather, this article's focus on fans making/crafting provides a different registering of fan immersion and fan community dynamics alternative to buying merchandise. Many of the examples given consider the process of making, presenting and discussing works created with other fans, and the act of gift giving, as distinct aspects to this form of fan labour compared to other consumptive practices, stressing the time spent making as well as the final creation as markers of affective authenticity.

Whilst there is ample research on fan practices such as fan fiction (Hellekson and Busse 2006), fan trailers and videos (Williams 2012), manga (Saito 2011) and cosplay (Winge 2006), fan studies has tended to 'privilege textual over tactile engagement' (Rehak 2014). Fan-made crafts, I argue, remain even more neglected. Likewise, while textual analysis locates the socio-political and environmental subtexts of Ghibli films (Smith and Parsons 2012; Lim 2013; Akimoto 2014; Parham 2016), this article explores how fan crafts mirror and/or appropriate said subtexts. Bode defines fan crafters as 'express[ing] their involvement in their chosen fandoms by making things by hand, sometimes to sell, sometimes to giveaway, sometimes to keep' (2014).

Fan-crafted creations can be considered paratexts, that is, objects 'both "distinct from" and alike - or [...] intrinsically part of - the text' (Gray 2010: 6), managing and evidencing meaning-making (25). By considering how such fan-made paratexts 'complement, extend, and/or enrich the original text, thus adding value' (Stork 2010), this 
article looks to greatly expand the affective textual realm of fan practices/labour that allows for identity performance and value generation, while encouraging community dynamics and/or collaboration (Stanfill and Condis 2014). Whilst understanding that such practices are not always harmonious (O’Neill and Ravetz 2013: 247-9), the article limits itself to fan craft culture leaving aside craft-made objects for business (Kacsuk 2011; Phillips 2014).

Implementing a netnography of three Studio Ghibli Facebook groups: 'Japan and Studio Ghibli fans - WORLDWIDE GROUP', 'Studio Ghibli Fans', and 'Studio Ghibli WORLDWIDE FANGROUP' that analyses fans' online postings of the crafts they have made with supporting commentary, this article looks at the "complex cultural practices in action, drawing attention to a multitude of grounded and abstract ideas, meanings, social practices, relationships, languages, and symbol systems' (Kozinets 2010: 25). Kozinets notes that whilst the popularity of Facebook evidences populist mainstream utilization, the site also fosters 'particular interest and identity groups' (2015: 16). Thus, the bounding of sample parameters in this research pertains to particular Ghibli-based interest groups that present and discuss their fan-crafted creations (Kozinets 2015). Being a fan of Ghibli myself and already a member of all three groups, I became aware of the prominence of fans crafting and sought to gain a deeper understanding of the reasons behind such acts, the process of creating, and what it meant to these fans to partake in such practices within the wider Ghibli fan community.

As such, building upon the netnographic observations of fan posts and feedback from other members, follow-up interviews were used to gain further insight into the creative process of craft-making, allowing fans to express in-detail their fan identity and the community they reside in (see: Bode 2014). These transcultural fan groups have geographically diverse members from the UK, North and South America, much of Europe, large parts of Asia, and sections of the Middle East. This is represented by the twelve fans who agreed to be interviewed in this research over a two-month period between May and June 2016. Since the communities were closed groups and online interviews gave me direct access to fans, consent was ascertained from all quoted individuals (see: Ess and AoIR 2002). All quoted comments from interviewees are unedited with an anonymized naming system used instead of respondents' real names.

\section{My online neighbour Totoro: Transcultural fan-craft community}


As noted, Susan Napier's research evidences how perceived ideologies of Ghibli and its films have been central to online Ghibli fandom and fan identity construction/performance. Napier writes that,

[o]nce attracted to MiyazakiWorld [...] the viewer is often drawn further in by the subtle yet rich emotional palette $[\ldots]$ the complex characterizations of the protagonists (who are frequently female), and the willingness to deal with powerful themes, from environmental and social collapse [...] to heartfelt coming-of-age tales. (2006: 49)

Fan posts explore contemporary cultural issues (see: Jenkins 2015), addressing consumer capitalism, increased monopolized power, and drastic environmental negligence, all of which are 'problems explored in the works of both Miyazaki and Takahata [and] is [...] why people are drawn to Studio Ghibli's output' (Napier 2006: 50). The Miyazaki Mailing List is a 'sacred space' for 'fans not only to discuss their specific interests in Ghibli products but also to deal with larger philosophical, intellectual, and political issues arising from the Ghibli oeuvre and Miyazaki's pronouncements, and, occasionally, emotional and personal ones as well' (51). Consequently, '[t]he responses of these fans reveal how the appeal of MiyazakiWorld becomes far more than enjoyable entertainment' (61). Napier's research illustrates how online fan discussion can show deep textual immersion and strong affective fan engagement, yet one might also consider how other fan activities shape such relationships.

Unlike Napier's mostly adult sample, the Facebook communities sampled herein range across a wide spectrum of ages. Lincoln Geraghty, in his study of fans collecting objects, argues that 'memories embedded within collections of toys, merchandise and collectibles are emblems of the self, markers of identity and symbolic of the cultural capital that fans accumulate in their life-long engagement with a media text' (2014: 4). Offering biographic accounts (see Hills 2014b), many of my respondents stressed affective relationships with Ghibli that began as young children, continuing on into adulthood, in line with Geraghty's observations:

I have been a fan for as long as I can remember, I have almost all his movies on BluRay today but I used to pop in the movies in my VCR all the time when I was little. It started with My Neighbor Totoro. Totoro was instantly my favorite because who wouldn't want to experience flying around with him as a kid? $\left(\right.$ I 2016) ${ }^{2}$ 
[I've been a fan] since I was 10 years old. My first experience with Ghibli was introduced to me by my sister when she showed me Princess Mononoke for the first time. I was immediately hooked. (II 2016)

I got into ghibli when I first spotted Totoro at this place my family used to rent movies from [...] I was like "woah, what is this big cat-rabbit looking thing" and I took it home and loved it. I rented it every week for months until my mom bought it for me. [...] As I got older, I found that I loved how Hayao Miyazaki saw the world. I wanted to be more like him. I wanted the worlds he created to be real. (III 2016)

Interestingly, several fans note that despite being fans of these films upon initial or early consumption, they were unaware they were Ghibli texts. This evidences not only how fans have different temporal entry points into the studio's corpus, but how affective relationships do not necessarily always begin with auteur and/or brand status ascribed to the films, yet still stressing a desire for collecting/consuming more of the catalogue:

My love for Studio Ghibli and their movies started with grave of the fireflies. I didn't really know who Miyasaki was at the time, I just thought that was a wonderful movie, sad, but very artistic, and historically accurate. (IV 2016)

[T]he first Ghibli movie I watched was Princess Mononoke around 14 years ago, I was around 12 years old... At that time, we had no concept of what anime was, let alone what Ghibli was. So for us, Princess Mononoke was like no cartoon we've ever experienced. ( $V$ 2016)

[M]y first Ghibli movie was Kiki's Delivery Service, except I didn't know it was Ghibli. All I knew was that it was my favorite movie, and I'd beg to watch it whenever I slept over at my cousins' house. (VI 2016)

Moving away from media texts consumed by fans, Geraghty focuses on the ancillary objects that oscillate around texts that 'become talking points and allow for social exchange between individuals as they become highly valued and desirable within the wider fan community' (2015: XX; see also: Rehak 2012). Such collectibles, he notes, have been salient 'in creating and sustaining Western fan cultures [of Japanese media culture]' (Geraghty 2014: 184; see also: Woo 2014). 
However, as previously argued, Ghibli objects do not travel transnationally with such ease as their cinematic counterparts. One fan from Abu Dhabi noted that, 'sadly I do not own (yet) any ghibli merch because their items are not always easily available' (VII 2016). Another fan from Florida, USA, echoes such sentiments explaining that Ghibli collecting practices are not 'easy in America and I think that's why it became so common to make your own [objects]' (I 2016). A fan from the UK makes the connection between price and availability as encouraging craft culture, noting that 'One of the reasons for making Ghibli crafts is down to money and availability - not being able to afford to import collectables that I might be interested in, or indeed knowing where these are available to purchase' (VIII 2016). Similarly, a Mexican fan recognises the transmedia aspects of Ghibli but has yet to experience them: 'I know there's a Ghibli museum and store in Japan, but until I can go there, I can keep making my own memorabilia, cause it's fun' (IV 2016).

Such quotes stress the 'vacuum' created by the studio as noted by Denison (2011: 223), whilst also partly evidencing particular contexts within which fans might turn to crafting. However, further analysis indicates affective relationships between fans, films, objects and making. Just as '[m]erchandise spans a range of items, from clothes and electronics to toys and drinks' (Geraghty 2014: 64), fan-crafts are equally myriad (Bode 2014). David Gauntlett posits that the process of making, seen in craft culture, is a means of social connection in three principle ways:

because you have to connect things together (materials, ideas, or both) to make something new. $[\ldots][\mathrm{B}]$ ecause acts of creativity usually involve $[\ldots]$ a social dimension and connect us with other people. [...] And [...] because through making things and sharing them in the world, we increase our engagement and connection with our social and physical environments. (2011:2)

In opposition to 'industrial' tools that simply promote mass consumption, Gauntlett uses the work of Ivan Illich (1973), who argues that 'convivial' tools encourage self-expression and dialogue (2014: 199). We can connect through creation in craft culture. Much like Miyazaki's philosophy, this is not entirely rejecting industry, but offering creative alternatives. Usually, the fan-as-producer of Ghibli objects is doing so through convivial construction, evidenced through the positivity of fan responses.

Craft fans link their own practices to Ghibli films: 
The things I make are quality hand-made with tremendous amounts of love and attention, just like a Studio Ghibli film is or even the characters in the films that make things! For all of my wooden items I use good quality, eco-friendly, sustainable wood, either beech or bamboo, these tie into the films (obviously Bamboo is Japanese) and there are strong messages of the importance of taking care of the planet in most films - hence the eco -friendly. (IX 2016)

Making my own craft prices inspired from the Ghibli characters, and each piece that I make reminds me of the movies... Because the ghibli world gives so much love and values to the audience, I wanted to give the same by making my craft project. (VII 2016)

People really love to immerse themselves in these films, so collecting the memorabilia and craft merchandise just goes along with that, if you took away the crafts of the Ghibli fans I think it would, in a way, remove the emotional attachment that they feel with the films. (IX 2016)

Whilst fans might not use media texts in civic action (Gray 2012; Jenkins 2015) and/or discursively use craft in political protest known as 'craftivism' (Gauntlett 2011: 55-6; Belford 2013), Ghibli fans' ideological alignment with the studio's films and their subtexts still allows for socio-political engagement with wider issues. Similar to Napier's sample, many of the respondents from this research project noted inspiration from the strong political stances around environmental issues and the positive representation of strong female characters present in Ghibli films. Furthermore, while some have argued about the detrimental social effects of the internet and its users (Keen 2007; Miller 2008), Gauntlett contests that 'the new visibilities of [...] [craft] activities via internet [...] enables the excited enthusiasts in one corner of the world to inspire and encourage similarly energized individuals elsewhere [previously not possible]' (2011: 62). While Gauntlett does not address fandoms specifically, transmedia fan-made Ghibli objects posted online operate in a system akin to Web $2.0 \mathrm{craft}$ cultures (see also: Anderson 2007). Concurrently, the social network facilities of Facebook allow for the comment culture of such communal spaces to prompt members 'to [give and] receive feedback on their creative endeavors' (Reagle Jr 2015: 178), by fans galvanized by the love of Ghibli and its fandom (78). Moreover, in the stressing the community aspect of 
craft-making, collaboration can become a core practice between fans (Jones 2014; Bode 2014).

People seem to love it [her crafts], which is great! I've had comments and messages from people who have heard of me and I'm not even quite sure how! It's quite surreal...I haven't had many people ask exactly how things are made as I tend to be very upfront, and try to put all that info out there so people don't need to ask... I do often get requests to make certain items, or customize current ones to tailor to the fans needs. (IX 2016)

I am always trying to look for new ghibli fans to share with theme my love for the ghibli world. (VII 2016)

I think it's truly a beautiful thing and when people post their art online no one ever argues over which one was better. The only thing that matters is that we all love Studio Ghibli. (I 2016)

[B]y crafting something from them I can show my deep appreciation of them in a personal way, both for myself and also for others to see that this is how much I love these films and characters. (VIII 2016)

Taylor and Payne argue that 'craft knowledge [...] is essentially communal and collaborative' (2013: 148). Therefore, such crafting can undermine 'notions of originality' (Taylor and Payne 2013: 148) and autonomous authorship (Knott 2013: 134-6). However, whilst still encouraging community, fans posting images and videos of their craft creations act as means of performing subcultural capital, reinstalling individual fan identity within the wider online fan community space (Chin 2014). As Stanfill and Condis remark, '[t]he emphasis in fan circulation of gifts is in producing and reinforcing fannish identities and relationships' (2014).

Yet, while fans may post images of their crafts online for others to see, yielding subcultural capital, craft capital and social capital to the respective poster, such crafts also adhere to fandom's gift economy. As Turk notes, '[f]andom has often been discussed [...] as a sharing economy, and specifically as a gift economy based on giving, receiving and reciprocating' (2014). Fans will post their creations/designs often accompanied with explanations of how they made them for others to learn how to craft such an object. Likewise, 
others have posted scanned copies of hard-to-acquire and out-of-print books from Japan that give you designs to make elaborate Ghibli origami. Such practices echo Paul Booth's 'digigratis' model, where fan knowledge and ownership of information is shared/made visible (2010: 133). Not only do these fans perform subcultural capital but also strengthen social cohesion within the fan space through the act of gift giving (Helens-Hart 2014). Turk argues such a gift economy is 'fundamentally asymmetrical: because a single gift can reach so many people, and especially because it can go on reaching people well after the initial moment of distribution' (2014).

However, craft culture in MiyazakiWorld not only sees fans posting designs for other fans to use (Gauntlett 2011: 82-3), but also many of the posts of objects made are offline gifts to other fans/friends/family:

I crocheted a small Princess Mononoke for my brother's birthday before Christmas (another fan!) because I knew he loved that film, as I do, but also because I love the character and the film and how strong she is. I also, a year earlier, crocheted a Ponyo for my brother's girlfriend [...] again because the complexity of the characters and the issues explored in the film. (VIII 2016)

I made $[\ldots]$ cupcakes as a present for a friend. He likes Totoro as well. I love making handmade presents, I think they are more special, cause you think of the person you are going to give it to, and then it becomes full of good energy and love. (IV 2016)

[Porco Rosso] stands as my second favorite Ghibli movie, and my bf's first favorite. That's what compelled me to make the cutting board gift for him. (V 2016)

Such quotes illustrate how 'our experience of fandom depends on the labor of others' (Turk 2014).

Likewise, craft making (Gauntlett 2011: 66-7), like object collecting, can connect parents with their children and be a process of gatekeeping whereby elders introduce their sons and daughters to their championed fan texts/objects:

I have made a dress for my daughter, and painted her chair with different ghibli characters. I also made some keychains for my childhood friend. My mother in law made me a knitted shirt and some small figurines of totoro too. ( $X$ 2016) 
Furthermore, wider websites have encouraged fans to create unofficial crafts such as Ghibliinspired meals (Lan 2015; Kendall 2012), Ghibli origami and paper-crafts (Tektonten 2016), and eco-friendly crafts such as picking up acorns and other plants to make Ghibli ornaments (McGee 2013), reinforcing brand, film and/or character identity through the act of making and sharing.

Such community and collaboration are also evident in offline communities. For instance, one fan from Boston, USA, explained that,

[w]hile I'm a fairly amateur artist, I'm definitely a huge fan. I'm actually going to a studio ghibli potluck dinner tomorrow here in Boston. A bunch of fans are all making ghibli themed dishes $[\ldots]$ getting together and sharing and watching movies! (XI 2016)

Indeed, culinary craft seems a particularly popular fan practice with a large number of fan postings showing cakes, bread, bento boxes and other Ghibli-themed food (see also Diana ND). The creation of ephemeral fan objects - food to be eaten - still creates experiential relationships and encourages 'affective play' (Hills 2002: 79):

I love making crafts, and I also love cooking and baking. I'm a vegan, so it's hard for me to find vegan pastries around, so I make them. Because of my love for Totoro, I decided to make a cake for my birthday with Totoro shape. (IV 2016)

The scenery was beautiful and the stories were always interesting. The way they portray food in all the films always gets me hungry as well. (II 2016)

However, while craft culture in MiyazakiWorld has been a central component of relationships between fans and films, the fan community itself it not always a core component within this affective dynamic (Sandvoss and Kearns 2014). Several responses, whilst clearly evidencing being fans of Ghibli, professed to not having extensive engagement with the wider community:

I'm not hugely involved in any fandom connected with Studio Ghibli. I watch as many films as I can [...] and I do love to read Tumblr blogs associated with fans and the films. (VIII 2016)

I enjoy watching the movies and occasionally making some crafts, I don't collect or paticipate in any ghibli related projects. ( $X$ 2016) 
Such responses illustrate how even within fan cultures not all participants operate in a monolithic way, accounting for different degrees of involvement (Denison 2010: 546). Moreover, this allows one to acknowledge the potential for lurkers on such sites: users who do "not post nor actively contribute to the discussion in order to be able to follow the various “threads" of information at any one time' (Hills 2002: 135), without suggesting that one position is of greater value than another.

For some fans, the act of making is enough of an affective link between text and audience and means of fan identity. In some cases, even more so than collecting/buying official merchandise:

I'm not really interested in mak[ing], say, a plastic lunchbox with Totoro, or novelty clothes (unless they were for an authentic costume). Essentially, I just want to bring the Ghibli world into the real world! (IX 2016)

I wouldn't say people make their own crafts to sell them but just to feel a little closer to the fandom. (I 2016)

Crafts I think are more personal, they have a little piece of the crafter's soul, energy, and effort. (IV 2016)

I [...] am astounded at the quality of some of the stuff out there, peoples imaginations are really captured and there is soooo much talent! (XII 2016)

Fan labour such as cosplay and screen-accurate replicas seek authenticity 'that faithfully represent characters' iconic attitudes [...] [offering] mimetic sensibility' (Ogonoski 2014; see also: Phillips 2014, Hills 2014a). Yet, respondents/posters often privilege authenticity not through level of replicability, what Hills terms 'mimetic fandom' (2014a), but through the process of craft embodying the films' ideologies read by fans through the act of making. But, like Hills, my analysis of 'challenges the overt or shorthand gendering of fan practices' (2014a), as both male and female fans enthusiastically make, give, and receive such objects from both sexes. Therefore, whilst craft has often been linked to a feminine/feminist act of creation (see Cherry 2011, Parker 2010), crafting in this instance, is not delineated or ontologically bound by a prescriptive gendering that ascribes socio-subversive potential in the practice. Rather, the authenticity in the act of making for these respondents is what 
heightens the tangible nature of the films through the creation of object that removes the consumerist aspect of merchandise, whilst still 'blurring the ontological distinction between screen texts and solid objects' (Rehak 2012: 30). This echoes Gauntlett's argument that 'handmade things are special because they carry the "authentic and personal" touch of the person who has made them' (2011: 65).

While it might be argued that fan labour can be exploited by websites harvesting original work for economic gain (Gauntlett 2011: 90), or by the industry/company creating the media championed by fans (Stork 2014; Jones 2014; Chin 2014), or that such practices are not connected to ecological/green principles (Parham 2016: 33), fans' activities and engagement with Studio Ghibli seem akin to 'affective modes of green media/popular culture [that] can encourage what we might call an "everyday ecology"' (34), whereby the ritualist ontological blurring between text and craft by fans offers a form of convivial technology utilization in accordance with Miyazaki's and the studio's own ideologies, whilst reinforcing Napier's MiyzakiWorld model.

\section{Conclusion}

If the media mix model that incorporates screen texts, manga and ancillary objects formulates what Ian Condry calls the 'soul of anime', that is 'best envisioned as a kind of energy that arises from the ways anime connects people; a connection that operates as a conduit of interest and activity; a soul, in other words, that arises out of collective action' (2013: 30), then we need to address how audiences actively engage with such flows of 'energy'. This is not to say that the media mix is not present in this case study, rather, such triangulations between audiences, texts and objects need to consider that fans are not always solely receivers. In some instances, there is a lack of consumption of texts and/or objects within transnational contexts, yet anime's media mix is restored, and thus nuanced/expanded, by fan-produced works. Moreover, fans, through their own makings, reinforce a strong brand identity, albeit one that is tied into their own affective relationships with Ghibli that implements grassroots production rather than simply being predetermined at industry level, within a self-sustaining craft culture. Moreover, 'fans derive pleasure from the labors they perform' (Chin 2014). Gauntlett makes the astute point that craftsman can 'feel supported and encouraged in their creative efforts [...] [but] do not necessarily need a huge audience or network. [...] [Rather, it] can occur through interactions with small numbers of like-minded people' (2011: 232, see also Cleverly and Shear 2013: 110). Such support networks are 
highly active within this research whether it is through online fan communities, offline gatherings, and/or gift cultures between loved ones. Moreover, it sheds light on a variety of fan productions expanding well beyond previously researched fan activities. In doing so, evidencing ideological implications and how they can tie into fan identity.

While in this instance, craft-making is not overtly politically motivated, the article concurs with Gauntlett's conclusion that 'making and sharing is already a political act' (2011:233). If Napier's MiyazakiWorld is an instance of Web 1.0 affirmational/writingbased fan engagement with the studio that illustrates socio-political affinities with its films, this article's Web 2.0 MiyazakiWorld of fans posting images, designs and/or recipes, supported by open-ended interviews, explores nuanced fan practices that not only evidence civic engagement derived from fan readings of Ghibli texts, but also manifests itself through craft culture, echoing Miyazaki's own views on nature and technology. Much like Miyazaki's negotiation of eco-politics and commercial business, '[t]he fannish gift economy [and fan crafting] may be used as a framework for understanding how fandom can function in opposition to a capitalist economy' (Jones 2014).

\section{Notes}

${ }^{1} \mathrm{Ni}$-No-Kuni's Western release was exclusively on the Playstation 3, whilst the Miyazaki boxset was exclusively on Blu-ray.

${ }^{2}$ All quotations from fans are reproduced verbatim.

\section{Bibliography}

Akimoto, D. (2014), 'Learning Peace and Coexistence with Nature through Animation: Nausicä̈ of the Valley of the Wind', Ritsumeikan Journal of Asia Pacific Studies, 33, pp.5463.

Aldred, J. (2014), '(Un)blocking the Transmedial Character: Digital Abstraction as Franchise Strategy in Traveller's Tale LEGO Games', in M.J.P. Wolf(ed.), Lego Studies: Examining the Building Blocks of a Transmedial Phenomenon, New York and London: Routledge, pp.105-117.

Allison, A. (2004), 'Cuteness as Japan's Millennial Product', in J. Tobin. (ed.), Pikachu's Global Adventure, Durham and London: Duke University Press, pp.34-49. 
Anderson, C. (2007), The Long Tail, London: Random House.

Bainbridge, J. and C. Norris (2008), 'Madman in the House: Understanding Media Merchandising, the Implication for Convergence and New Knowledge Economies', Online Proceedings of 'Sustaining Culture' (2008), Annual Conference of the Cultural Studies Association of Australia (CSAA) UniSA, Adelaide $6^{\text {th }}-8^{\text {th }}$ December 2007.

Baseel. C. (2015), ‘Keeping Totoro’s Forest Safe: Anime Legend Hayao Miyazaki Volunteers in Conservation Event', Rocket News 24, 20 January, http://en.rocketnews24.com. Accessed 13 April 2015.

Bédard, P. (2015), 'In Search of Identity: Fanfics, Cosplay, and Character Building in "Adventure Time"', Inmediares, 5 January, http://mediacommons.futureofthebook.org/. Accessed 14 April 2015.

Beflord, T. (2013), 'Catalytic Clothing and Tactility Factory: Crafted Collaborative Connections', in A. Ravetz, A. Kettl. and H. Felcey (eds.), Collaboration Through Craft, London: Bloomsbury, pp. 77-87.

Blakey, S. and L. Mitchell (2013), 'A Question of Value: Rethinking the Mary Greg Collection', in A. Ravetz, A. Kettle and H. Felcey (eds.), Collaboration Through Craft, London: Bloomsbury, pp. 170-185.

Bode, D. Sterling. (2014), 'Beyond Souvenirs: Making Fannish Items by Hand', Transformative Works of Culture, 16, http://journal.transformativeworks.org. Accessed 3 May 2016.

Booth, P. (2010), Digital Fandom: New Media Studies, New York: Peter Lang.

Cherry, B. (2011), 'Knit One, Bite One: Vampire Fandom, Fan Production and Feminine Handicrafts', in G. Schott and K. Moffat (eds.), Fanpires: Audience Consumption of the Modern Vampire, Washington: New Academia Publishing, pp.137-55.

Chin, B. (2014), 'Sherlockology and Galactica.tv: Fan Sites as Gifts or Exploited Labor?', Transformative Works and Cultures, 15, http://journal.transformativeworks.org. Accessed 3 May 2016. 
Cleverly, J. and T. Shear (2013), 'Designing Collaboration: Evoking Dr Johnson Through Craft and Interdisciplinarity', in A. Ravetz, A. Kettle and H. Felcey (eds.), Collaboration Through Craft, London: Bloomsbury, pp.100-113.

Condry, I. (2013), The Soul of Anime: Collaborative Creativity and Japan's Media Success Story, Durham and London: Duke University Press.

Cooper-Chen, A.M. (2010), Cartoon Cultures: The Globalization of Japanese Popular Media, New York: Peter Lang.

Cross, G. (2006), 'Foreword', in A. Allison, Millennial Monsters: Japanese Toys and the Global Imagination, Berkeley and London: University of California Press, pp.xv-xviii.

Davis, D.W. and E.Y. Yeh. (2008), East Asian Screen Industries, London: BFI Publishing. Denison, R. (2008), 'The Language of the Blockbuster: Promotion, Princess Mononoke and the Daihitto in Japanese Film Culture', in L. Hunt and L. Wing-Fai. (eds.), East Asian Cinemas: Exploring Transnational Connections on Film, London and New York: I.B. Tauris, Pp.101-119.

- (2010), 'Anime Tourism: Discursive Construction and Reception of the Studio Ghibli Art Museum', Japan Forum, 22:3-4, pp.545-563.

- (2011), 'Transcultural Creativity in Anime: Hybrid Identities in the Production, Distribution, Texts and Fandom of Japanese Anime', Creative Industries Journal, 3:3, pp.221-235.

—. (2015), Anime: A Critical Introduction, London and New York: Bloomsbury.

Diana (ND), 'Studio Ghibli Food Series', Fiction Food Café, http://www.fictionfood.com/p/food-from-world-of-studio-ghibli.html. Accessed 8 July 2016.

Ess, C. and AoIR. (2002), 'Ethical Decision-Making and Internet Research. Recommendations From the AoIR Ethics Working Committe', AoIR Association of Internet Researchers, http://aoir.org/reports/ethics.pdf. Accessed 20 May 2015.

Gauntlett, D. (2011), Making is Connecting: The Social Meaning of Creativity, From DIY and Knitting to YouTube and Web 2.0, Cambridge and Malden: Polity. 
— (2014), 'The LEGO System as a Tool for Thinking, Creativity, and Changing the World', in M.J.P. Wolf (ed.), Lego Studies: Examining the Building Blocks of a Transmedial

Phenomenon, New York and London: Routledge, pp.189-205.

Geraghty, L. (2014), Cult Collectors: Nostalgia, Fandom and Collecting Popular Culture, London and New York: Routledge.

Granshaw, L. (2015), “'Spirited Away” Designs From Her Universe Arrive at Hot Topic', The Daily Dot, 11 December, http://www.dailydot.com/. Accessed 10 July 2016.

Gray, J. (2008), Television Entertainment, New York and London: Routledge.

— (2010), Show Sold Separately: Promos, Spoilers, and Other Media Paratexts, New York and London: New York University Press.

- (2012), 'Of Snowspeeders and Imperial Walkers: Fannish Play at the Wisconsin Protests', Transformative Works and Cultures, 10, http://journal.transformativeworks.org. Accessed 3 May 2016.

Helens-Hart, R. (2014), 'Promoting Fan Labor and "All Things Web": A Case Study of Tosh.O', Transformative Works and Cultures, 15, http://journal.transformativeworks.org. Accessed $3^{\text {rd }}$ May 2016.

Hellekson, K. and K. Busse (eds.), (2006), Fan Fiction and Fan Communities in the Age of the Internet, Jefferson and London: McFarland.

Hills, Matt. (2002), Fan Cultures. London and New York: Routledge.

— (2009), 'Interview With Matt Hills, Part 2', Doctorwhotoys.net, http://doctorwhotoys.net/matthills1.htm. Accessed 6 April 2016.

— (2011), Cultographies: Blade Runner, New York: Wallflower Press. 
— (2014a), 'From Dalek Half Balls to Daft Punk Helmets: Mimetic Fandom and the Crafting of Replicas', Transformative Works and Cultures, 16,

http://journal.transformativeworks.org. Accessed 3 May 2016.

— (2014b), 'Returning to "Becoming-a-Fan" Stories: Theorising Transformational Objects and the Emergence/Extension of Fandom', in L. Duits, K. Zwaan and S. Reijnders (eds.), The Ashgate Research Companion to Fan Cultures, Farnham and Burlington: Ashgate, pp.9-21.

Jenkins, H. (2006), Convergence Culture: Where New and Old Media Collide, New and London: New York University Press.

—. (2015), “"Cultural Acupuncture”: Fan Activism and the Harry Potter Alliance', in L. Geraghty (ed.), Popular Media Cultures: Fans, Audiences and Paratexts, Basingstoke and New York: Palgrave Macmillan, pp.206-229.

Johnson, D. (2013), Media Franchising: Creative License and Collaboration in the Culture Industries, New York and London: New York University Press.

Jones, B. (2014), 'Fifty Shades if Exploitation: Fan Labor and Fifty Shades of Grey', Transformative Works of Culture, 15, http://journal.transformativeworks.org. Accessed 3 May 2016.

Kacsuk, Z. (2011), 'Subcultural Entrepreneurs, Path Dependencies and Fan Reactions: The Case of Naruto in Hungary', in J. Berndt (ed.), Intercultural Crossovers, Transcultural Flows: Manga/Comics. Global Manga Studies, vol. 2. Kyoto: Kyoto Seika University International Manga Research Center, pp.17-32.

Kay (2014), 'Miyazaki Blu-ray Collection to be Released With Special Content But Won't Come Cheap', Rocket News 24, 3 April, http://en.rocketnews24.com . Accessed 13 April 2015.

Keen, A. (2007), The Cult of the Amateur: How Today's Internet is Killing Our Culture and Assaulting Our Economy, London and Boston: Nicholas Brealey. 
Kelts, R. (2006), Japanamerica: How Japanese Pop Culture Has Invaded the U.S., New York and Basingstoke: Palgrave Macmillan.

Kendall, P. (2012). 'From My Neighbor Totoro to Ninja Turtles: Anime Food in Real Life!', Rocket News 24, 19 November, http://en.rocketnews24.com. Accessed 13 April 2015.

— (2014), 'This New Totoro Plush is Super Pricey, Rarer than Encounter with the Big Guy Himself', Rocket News 24, 15 November, http://en.rocketnews24.com. Accessed 13 April 2015.

Knott, S. (2013), 'Department 21: The Craft of Discomfort', in A. Ravetz, A. Kettle and H. Felcey (eds.). Collaboration Through Craft, London: Bloomsbury, pp.130-141.

Kozinets, R.V. (2010), Netnography: Doing Ethnographic Research Online, Los Angeles: Sage.

— (2015). Netnography: Redefined. $2^{\text {nd }}$ Edition. Los Angeles, London, New Delhi, Singapore, and Washington D.C. Sage.

LaMarre, T. (2009), The Anime Machine: A Media Theory of Animation, Minneapolis and London: University of Minnesota Press.

Lan, C. (2015), 'Here's How to Eat Everything You've Ever Wanted From A Miyazaki Film', BuzzFeed, 28 October, https://www.buzzfeed.com/christinalan/heres-howto-eat-everything-youve-ever-wanted-fr?utm term=.wx8KDlxb1Y\#.axMzWGL4Bn. Accessed 8 July 2016.

Lawrence, J.S. (2006), 'Introduction: Spectacle, Merchandise, and Influence', in M.W. Kapell and J.L. Lawrence (eds.), Finding the Force of the Star Wars Franchise: Fans, Merchandise, and Critics, New York: Peter Lang, pp.1-18.

Lim, T.W. (2013), 'Spirited Away: Conceptualizing a Film-Based Case Study Through Comparative Narratives of Japanese Ecological and Environmental Discourses', Animation: An Interdisciplinary Journal, 8:2, pp.149-162. 
Lynch, G. (2014), 'Finally, There’s a Studio Ghibli Hayao Miyazaki Blu-ray Box Set', Gizmodo, 12 November, http://www.gizmodo.co.uk/. Accessed 13 April 2015.

McGee, O. (2013), 'Bring Totoro home from the forest with these adorable acorns!', Rocket News 24, 24 December, http://en.rocketnews24.com. Accessed 13 April 2015.

Miller, V. (2008), 'New Media, Networking and Phatic Culture', Convergence, 14:4, pp.387400.

Miyazaki, H. (2009), Starting Point: 1979-1996, San Francisco: Viz Media.

Napier, S.J. (2006), 'The World of Anime Fandom in America', in F. Lunning (ed.), Mechademia, 1: Emerging Worlds of Anime and Manga, Minneapolis: University of Minnesota Press, pp.47-63.

- (2007), From Impression to Anime: Japan as Fantasy and Fan Cult in the Mind of the West, New York and Basingstoke: Palgrave Macmillan.

Ogonoski, M. (2014), 'Cosplaying the Media Mix: Examining Japan’s Media Environment, its Static Forms, and its Influence on Cosplay', Transformative Works and Cultures, 16, http://journal.transformativeworks.org. Accessed $3^{\text {rd }}$ May 2016.

O’Neill, C.J. and A. Ravetz (2013), 'Expanded Crafts, Dispersed Creativity: A South Asian Residency', in A. Ravetz, A. Kettle and H. Felcey (eds.), Collaboration Through Craft, London: Bloomsbury, pp.233-243.

Osmond, A. (2008), Spirited Away, Basingstoke and New York: Palgrave Macmillan. Parham, J. (2016), Green Media and Popular Culture: An Introduction, London and New York: Palgrave.

Parker, R. (2010), The Subversive Stich: Embroidery and the Making of the Feminine, London: I.B. Tauris.

Phillips, F. (2014), 'The Butcher, the Baker, the Lightsaber Maker', Transformative Works and Cultures, 16, http://journal.transformativeworks.org. Accessed 3 May 2016. 
Reagle Jr., J.M. (2015), Reading the Comments: Likers, Haters, and Manipulators at the Bottom of the Web, Cambridge and London: The MIT Press.

Rehak, B. (2012), 'Materializing Monsters: Aurora Models, Garage Kits, and the Object Practices of Horror Media', Journal Of Fandom Studies, 1: 1, pp.27-45.

Rehak, B. (2014), 'Materiality and Object-Oriented Fandom', Transformative Works and Cultures, 16, http://journal.transformativeworks.org. Accessed 3 May 2016.

Saito, K. (2011), 'Desire in the Subtext: Gender, Fandom, and Women's Male-Male', in F. Lunning (ed.), Mechademia 6: User Enhanced, Minneapolis and London: University of Minnesota Press, pp.171-192.

Sandvoss, C. and L. Kearns (2014), 'Fan Interpretive Communities to Interpretative Fairs: Ordinary Fandom, Textual Selection and Digital Media', in L. Duits, K. Zwaan and S. Reijnders (eds.), The Ashgate Research Companion to Fan Cultures, Farnham and Burlington: Ashgate, pp.91-106.

Schodt, F.L. (2007), The Astro Boy Essays: Osamu Tezuka, Mighty Atom, and the Manga/Anime Revolution, Berkley: Stone Bridge Press.

Seroff, A. (2012), ‘Adventure Time’s “Flippin’ Awesome” Recognition of Crossover Fandom', Inmediares, 11 October, http://mediacommons.futureofthebook.org/. Accessed 14 April 2015.

Smith, M.J. and E. Parsons (2012), 'Animating Child Activism: Environmentalism and Class Politics in Ghibli's Princess Mononoke (1997) and Fox's Fern Gully (1992)', Continuum: Journal of Media and Cultural Studies, 26:1, pp.25-37.

Stanfill, M. and M. Condis (2014), 'Fandom and/as Labor', Transformative Works and Cultures, 15, http://journal.transformativeworks.org. Accessed 3 May 2016.

Steinberg, M. (2012), Anime Media Mix: Franchising Toys and Characters in Japan, Minneapolis and London: University of Minnesota Press. 
Stork, M. (2014), 'The Cultural Economics of Performing Space: Negotiating Fan, Labor, and Marketing Practice in Glee's Transmedia Geography', Transformative Works and Cultures, 15, http://journal.transformativeworks.org. Accessed 3 May 2016.

Taylor. Simon. and Payne. Rachel. (2013). 'Skills in Making.' In Ravetz, A. Kettle. A. and Felcey. H. (eds). Collaboration Through Craft. London. Bloomsbury. pp:142-156.

Tektonten (2016), 'Studio Ghibli', Tektonten Papercraft, http://tektonten.blogspot.co.uk/search/label/Studio\%20Ghibli. Accessed 8 July 2016. Tobin, J. (2004), 'Introduction', in J. Tobin (ed.), Pikachu's Global Adventure, Durham, N.C.: Duke University Press, pp.3-11.

Turk, T. (2014), 'Fan Work: Labor, Worth, and Participation in Fandom's Gift Economy', Transformative Works and Cultures, 15, http://journal.transformativeworks.org.Accessed 3 May 2016.

Williams, K.A. (2012), 'Fake and Fan Film Trailers as Incarnations of Audience Anticipation and Desire', Transformative Works and Cultures, 9, http://journal.transformativeworks.org. Accessed 3 May 2016.

Winge, T. (2006), 'Costuming the Imagination: Origins of Anime and Manga Cosplay', in F. Lunning (ed.), Mechademia 1: Emerging Worlds of Anime and Manga, Minneapolis and London: University of Minnesota Press, pp.65-76.

Woo, B. (2014), 'A Pragmatics of Things: Materiality and Constraint in Fan Practices', Transformative Works and Cultures, 16, http://journal.transformativeworks.org. Accessed 3 May 2016. 